\title{
SCINOW: MULTIMODAL EDUCATIONAL RESOURCES
}

\author{
Brontë Ammundsen
}

A thesis submitted to the Victoria University of Wellington in fulfilment of the requirements for the degree of

Master of Innovation and Commercialisation

Victoria University of Wellington

2017 


\begin{abstract}
The necessity for this project was identified as a response to declining levels of science engagement, academic success and literacy observed in New Zealand secondary science education (OECD, 2016). As international advancements in sciences and technology create shifts in the current economic landscape, increasing importance is being placed on knowledge-intensive industries. This changed weighting of industry contributions to economic prosperity creates a simultaneous change in future workforce skill requirements (Gilbert \& Bull, 2013). With the importance of education in long-term social and economic prosperity being long acknowledged, the changing economic climate intensifies the urgent need to address New Zealand's declining science engagement and academic success.
\end{abstract}

While the most significant facets of educational operations lie in education pedagogy and policy, the wide range of factors involved in educational outcomes yield expansive opportunities for potential innovations and commercialisation in the education sector. The opportunity for this project was derived from identifying the elements that contribute to these challenges, and isolating a gap in the market of science education resources. The purpose of this project was to research this potential market gap, as well as identifying how to appeal to it. This led to the proposal for the SciNow multimodal resource database, a resource database designed to provide engaging lesson and study materials to science students and teachers with an emphasis on real-life application of content. Through utilising the concept of multimodality, the database design proposes offering materials through ranging modes of communication to increase appeal to varying student learning preferences (Jewitt, 2008). The overall intention for the SciNow database is to raise attractiveness of science education by making it more interesting and relevant to students, thereby positively affecting educational outcomes and in turn leading to economic benefits in the form of a more ideally skilled workforce.

While initial investigation focused on creating a business model for commercialising the SciNow resource database, this intention was adjusted in response to literature reviews revealing the significant performance gap between high and low achievers in science education (Education Review, 2016). In addition to New Zealand exhibiting one of the largest performance gaps in the OECD, concerns are exacerbated by the lowest performing 
population's overrepresentation of Maori and Pasifika students and students from low socioeconomic backgrounds (OECD, 2015). In response to the level of inequality in science education, the SciNow proposal was adjusted to be provided to all students and teachers nationwide for free.

The methodology implemented in this project was of a qualitative nature (Morgan, 1997). Interviews were conducted with secondary science teachers and students in which questioning focused on experiences with science education, including education resource availability and provision. Further focus groups were held with university students from wide-ranging backgrounds to gather reflective insight into experiences with science in school and in subsequent life.

The key findings indicated a desire for improved resource availability and quality, responding favourably to the proposition of the SciNow resource database. Further findings validated the proposed use of multimodality for engagement and focus on real-life content application.

Considering research findings, literature reviews, and the decision to provide the service freely, a flexible business model and case for investment is proposed and outlined in a strategic assessment business case. This business case proposes a three-phase process of development and implementation, influenced by the lean start-up business model. This three-phased plan begins with further research and subsequent development of a prototype as a minimum viable product. Following development, the prototype will then undergo testing and enhancement through feedback analysis, followed finally by expansion of the prototype to encompass the full database spectrum. The initial governing body will be composed of a core working group. Upon formation of a charitable trust, this core working group will evolve into an advisory board to act alongside the more commercially focused charitable trust board.

Key implications derived from this project are dual. In part, the project research emphasises the necessity for the education sector to consider more deep-rooted changes in the New Zealand education system (Bull, Gilbert, Barwick, Hipkins, \& Baker, 2010). Significant changes are needed to truly optimise New Zealand science education, and provision of a 
resource database can only accommodate educational challenges, not fix them. However, the research and business case demonstrate that execution of the SciNow proposal is feasible, with the intended research and development crucial in maximising potential benefit of the service. Upon completion of this project, further work is intended to bring the SciNow concept to fruition. 


\section{ACKNOWLEDGEMENTS}

To everybody that helped me along this journey, whether through contributing to research or simply being a listening ear when needed, I thank you.

To the inspiring teachers and educational researchers throughout New Zealand, your passion for education, for fostering knowledge, for encouraging inquisition, for your contributions to our students, past, present, and future, I couldn't offer you more praise.

To Azra and Jenny, thank you for creating this opportunity and supporting me (often with considerable patience) through every step of the way.

To my loving parents, for always supporting me, for always emphasising the importance of education, for expressing pride in all my achievements, and for always telling me I could do anything I put my mind to (except draw).

To my brother Louis, for never letting me abandon science, for never believing my claims that it "just wasn't interesting to me", for encouraging every spark of intrigue into the scientific world. Without your influence, I would never have gotten to where I am today.

To Julian, for letting me take over the walls with study notes, for sharing wine and chocolate with me when I needed it most, for scorning my desperate attempts to procrastinate, and for calling me out on any expression of self-deprecation.

To Mary and Mikey, for always being there. For the blissful escape to Waikanae, for letting me know there is always somewhere for me to feel loved, and for always, always, leaving me feeling special.

To Marvin, for being by my side through every long day at my desk. For watching over me when I work, and for forcing me to take breaks. For making me get fresh air, and for teaching me how many ways a cat can take over a computer chair.

To Nicholas;

you leave this wordsmith speechless. 


\section{Table of Contents}

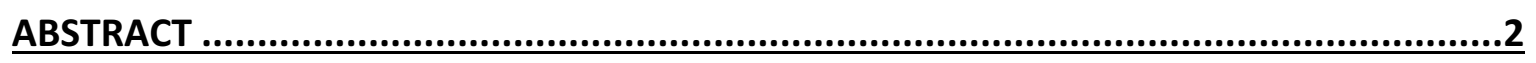

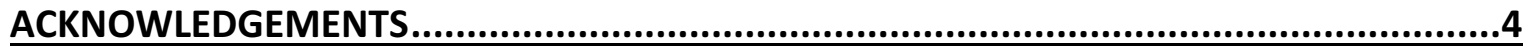

CHAPTER 1: INTRODUCTION TO THE SCINOW PROJECT REPORT .............................10

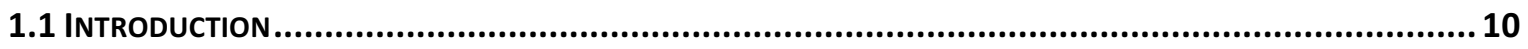

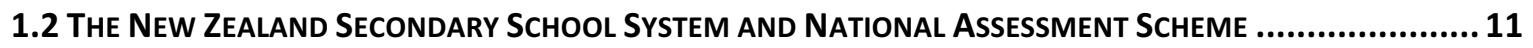

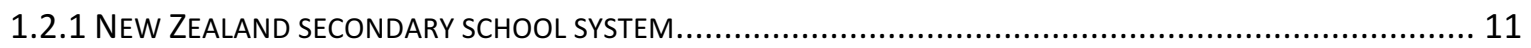

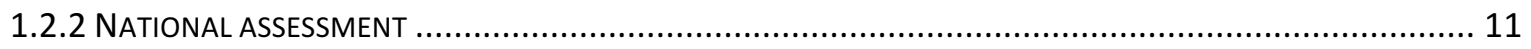

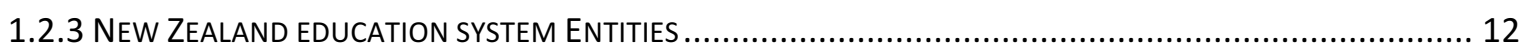

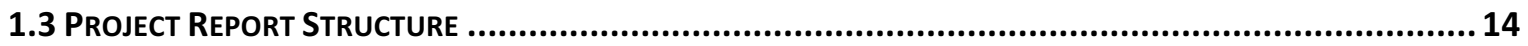

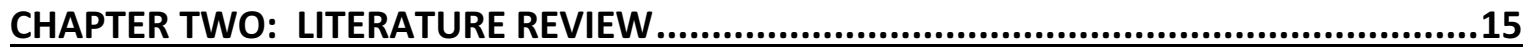

2.1 IDENTIFICATION OF SCIENCE EdUCATION CHALLENGES IN TEACHING AND LEARNING ............................15

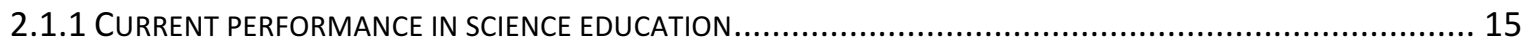

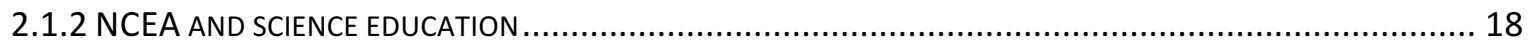

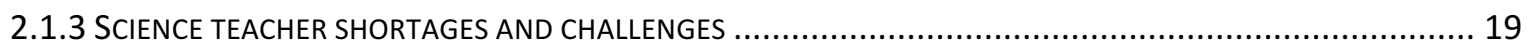

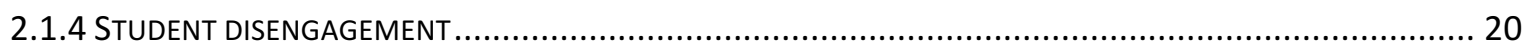

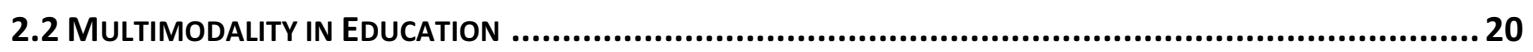

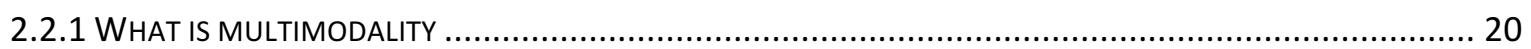

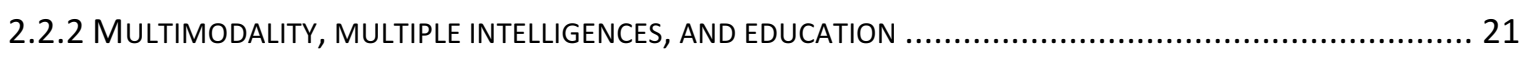

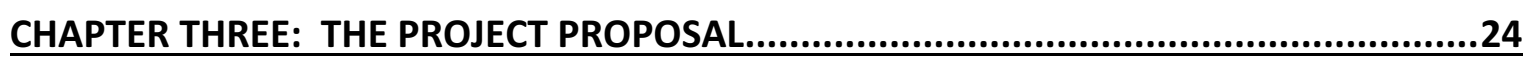

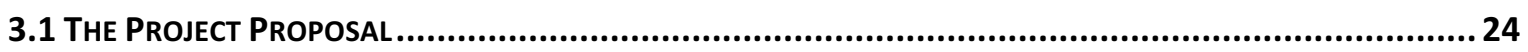

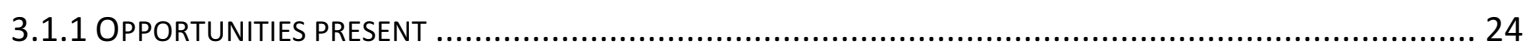

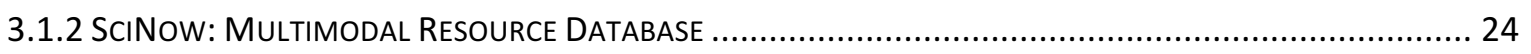

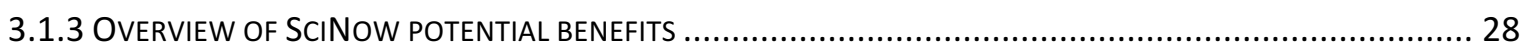

3.2 PROJECT REPORT SCOPE

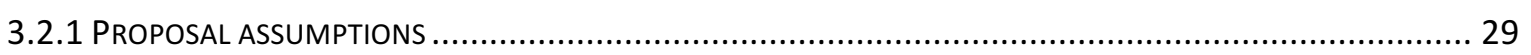

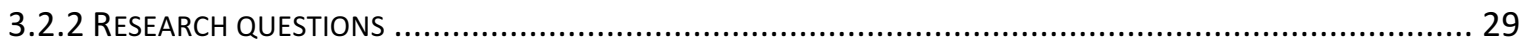

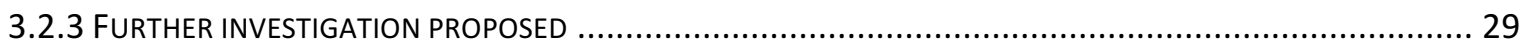

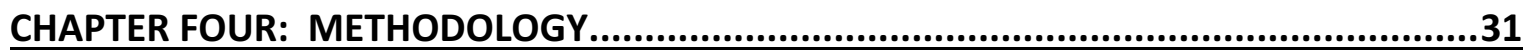

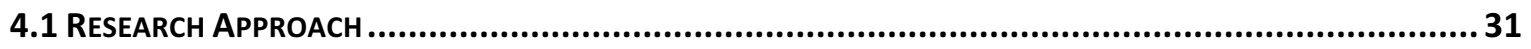

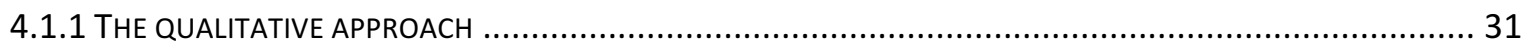

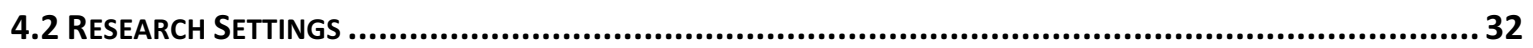

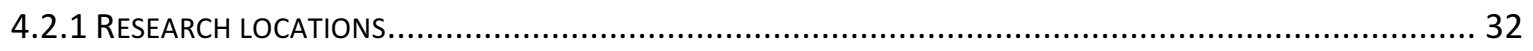

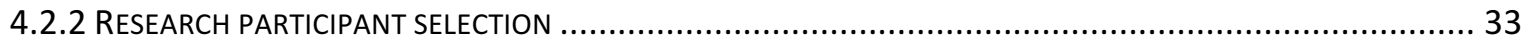

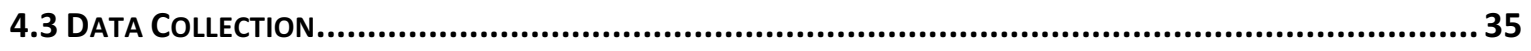

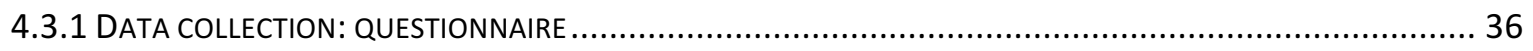

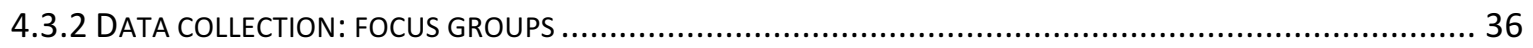

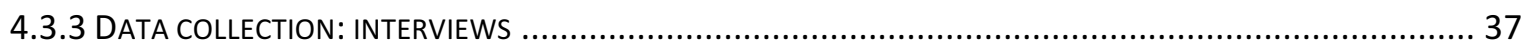

4.4 DATA ANALYSIS 


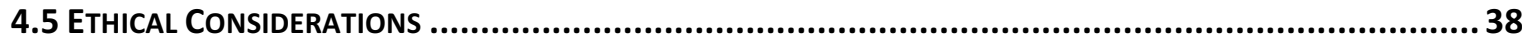

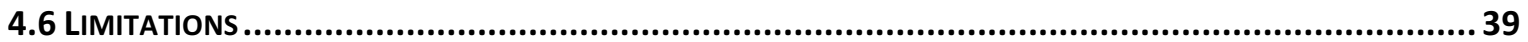

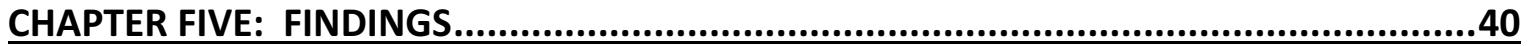

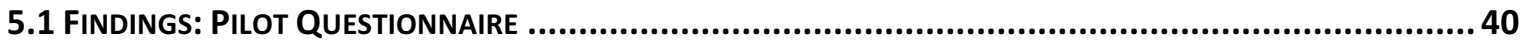

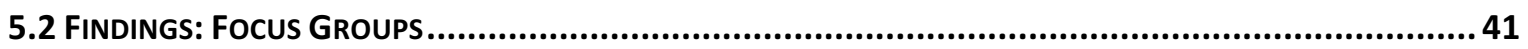

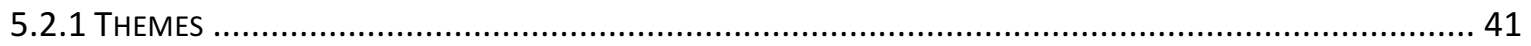

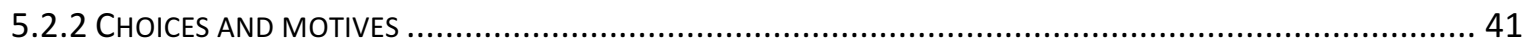

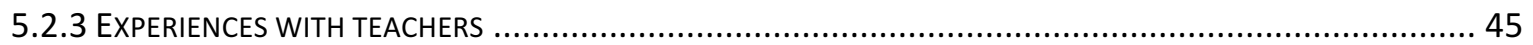

5.2.4 CONTENT, CONTEXT, CURRICULUM, \& CAREERS................................................................ 47

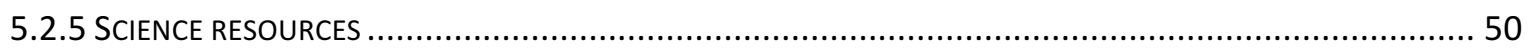

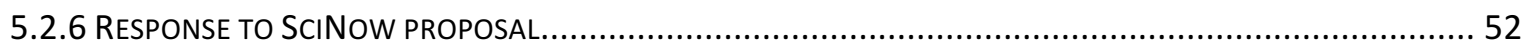

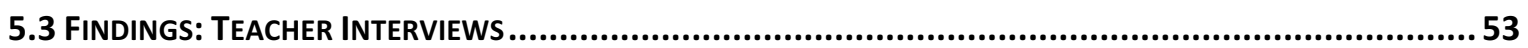

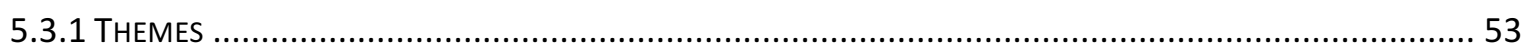

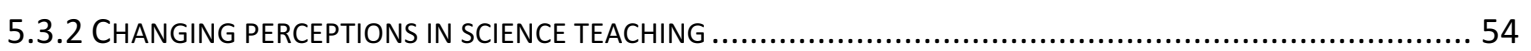

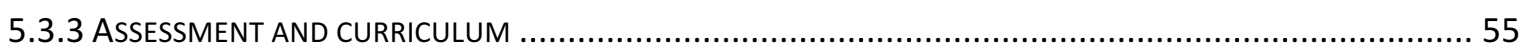

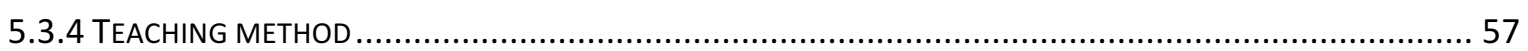

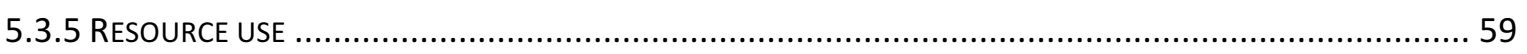

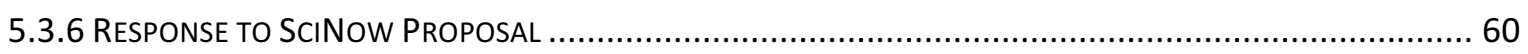

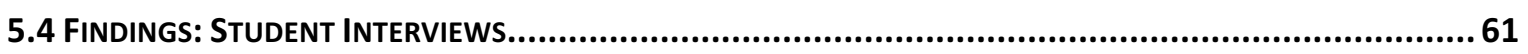

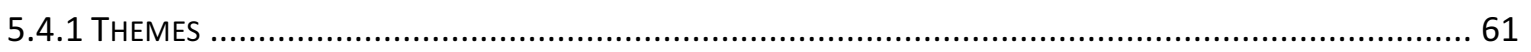

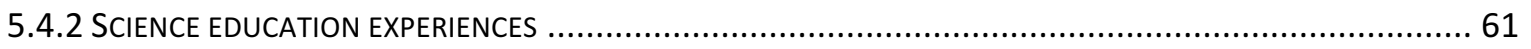

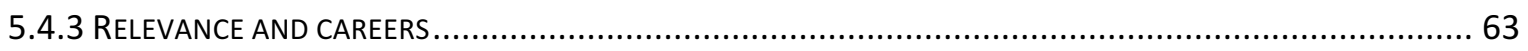

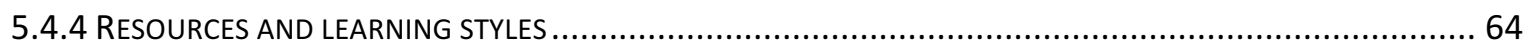

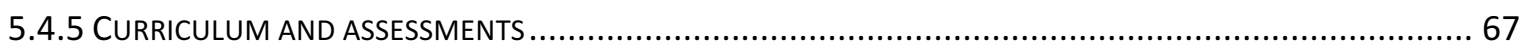

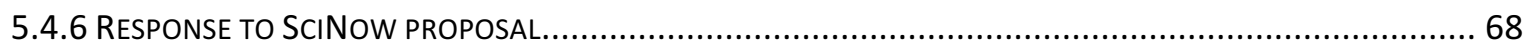

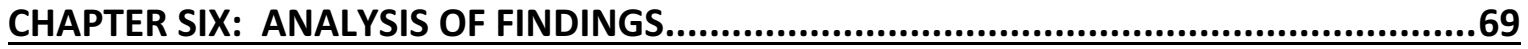

6.1 INTRODUCTION TO ANALYSIS ..................................................................................69

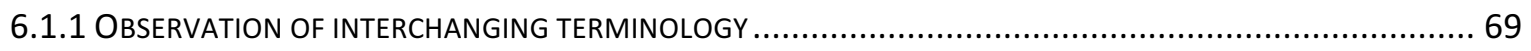

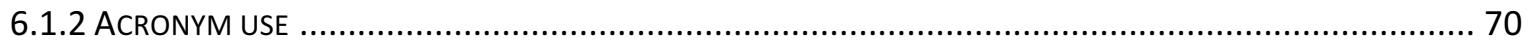

6.2 Studying SCIenCE: ChOices, MotiveS, ANd ExperienCeS .................................................. 70

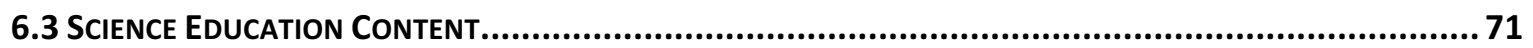

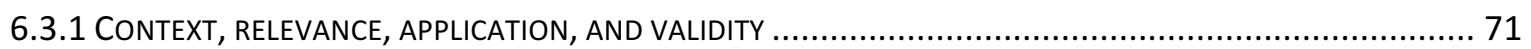

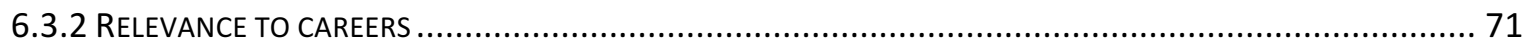

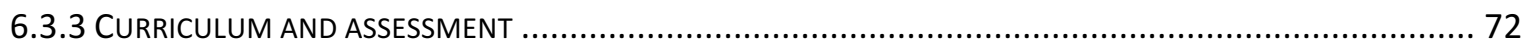

6.4 TEACHING Method, Learning StyleS, AND EXPERIENCES With TEACHERS ............................... 72

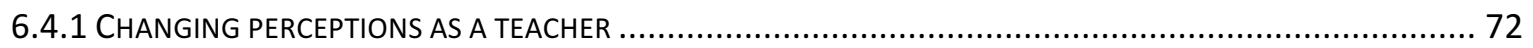

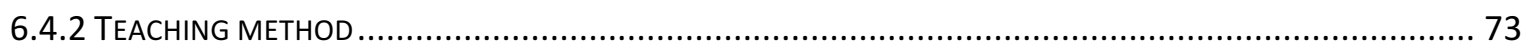

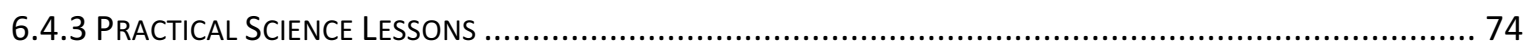

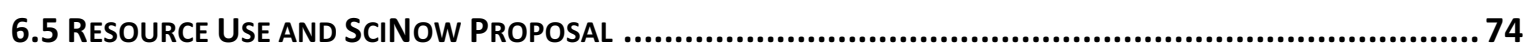

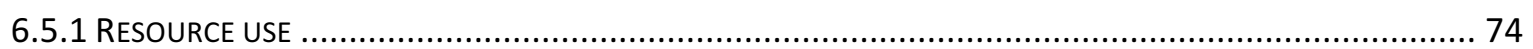

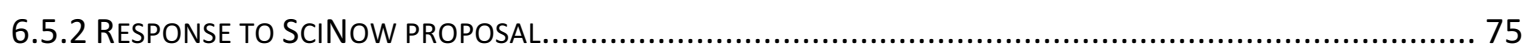

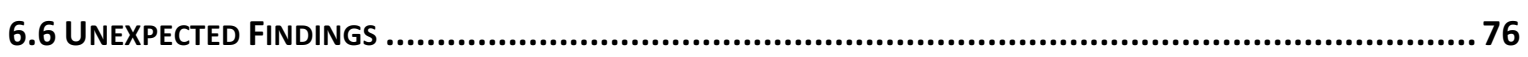

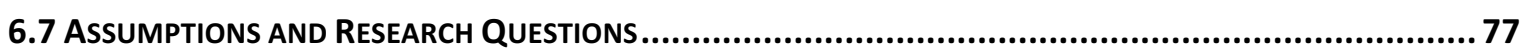

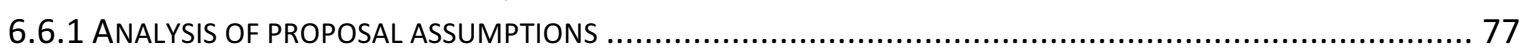

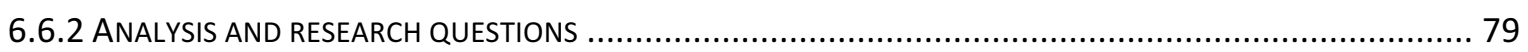

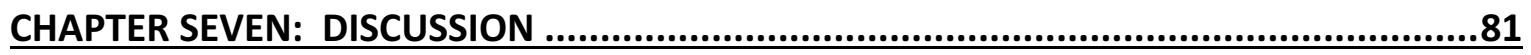

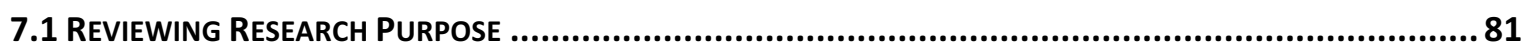




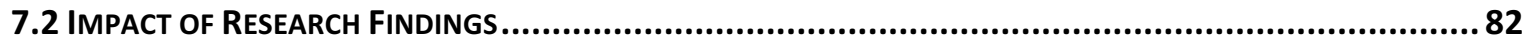

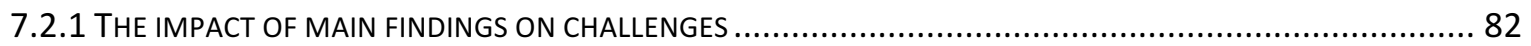

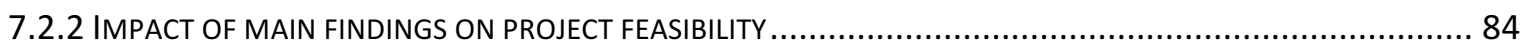

7.3 PROGRESSION OF INITIAL ASSUMPTIONS ................................................................ 85

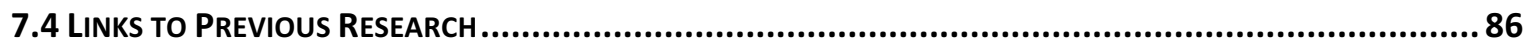

7.5 IMPLICATIONS OF RESEARCH AND FUTURE RECOMMENDATIONS................................................8 87

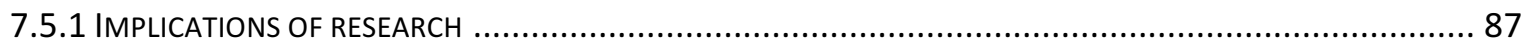

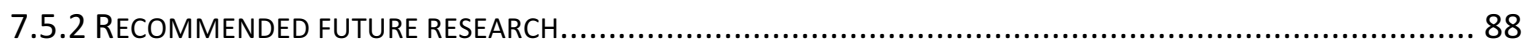

CHAPTER EIGHT: STRATEGIC ASSESSMENT BUSINESS CASE ...................................90

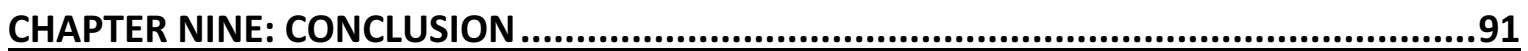

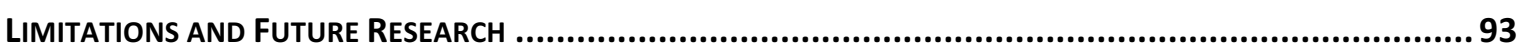

KEY IMPLICATIONS ............................................................. ERROR! BOOKMARK NOT DEFINED.

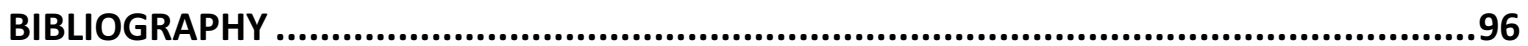

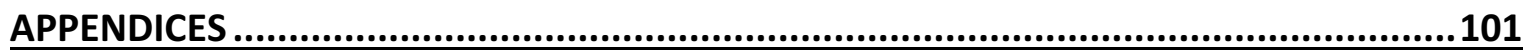

APPENDIX A: PILOT QUESTIONNAIRE QUESTION SCHEDULE ..................................................... 102

APPENDIX B: QUESTION SCHEDULE FOR FOCUS GROUP RESEARCH ............................................. 103

APPENDIX C: QUESTION SCHEDULE FOR TEACHER INTERVIEWS .............................................. 105

APPENDIX D: QUESTION SCHEDULE FOR SECONDARY SCHOOL STUDENT INTERVIEWS ............................. 106

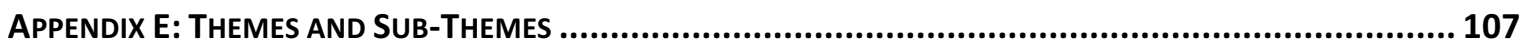

APPENDIX F: EXAMPLE OF ETHICS INFORMATION SHEET....................................................... 109

APPENDIX G: EXAMPLE OF ETHICS CONSENT FORM.............................................................. 111

\section{LIST OF FIGURES}

Figure 2.1: Average science performance by quarters of socio-economic status.........................................15

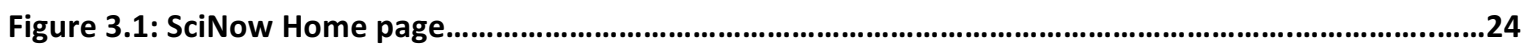

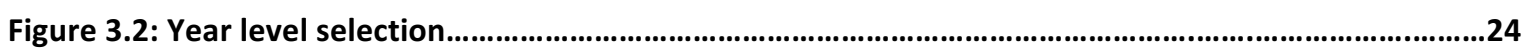

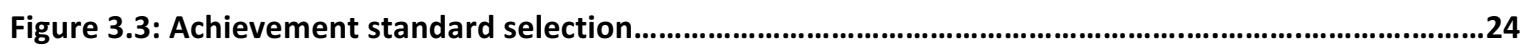

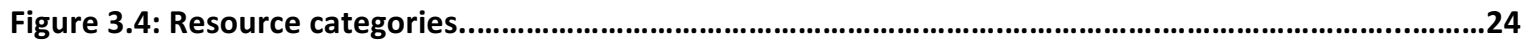

Figure 4.1: Flowchart representing number of participant teachers per school.........................................30

Figure 4.2: Flowchart representing number of student participants per school, group, and year

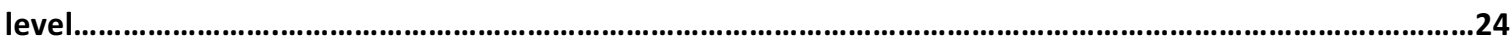

\section{LIST OF TABLES}

Table 1.1: Year group and qualification allocations based on age and years of schooling............................9

Table 3.1: Brief introduction of how SciNow intends to accommodate challenges in science

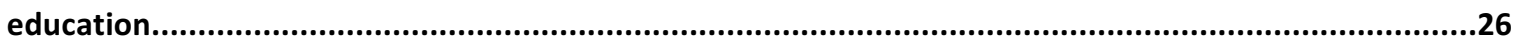

Table 5.1: Table of participant's attitudes towards "science in general" and "science in school"...............40 


\section{List of Acronyms}

AS Achievement Standards

BoT Board of Trustees

CIE Cambridge International Examinations

CRI Crown Research Institute

EDUCANZ Education Council of Aotearoa New Zealand

ERO Education Review Office

IB International Baccalaureate

MBIE Ministry of Business, Innovation, and Employment

MI Multiple Intelligences

MoE Ministry of Education

NCEA National Certificate of Educational Achievement

NEG National Educational Guidelines

NSSI National Statement of Science Investment

NZC New Zealand Curriculum

NZCER New Zealand Council for Educational Research

NZQA New Zealand Qualifications Authority

OECD Organization for Economic Cooperation and Development

PaCT Progress and Consistency Tool

PISA Programme for International Student Assessment

PPTA Post Primary Teachers Association

STEM Science, Technology, Engineering, and Mathematics 


\section{Chapter 1: \\ Introduction to the SciNow Project Report}

\subsection{Introduction}

This project is presented in two parts. The first part is an investigation into challenges identified in New Zealand science education, as observed by science education researchers such as Rosemary Hipkins, Edith Hodgen and Derek Hodson, and the Chief Advisor of Science to the Prime Minister. The second part presents a business case exploring the proposition for an innovative solution to challenges identified.

The challenges identified in part one include New Zealand's decline in student engagement and academic success in sciences (Bull, Gilbert, Barwick, Hipkins, \& Baker, 2010), a significant performance gap between the highest and lowest achievers in sciences (WoodsMcConney, Oliver, McConney, Maor, \& Schibeci, 2013), and an overrepresentation of Maori students, Pasifika students, and students from disadvantaged socioeconomic backgrounds in the low achieving population (Education Review, 2016). These challenges are further explored in chapter three, followed by an exploration of possible solutions.

The consequent business case aims to demonstrate a business model for an innovative service proposed to accommodate the identified challenges. Investigation and review of literature has led to the conception of SciNow, a multimodal resource database designed to aid in science teaching and learning. The functioning of the database and how it proposes to aid student engagement and achievement in science education as well as reduce the performance inequality will be discussed in the findings and analysis and in the business case. This project relates predominantly to the educational industry. However, there is also inclusion of the relevance of science education to the science and technology industries. 


\subsubsection{New Zealand secondary school system}

There are three types of schools in New Zealand: private schools, state schools, and state integrated schools (for example Catholic schools and Steiner schools). State and state integrated schools are government funded, while private schools receive approximately $25 \%$ of government funding. Approximately $85 \%(800,000)$ of New Zealand students attend freely provided state schools (Education Counts, 2017).

Prior to the introduction of the National Certificate of Educational Achievement (NCEA), student year levels were classified by 'forms', with intermediate and secondary school years spanning 'form 1' to 'form 7'. Between 2000 and 2007, most schools in New Zealand adjusted to designating school levels based on the years of schooling completed (that is, year 9 students would be in their $9^{\text {th }}$ year of school).

Secondary school generally spans 5 of the 13 years of schooling. Table 1 demonstrates the age groups, school levels, and assessment levels. For the purposes of this study, all future references to school age will use the current Year Levels.

\begin{tabular}{|l|l|l|l|}
\hline Age & Form Level (Pre 2000) & Year Level (Post 2000) & Official Qualification \\
\hline $13-14$ & Form 3 & Year 9 & N/A \\
\hline $14-15$ & Form 4 & Year 10 & N/A \\
\hline $15-16$ & Form 5 & Year 11 & NCEA Level 1 \\
\hline $16-17$ & Form 6 & Year 12 & NCEA Level 2 \\
\hline $17-18$ & Form 7 & Year 13 & NCEA Level 3 \\
\hline
\end{tabular}

Table 1.1 Year group and qualification allocations based on age and years of schooling.

\subsubsection{National assessment}

The NCEA has been the official qualification of New Zealand secondary schooling since 2002, replacing previous qualifications from 2002 to 2004 (New Zealand Qualifications Authority [NZQA], n.d.). The NCEA system has 3 levels (level 1, level 2, and level 3), with 
an increase in difficulty at higher levels. A level is completed by attaining a set number of credits, for which the student is awarded a certificate. For example, to receive the Level 1 certificate 80 credits must be achieved from classes at any level $(1,2$, or 3$)$. This will usually include literacy and numeracy requirements.

Students are awarded credits for completing achievement standards (AS) through either internal or external assessment. Each subject has a range of AS, each with a goal specific to that subject. When a student achieves a standard, they gain a pre-determined number of credits.

New Zealand schools can choose to offer Cambridge International Examinations (CIE) or the International Baccalaureate (IB) as alternative qualifications as well as or instead of NCEA (Citizens Advice Bureau, 2014). In 2016, approximately 60 schools offered CIE (Association of Cambridge Schools in NZ, 2009) and 23 offered IB (IB Schools of New Zealand, n.d.).

\subsubsection{New Zealand education system Entities}

Selected core entities involved in overseeing the functioning of New Zealand education are the Ministry of Education (MoE), the New Zealand Qualifications Authority (NZQA), the Education Review Office (ERO), the Education Council of Aotearoa New Zealand (EDUCANZ), and the Board of Trustees (BoT) that governs each individual school (Ministry of Education [MoE], 2014). Each entity has its own specific responsibilities, as described below.

\subsubsection{The Ministry of Education}

As the lead advisor to the Government on the education system, the MoE is responsible for overseeing the New Zealand education system through many roles, such as provision of education services and support to teachers, students, and families; provision of funding, resources, and property to educational services; and monitoring school performance (MoE, 2016). It is the MoE that develops and implements education policies and policy changes. The Ministry is funded through taxpayer funding allocated by the Government. 
The MoE directs educational agencies and providers, and is responsible for aiding each BoT to enhance school performance and meet National Educational Guidelines (NEGs), the guidelines for school performance management systems and measurement of teacher and principal performance (MoE, 2015). The MoE and therefore the Government are major stakeholders in New Zealand education. All other entities including; BoTs, the ERO, NZQA, and EDUCANZ all answer to the MoE through the minister.

\subsubsection{The New Zealand Qualifications Authority}

The NZQA oversees secondary school student's academic qualifications under the NCEA system (NZQA, n.d.). The Minister of Education is responsible for appointing NZQA board members, who are responsible for ensuring NZQA implement Government policies and goals.

\subsubsection{The Educational Review Office}

The ERO is a government department tasked with providing regular reports evaluating education quality of all New Zealand pre-tertiary education services (Education Review Office [ERO], 2014). The ERO conducts reviews and issues reports every three years on average, however in areas where school performances are poor or there is a perceived risk to the education and/or safety of students the reviews may be more frequent. The ERO reports to BoTs and the Government, and ERO reports are available to the public.

\subsubsection{Education Council of Aotearoa New Zealand}

The Education Council of Aotearoa New Zealand (EDUCANZ) is responsible for the registration and certification of New Zealand teachers (MoE, 2016). EDUCANZ supports the processes that ensure all teachers meet necessary teaching standards and competency.

\subsubsection{The Board of Trustees}

The BoT is the Crown entity responsible for governance and management control of its school, including the employment of the school principal and other staff (New Zealand School Trustees Association, 2015). All state and integrated schools have a BoT, which is responsible for consulting with staff, parents, and students to ensure the school provides 
educational quality and a strategic direction for any improvements. The BoT is also responsible for the school's finance, administration, property, and curriculum.

\subsection{Project Report Structure}

This chapter has introduced the project and scene setting for this report, with a description of the New Zealand school system and the NCEA.

Chapter two discusses literature reviewed for this study, in which the challenges that motivated this research are identified and the concept of multimodality is introduced.

Chapter three presents the project proposal, discussing the opportunities identified, project objectives, key assumptions and unknowns, and recommended future investigation.

Chapter four describes the research methodology, encompassing the research approach, participant selection, data collection and analysis, and research limitations.

Chapter five presents the research findings, followed by interpretation and analysis of findings in chapter six.

Chapter seven discusses the major findings and reflects on remaining unknowns.

Chapter eight presents the business case, in which findings and recommendations from the research are consolidated into one concise report designed for an investor audience.

Chapter nine concludes this project report, drawing conclusions from the research and business case, including implications of this research and recommendations for future research. 


\section{Chapter Two:}

\section{Literature Review}

\subsection{Identification of Science Education Challenges in Teaching and Learning}

\subsubsection{Current performance in science education}

\subsubsection{Performance measurement}

New Zealand is a member of the Organization for Economic Cooperation and Development (OECD), an international forum for member governments to aid each other to promote economic growth, sustainable development, and prosperity. The OECD conducts the Programme for International Student Assessment (PISA), an international study every three years. Available to both OECD members and non-members, the PISA assesses the performance of 15-year-old students in mathematics, reading, and sciences (Organisation for Economic Co-operation and Development [OECD], 2016). The results provide insight into student achievement and the understanding of current teaching, and can be informative in the future policy development. The implementation, representative sample selection, analysis of results, and reporting of PISA in New Zealand is the responsibility of the MoE research division (MoE, 2016).

The most recent PISA study was held in 2015, with over half a million 15-year-olds partaking. In New Zealand, 4,500 students from 183 schools were randomly selected to participate. The 2015 study had an international focus on sciences, with OECD SecretaryGeneral Angel Gurría stating at the launch of the 2015 results that “....with rapid scientific and technological progress, the advent of the internet-of-things and the prevalence of social media, the ability to understand and discriminate information based on evidence and facts is critical" (OECD, 2016).

PISA results are presented by giving each country a mean score out of 1000 based on a selection of questions measuring literacy in science, mathematics, and reading. A scale of proficiency levels describes the abilities associated with a score. Level 2 proficiency is considered the baseline indicator of basic scientific literacy. While other proficiency testing 
is conducted in New Zealand and internationally, this project report predominantly focuses on PISA measurements in science.

\subsubsection{New Zealand science education performance}

Core findings from the New Zealand 2015 PISA results in science will be discussed below. A more comprehensive assessment is provided in chapter eight.

New Zealand student performance in sciences has remained above global average since the initiation of the PISA testing. The overall trend shows a decline from 2000 to 2015 (Kirkham \& May, 2016).However, due to changes in the assessment of scientific literacy, results from 2000 and 2003 are not comparable (Education Counts, 2017).

While our status as above average performers can be commended, it is pertinent to remember that this means little without establishing what the global average is. Reviewing global performance reveals that worldwide, more than $20 \%$ of students fall short of baseline science proficiency (OECD, 2016). PISA testing has indicated that approximately $83 \%$ of New Zealand students can do basic science tasks, 4\% higher than the OECD member average of $79 \%$.

While the mean score of New Zealand is above global average, the difference in achievement between higher and lower performers in sciences and other subjects is one of the widest gaps in the OECD countries. Measured by comparing the top $10 \%$ and bottom $10 \%$ performers, top performers in science in New Zealand continue to do well (Kirkham \& May, 2016). However, the number of low performers has increased since 2012. As a result, the unfavourable gap between highest and lowest performers is the $3^{\text {rd }}$ highest in the world (OECD, 2016).

Further investigation into performance inequalities shows significant discrepancies in student performances based on socio-economic status (Education Review, 2016) as seen in Figure 2.1 below. 


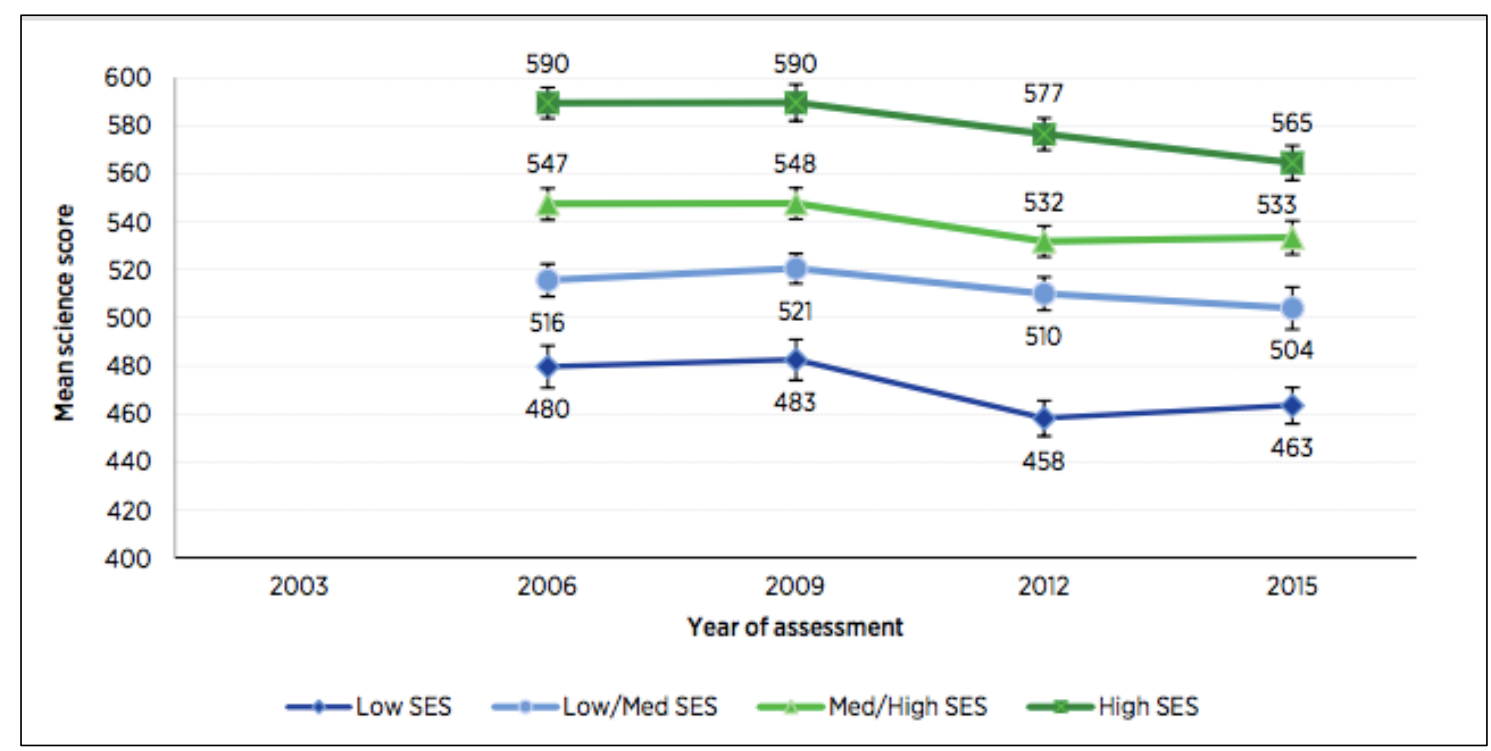

Figure 2.1 Average science performance by quarters of socio-economic status.

Reprinted from PISA 2015: New Zealand Summary Report by S. May, J. Flockton \& S. Kirkham, 2016, Wellington, Ministry of Education. Used under Creative Commons Attribution 2.0 Generic Licence

\subsubsection{Limitations on assessing student performance}

Although New Zealand schools utilise student management systems (SMS) and participate in international performance measurement tests, research addressing performance in science education has limitations (Qin, 2016).

The lack of standardised SMS practices means management of student information has had no common approach regarding what student information should be monitored and how (Provost, 2016). Standardisation of performance measurement is complicated due to the multiple factors that can influence results, such as varying views of stakeholders in determining what constitutes high performance (NZQA, 2011). This hinders the exchange and transfer of information between schools and during SMS changes, as well as preventing what could be a high quality dataset for internal MoE reporting and analysis (MoE, 2016). The MoE is currently working to address these challenges through the Student Information Sharing Initiative project, in which they intend to improve student data management $(\mathrm{MoE}$, 2016).

Confidentiality regulations limit the availability of data (Haug, Jaforullah, \& Alexander, 2010). While certain data sets are publicly available, data is supplied as qualitative 
information and aggregated content (Qin, 2016). For example, ERO reports on school performance provide assessments of school quality with qualitative indicators (ERO, 2016), while NCEA results are available in reports composed of aggregated datasets (NZQA, 2016).

Limited funding for educational research creates difficulty in developing and sustaining research, with short-term research contracts limiting longitudinal research (Wylie, 2013). This challenge is echoed in the first OECD review noting that New Zealand invested significantly less in educational research and development than other developed countries ( Centre for Educational Research and Innovation [CERI], 2001).

Moreover, the opinions and engagement of students themselves are difficult to assess. This is in part because responses are hard to measure in a quantitative fashion, but also implementation, data collection, analysis, and comprehensive reporting on such a large sample population is costly.

\subsubsection{NCEA and science education}

While the NCEA program garners some positive feedback, difficulties have also been experienced that may contribute to current performance in science education.

In the early years after its introduction in 2002, NCEA was criticised for inconsistent internal assessment standards, poor planning and for encouraging mediocrity (NZ Herald, 2007). A lack of training before or during the implementation was censured as some principals and teachers reported they were unable to understand the assessment standards or overarching standard schemes, and were consequently unable to develop appropriate teaching strategies (Gracie, 2015).

Retired teacher Graham Gracie (2015) describes NCEA as a failed experiment, stating "It is meant to be a standards-based assessment, but the standards are norm-referenced so that if the teachers do a better job, the pass rates do not change" (para. 4).

Conversely, Qin (2016) concluded in an empirical study of NCEA performance with positivity, suggesting that with continued development and improvements NCEA had the 
capacity to be a successful system and that ongoing research could improve alignment with International assessment practices.

Further criticism has arisen regarding the distinction between achievement standards reducing the ability to interlink different science disciplines. Taylor (2014) proposed that by being trained to meet distinct targets, students are unable to be educated about the cognitive systems of meaning interspersed throughout varying disciplines. A participant in Taylor's research explained that they preferred teaching integrated physics before it was separated into achievement standards, saying "the concepts [in science disciplines] don't work in isolation" (p. 28). In addition, teachers have cautioned that by omitting unifying theories that link concepts, students are left with a disparate collection of isolated facts lacking authentic thinking experiences (Gilbert, 2004, as cited in Taylor, 2014).

\subsubsection{Science teacher shortages and challenges}

\subsubsection{Science teacher shortages}

Another barrier experienced by science education is an ongoing shortage of science teachers, with close to 200 job vacancies for science and mathematics teachers being unfilled in December 2016 (Dougan, 2016). While shortages persist, schools are being forced to cut subjects, encourage retired teachers to return to the workforce, and have teachers teaching classes outside of their specialist areas (Shuttleworth, 2016). These shortages result in some students receiving inadequate science education from underqualified teachers, while others have no option to pursue advanced sciences as schools' axe classes they are unable staff (Shuttleworth, 2016).

\subsubsection{Workload challenges}

A national survey conducted by the New Zealand Council for Educational Research (NZCER) in 2012 demonstrated that secondary teachers across New Zealand report challenges associated with their workload (Wylie, 2013). Paperwork and assessment moderation contributed to workloads large enough to be considered a major issue facing schooling by $49 \%$ of principals and $58 \%$ of teachers in 2012 (Hipkins, 2013), while " $37 \%$ thought their workload was so high that they could not do justice to the students they taught, 
$52 \%$ disagreed that their workload was fair, and $41 \%$ disagreed that their workload was manageable" (p. 44).

Similarly, the NZ Post Primary Teachers Association (PPTA) survey in 2010 (New Zealand Post Primary Teachers Association [PPTA], 2010) revealed teachers stating that they lack time to develop resources for teaching and struggle to locate update information on assessments; "Hours and hours chasing my tail to locate the most update and relevant information from NCEA, NZQA, TKI and Techlink websites - so many changes - so little time" (p. 8).

\subsubsection{Student disengagement}

Student disengagement in science education has been a topic of discussion both in New Zealand and internationally (OECD, 2016). Factors related to levels of student engagement are multitudinous, for example quality of teaching, interest in a subject, ethnicity, and perceptions of content relevance (Woods-McConney et al., 2013). Factors contributing to student disengagement are discussed in the resarch findings and analysis in chapters five and six.

\subsection{Multimodality in Education}

\subsubsection{What is multimodality}

\subsubsection{What is multimodality}

Multimodality theory is an inter-disciplinary approach to communication, in which communication and representation of information can be relayed through more than just language. Through utilising different modes of communication, people can communicate with one another in both formal and informal contexts with an increased ability to express themselves and the information conveyed.

This utility of different modes of communication is increasingly relevant as the general population experiences increased availability of and exposure to constantly evolving technologies and tools, allowing people to incorporate multiple modes into their 
interactions. For example, the incorporation of creative outlets into regular communication, such as music and art.

A "mode" can be defined as a culturally recognizable channel of communication (Murcia, 2010). Obvious examples include writing, image, and video, while more subtle modes exist in forms such as posture and other body expressions.

Based on a model of working memory, modality theory proposes that there is a distinction between visual and verbal channels in information processing, thereby maximising learning capacity and cognitive processing ability through use of multiple modes. Educational researcher Moreno (2006) discusses the cognitive elements of learning with media as the vehicle in which instructions are delivered; method is the technique provided by the media, and modality is the channel used by the learner to process information.

\subsubsection{Multimodality vs Multimedia}

Multimodality and multimedia, though closely related and both emerging as educational research foci, are distinguishable from one another.

Lauer (2009) differentiates the two through the explanation that multimodal emphasises design and process, while the term multimedia is more valued in the public sphere due to its emphasis on the production of deliverable text. Additionally, Lauer elaborates that multimedia can be perceived as a gateway term and as more familiar for communication with those outside of academia.

\subsubsection{Multimodality, multiple intelligences, and education}

\subsubsection{Multimodality in education}

The use of technology and media in the classroom has been an emerging educational research focus as the impact of technology on students' lives rises. As technology interweaves throughout the environments outside of the classroom, students experience a diversity of learning arenas and communication modes. This can make a contrasting classroom environment easily appear disjointed and outdated. As students evolve with this technological landscape, educators can face challenges when trying to gain the attention and 
engagement of students in classroom settings that diversify from the settings they have grown to feel more comfortable in.

Indiana University's High School Survey of Student Engagement found in 2014 that 82\% of students from 59 schools mentioned that they are sometimes or often bored in class, with the most popular reasons for boredom being "Material wasn't interesting" and "Teaching methods not interesting" (National Association of Independent Schools, 2014).

In response to the changing environment outside of the classroom, it has been strongly suggested that the technological mode has potential to positively impact student engagement and learning when used as a vehicle of science instruction.

Jewitt (2008) reveals that the ways young people learn and interact are affected by the modern abilities of communication and digital technology around them. Through identifying the modern mechanisms of how we learn and incorporating them into educational pedagogy, it may have a positive impact on the quality of education and ability to teach. Jewitt goes on to explain that the way in which ideas are communicated and represented effects both what can be learned from the idea and how it is to be learned: "how knowledge is represented, as well as the mode and media chosen, is a critical aspect of knowledge construction, making the form of representation integral to meaning and learning" (2008, p. 241).

In a world with changing communication requirements, work environments and other facets of the future workforce require accommodation through pedagogical changers (Gilbert \& Bull, 2013). As the technology and science industries grow rapidly, it is vital to educate today's students of relevant skillsets to prepare them as tomorrow's workforce (Bull, Gilbert, Barwick, Hipkins, \& Baker, 2010).

\subsubsection{Multiple Intelligences in learning}

Complimentary to the use of multimodality in education is Gardner's theory of multiple intelligences (MI). Since its conception, MI theory has been globally applied to different scenarios, with the educational community being highly receptive (Davis, Christodoulou, Seider, \& Gardner, 2011). Relevance of MI to education has featured in literature and been 
incorporated into the pedagogy and curriculum of many schools (Chen, Moran, \& Gardner, 2009).

Developed in the late 1970 's, MI theory proposes that rather than a unitary scale of intelligence, individuals each possess a unique profile of eight or more largely autonomous intelligences (Davis et al., 2011). With traditional schooling focusing on just two intelligences, verbal/linguistic and logical/mathematical, Campbell, Campbell, \& Dickinson (1996) point out that students with profiles that deviate from traditional academic intelligences may perform weaker than their potential and face limitations in realising their strengths.

Use of multimodality can aid in the realisation of pedagogies inspired by MI theory. With advances in digital media and technology coupled with the ease in which computers can deliver content, MI inspired lesson approaches can be delivered through multimodality, enabling individuals to learn through strategies that best align with their intelligence profiles.

The combined benefit of multimodality and MI theory allows students to experience learning in ways they are most engaged and most comfortable with, while also being challenged to experience and learn in alternative ways. 


\section{Chapter Three:}

\section{The Project Proposal}

\subsection{The Project Proposal}

\subsubsection{Opportunities present}

Opportunities have been identified in attempts to accommodate and overcome the challenges faced by science education, such as opportunities to improve student engagement in sciences; to support the continued development of NCEA; to reduce inequality in science performance; and to improve the state and outcome of science education. The MoE has developed projects such as the Curious Minds programme (MoE, 2017) and proposed reforms such as the Communities of Online Learning (MoE, 2016). Non-profit organisations have been developed, such as the Teach First NZ scholarship programme endeavouring to encourage and train top graduates to fulfil teacher shortages in low decile schools (Teach First NZ [TFNZ], n.d.).

As many of these endeavours are long-term projects in which progress may not be observed for years (MoE and MBIE, 2014), opportunities are present in the need for more immediate aid, such as the availability and quality of science education resources and learning support. Both commercial and non-commercial sources exist for students to access as individuals, such as free resource website No Brain Too Small (Standley \& Standley, 2011), tutoring company Inspiration Education Limited (Inspiration Education Limited, 2010), and commercial resource supplier Study Pass (Growing Minds Limited, n.d.).

While these endeavours may be successful in fulfilling aspects of opportunities present, this researcher identifies an opportunity in providing improved ongoing support for science education. The concept named SciNow is a comprehensive science education resource database utilising multimodality for the communication of NCEA assessment content.

\subsubsection{SciNow: Multimodal Resource Database}

SciNow is designed to be an accessible online web service. The content of SciNow is proposed to be directly aligned with NCEA, providing content for every science 
achievement standard. Content will be available in multiple modes of communication, ranging from written content to animated lesson delivery.

While similar resource databases are available, SciNow is intended not to compete with other sources but instead to work with them and build upon them to maximise aid to students and teachers. The relationship and comparisons between SciNow and other services will be further discussed in the upcoming business case.

\subsubsection{The SciNow Web Service Design}

The SciNow design is heavily influenced by the concepts of multimodality and MI in learning. Through simple navigation, the design allows students and teachers to select their subject and year level to reach a display of all achievement standards within that subject. By selecting an achievement standard, viewers are given a selection of categories for content delivery.

Each resource will be created based on the NZQA achievement standard requirements, aligning viewable content with assessment requirements. An additional category will be devoted to providing a real-life context for each lesson, to overcome the propensity for students to become disengaged and disinterested in decontextualized content (Tytler, 2007).

The following figures demonstrate a rudimentary design for the basic structure of the SciNow service.

Figure 3.1 demonstrates a basic home page, where NCEA science subjects are listed. Selecting the subject of choice will take the user to a second page, as seen in Figure 3.2, where the year level of study is selected. 


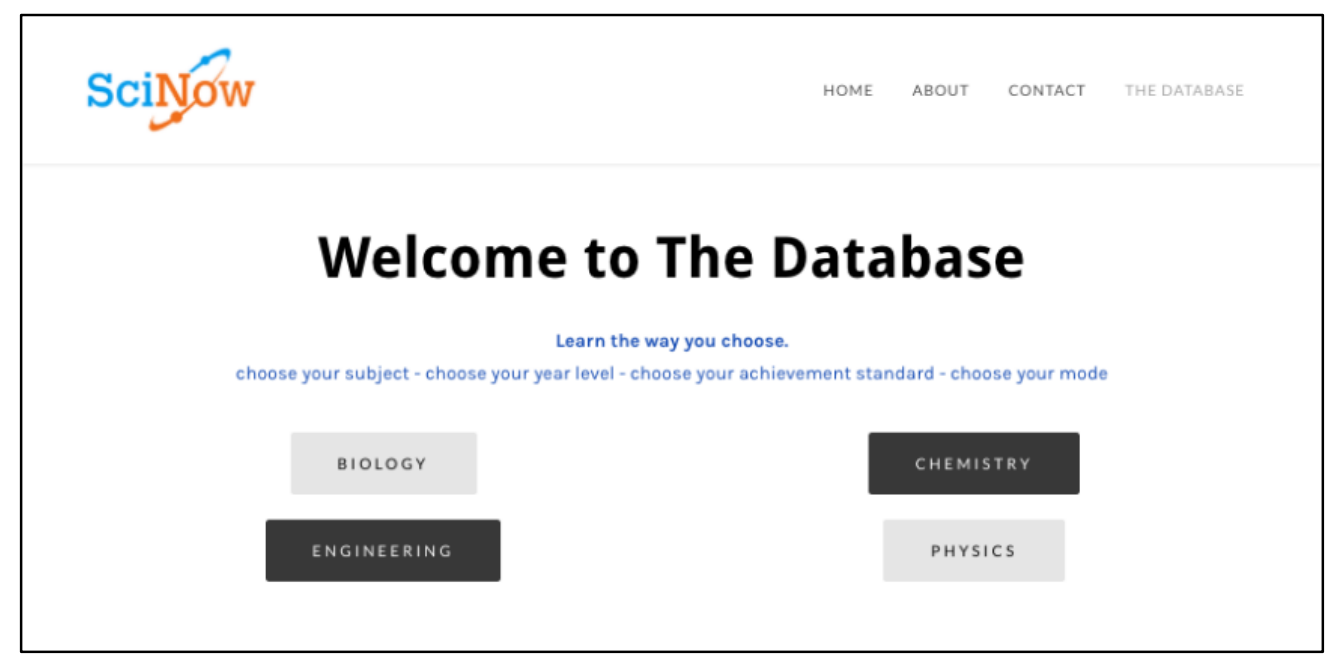

Figure 3.1: SciNow Home page

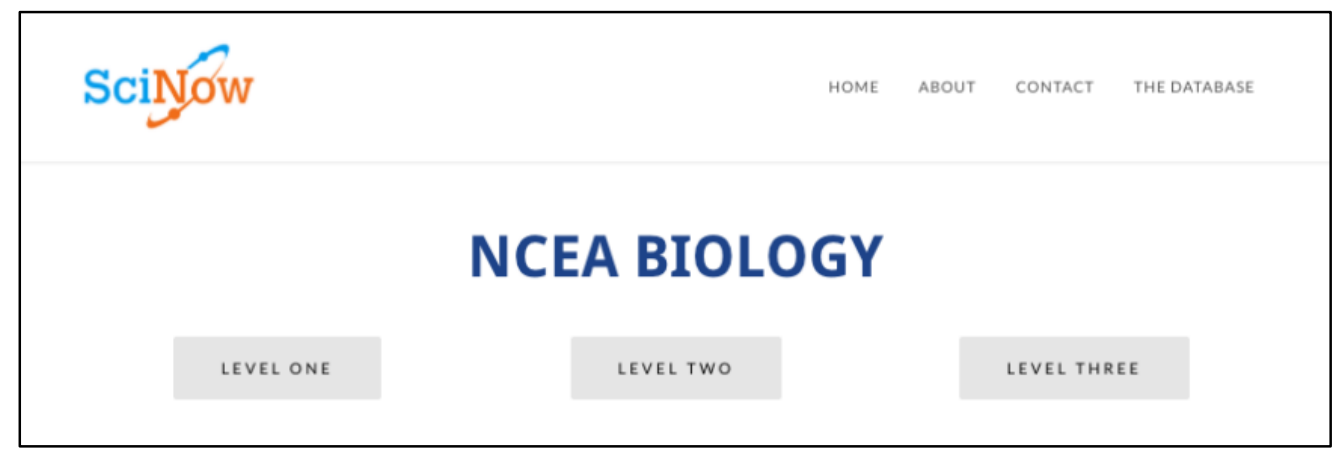

Figure 3.2: Year level selection

Figure 3.3 demonstrates the landing page after selecting the target year level, in which all the current achievement standards are listed and categorised based as internal or external assessments. After selecting an achievement standard, the user is directed to a page where the different categories of resources are represented, seen in Figure 3.4, demonstrating the use of multimodality. 


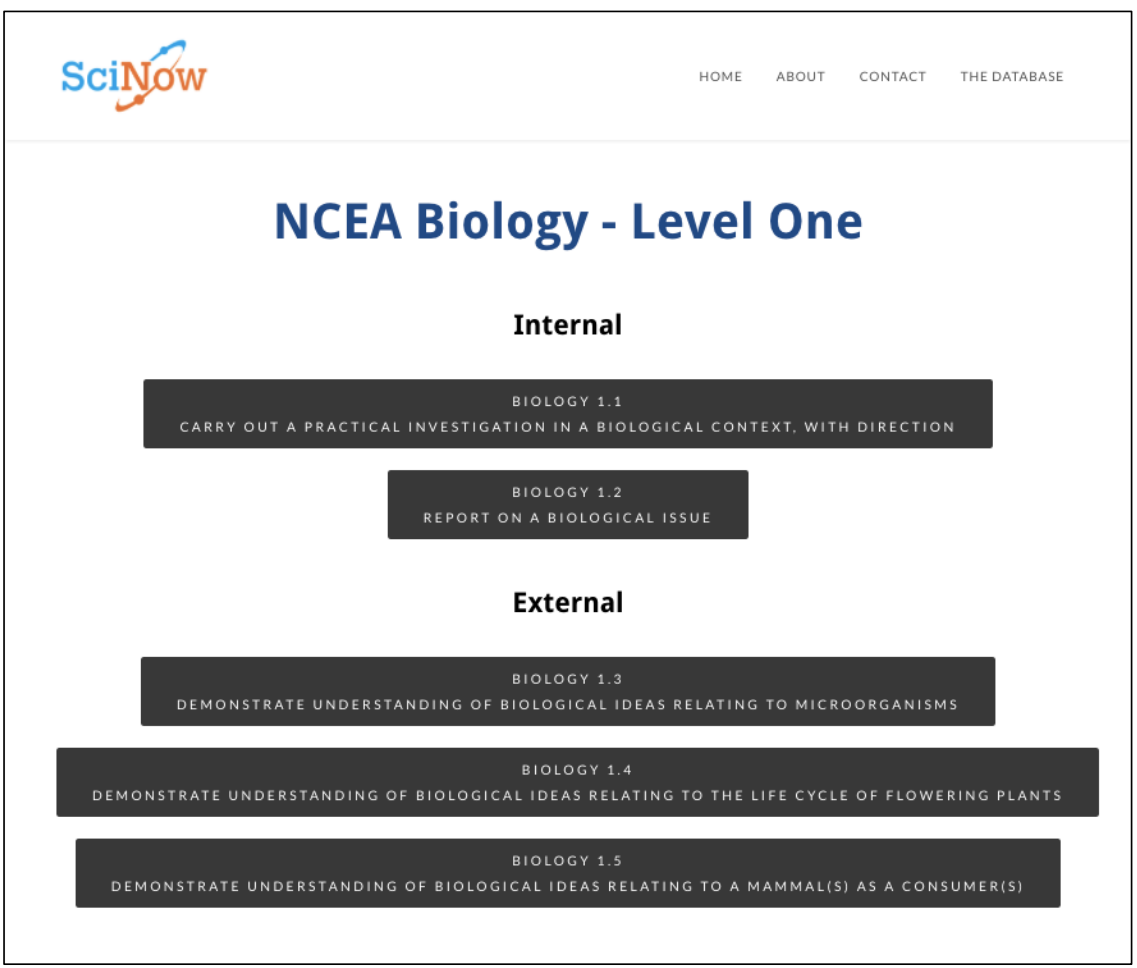

Figure 3.3: Achievement standard selection

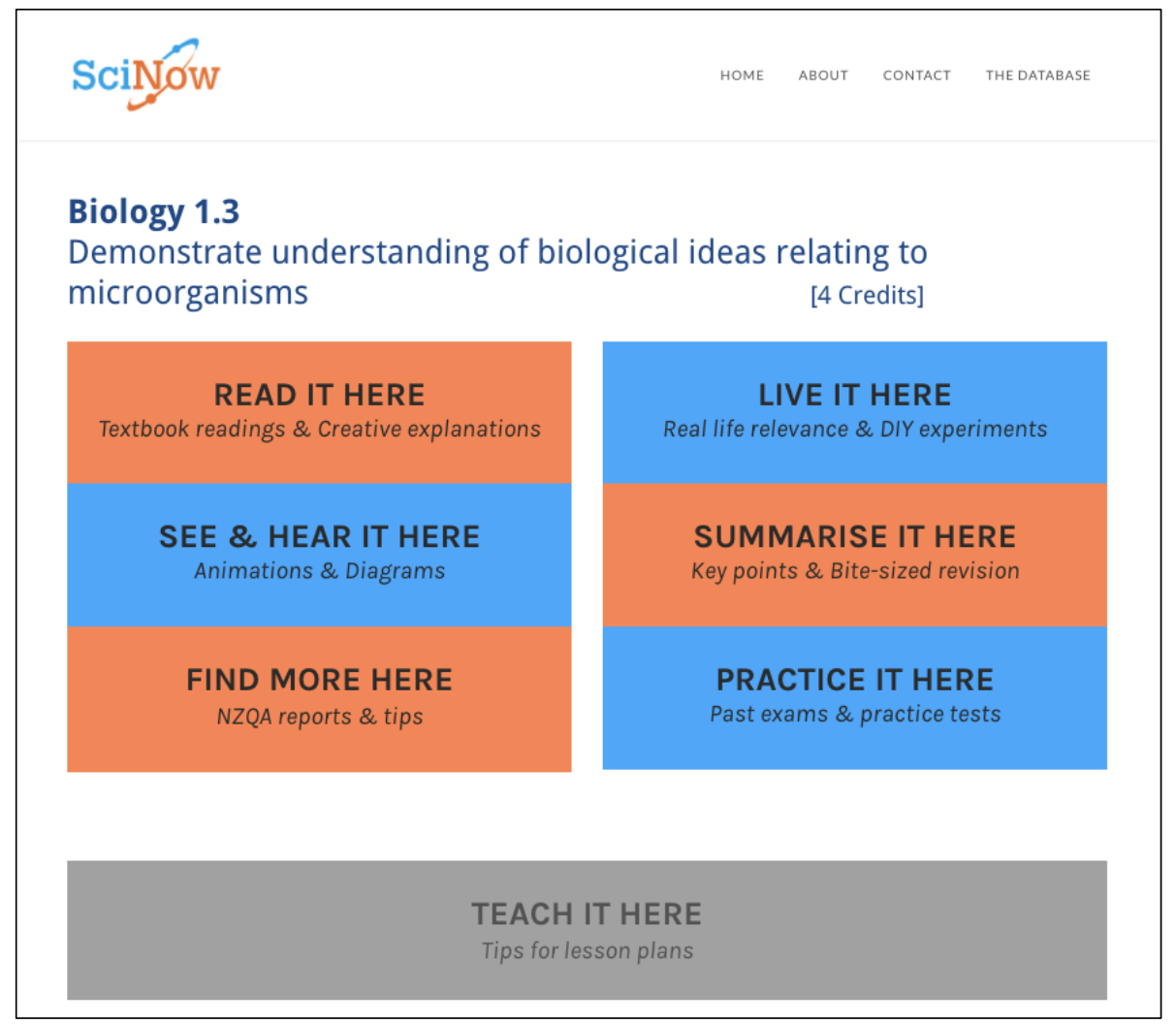

Figure 3.4: Resource categories 


\subsubsection{Overview of SciNow potential benefits}

The table below provides a brief overview of the benefits that SciNow is designed to achieve, with discussion of how SciNow may or may not overcome these challenges in later chapters.

\begin{tabular}{|l|l|}
\hline Challenges Identified & Benefits of SciNow \\
\hline Student disengagement & $\begin{array}{l}\text { The availability of multimodality is intended to appeal to } \\
\text { different intelligences, providing choice in lesson } \\
\text { communication. }\end{array}$ \\
\hline Student disengagement (2) & $\begin{array}{l}\text { Provide lesson content with examples of real-world } \\
\text { application. }\end{array}$ \\
\hline Shortage of Teachers & $\begin{array}{l}\text { While underqualified teachers are required to fulfil gaps in } \\
\text { staff, SciNow is available to supplement communication of } \\
\text { content for teacher as well as aid in lesson planning for } \\
\text { unfamiliar subjects. }\end{array}$ \\
\hline $\begin{array}{l}\text { Shortage of time to compile } \\
\text { resources }\end{array}$ & $\begin{array}{l}\text { Pre-prepared resources designed to aid lesson planning for } \\
\text { teachers when facing time limitations. }\end{array}$ \\
\hline Inequality in Education & $\begin{array}{l}\text { Use of multimodality and designed for multiple } \\
\text { intelligences intends to include recognition of multiple } \\
\text { intelligences and engagement preferences. }\end{array}$ \\
\hline Inequality (2) & Free provision nationwide limits means-based exclusion \\
\hline Inequality (3) & $\begin{array}{l}\text { Research into engagement will include investigation into } \\
\text { engagement preference differences between cultures and } \\
\text { different backgrounds. }\end{array}$ \\
\hline Challenges with NCEA & $\begin{array}{l}\text { As a web service, ongoing updates and regular } \\
\text { maintenance can keep information relevant. }\end{array}$ \\
\hline Challenges with NCEA (2) & $\begin{array}{l}\text { Provision of a database with consolidation of all available } \\
\text { information from various channels (TKI, NZQA, MoE). }\end{array}$ \\
\hline Challenges with NCEA (3) & $\begin{array}{l}\text { Streamlined information delivery also designed to } \\
\text { communicate the functioning and the benefits of NCEA to } \\
\text { parents and teachers. }\end{array}$ \\
\hline
\end{tabular}

Table 3.1 Brief introduction of how SciNow intends to accommodate challenges in science education.

\footnotetext{
${ }^{a}$ In line with findings from the 2016 PPTA report that placed resource development in the top ten most significant tasks for time commitment (PPTA, 2016)

$\mathrm{b}$ This research acknowledges the challenge of reaching students without access to devices.
} 


\subsection{Project Report Scope}

\subsubsection{Proposal assumptions}

1. Use of multimodality will engage and interest students.

2. Students will utilise the service for study.

3. Teachers would willingly adopt use of the service into their classes.

4. Labour will be available to create, develop, maintain, and update the service.

5. Implementation and use of the service will encourage more secondary students to study science.

6. The SciNow service will aid overcoming the challenges identified.

\subsubsection{Research questions}

1. To what extent do students and teachers identify challenges in line with those identified from literature, and/or are there any disparities between challenges identified?

2. To what extent do students and teachers express a want or need for this resource service and/or any other educational resource provision?

3. To what extent is it feasible to provide this service for free, considering the challenges identified and the proposed benefits?

\subsubsection{Further investigation proposed}

The research conducted within this report can be considered a preliminary starting point for development of the SciNow resource database. While both literature reviewed and the research conducted indicate the opportunity for education resource development, further investigation is required to address remaining assumptions and unknowns.

Investigation will require development of a prototype that can be tested in a controlled environment. Prototype testing would more conclusively address assumptions such as the level of success of the service. Research with a wider sample size would also provide more validation regarding the assumptions that schools and students will utilise SciNow and that teachers would willingly adopt the service into their classrooms. 
Upon determining whether the service is successful, the key unknowns will need to be investigated. These include determining the costs of development and maintenance for the service, the cost and process of implementation, the labour required for regular maintenance in alignment with curriculum and assessment changes, and availability of a workforce with skills to accommodate production of resources while ensuring quality of content. Determination of these unknowns is required before the feasibility of funding and/or commercialising the service can be confirmed. 


\section{Chapter Four:}

\section{Methodology}

This chapter presents the methodological approaches for research data collection, with the findings presented in chapter five.

\subsection{Research Approach}

This research was devised using a qualitative and interpretive paradigm.

\subsubsection{The qualitative approach}

Qualitative research employs a broad range of research methods, making it a versatile tool for data collection. While this versatility can make qualitative research difficult to define, this research defines it in accordance with the work of Ritchie and Lewis (2003), as an interpretive approach with an emphasis of participant input regarding explanation and evaluation.

"[The qualitative approach] specialises in the design, conduct and interpretation of research studies using in-depth interviews and focus groups . . . primarily involving individual interviews and focus groups, for explanatory, evaluative or strategic purposes.” (p. xiii)

The flexibility of this approach was helpful in providing detailed data that retained the complexity of participant's responses. This benefit enabled the analysis to draw on data gathered from participants with a range of backgrounds both in personal experiences with science education and resources, and any other experiences that may have influenced their engagement and interest in sciences.

The qualitative approach allows incorporation of an analysis scheme that focuses on identification of emergent series of themes apparent across the range of data sources, as well as considering possible outside variables (Ritchie \& Lewis, 2003). 
The researcher's role has been described in in qualitative literature with the concept of the "researcher as instrument" (Barett, 2007), due to the many tasks the researcher will perform in the processes from data collection to analysis. These include the salient roles of content analysis and derivation of key themes; these aspects being almost entirely reliant on the perception of the researcher.

Steps were taken to avoid use of leading questions or statements, and a strong emphasis was placed on accurately wording participant contributions during transcription and data interpretation.

\subsection{Research Settings}

The following section describes the locations and participants involved in this research. One-on-one interviews were held with secondary school science teachers, group interviews with secondary school students, and focus groups with university students.

A purposive sampling technique was utilised, defined by Bryman (2012) as a form in which the researcher aims to sample participants based on relevance to research questions. This purposive sampling is apparent in the strategized selection of participants, that is, by actively seeking teachers and students that have experienced science education in New Zealand, whether currently or in the past. However, limitations of target participant availability compromised the extent of the purposive nature.

\subsubsection{Research locations}

Research sites were largely dictated by the needs of participants, though limitations such as timing, travel costs, and availability of participants were present.

Focus groups for university students were held at Victoria University. University provision of student facilities enabled booking of private rooms for hosting focus groups in an optimal location for university students, thereby improving appeal during participant recruitment. 
Locations for secondary school interviews were dictated by the participant preferences in location. Interviews with teachers and with secondary school students were held on their school premises with authorisation attained from school principals in advance. In a unique case, two interviews with high school students were held in a booked private meeting room at the Auckland Public Library.

All secondary schools have been assigned a code number for anonymity.

\subsubsection{Research participant selection}

\subsubsection{Focus group participants}

An online questionnaire targeting university students was created to gather general information about students and to recruit participants for focus group interviews.

This also served as a pilot questionnaire, aiding in the construction of question schedules for future interviews. Piloting a questionnaire allows the researcher to attain feedback on clarity and layout, the readability of responses gathered, and identification of redundant content.

The online questionnaire was distributed through the Victoria University network, utilising university group social media and a widely-used intranet in which staff can communicate with students. Of 71 students who completed the questionnaire, 42 students attended a focus group.

The questionnaire demonstrated the varying backgrounds of university student participants, including their varying levels science education experiences.

Students invited to volunteer for the focus groups were offered incentive to attend in form of food and refreshments at the group, and a \$20 supermarket voucher.

\subsubsection{Secondary school participants}

The selection of secondary school participants began with recruitment of high school science teachers, through which students were selected. 
Teacher participants were met at the WellSET Discussion Day conference for Wellington High School teachers in June 2016. When discussing this research, willing and able teachers provided their details for contact upon finalisation of ethics approval.

Due to delays in attaining ethics approval, many of the originally willing teachers were no longer available to aid in research due to the proximity of end of year exams. Those that were still willing and able to take part confirmed times and locations for interviews, as well as sourcing high school students for student interviews and colleagues for further teacher interviews.

Further secondary school student participants were recruited when an Auckland school student offered to arrange students for further research, having seen this research promoted on social media. Attempts to contact their school proved inconclusive., However, on the basis that all ethical policies were adhered to, two separate interview groups of eligible students were organised and held at the Auckland Public Library.

In total, five teachers and 33 students were interviewed from four different schools.

Though some teacher participants were willing to include their name in the research, all teachers were fully anonymised with a simplistic coding system to prevent confusion. All student participants also have complete anonymity, and each has been assigned a pseudonym.

Figure 4.1 briefly demonstrates the teachers interviewed per school while Figure 4.2 categorises student participants based on school, year level, and number of students per interview group. School codes and teacher pseudonyms are used. 


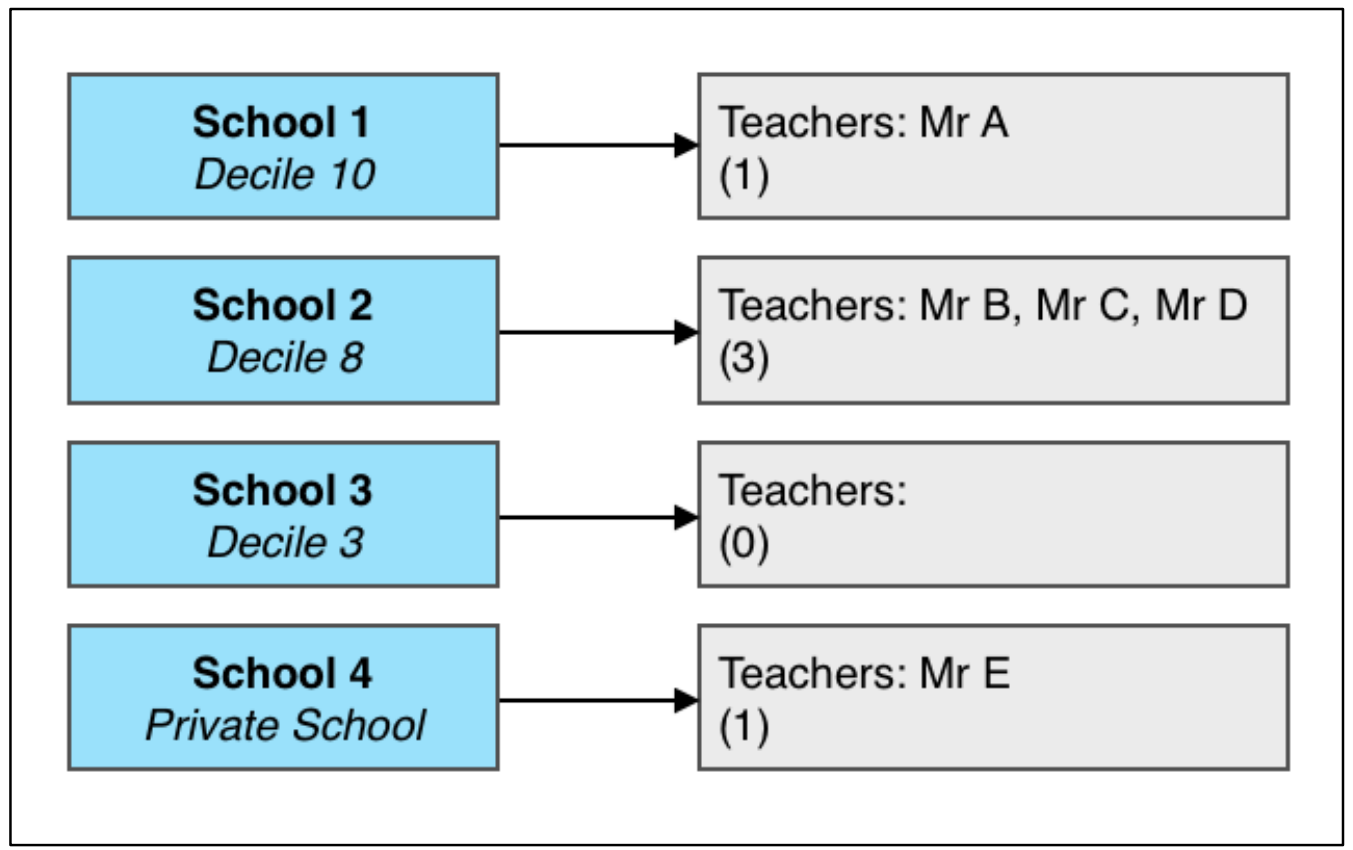

Figure 4.1 Flowchart representing number of participant teachers per school.

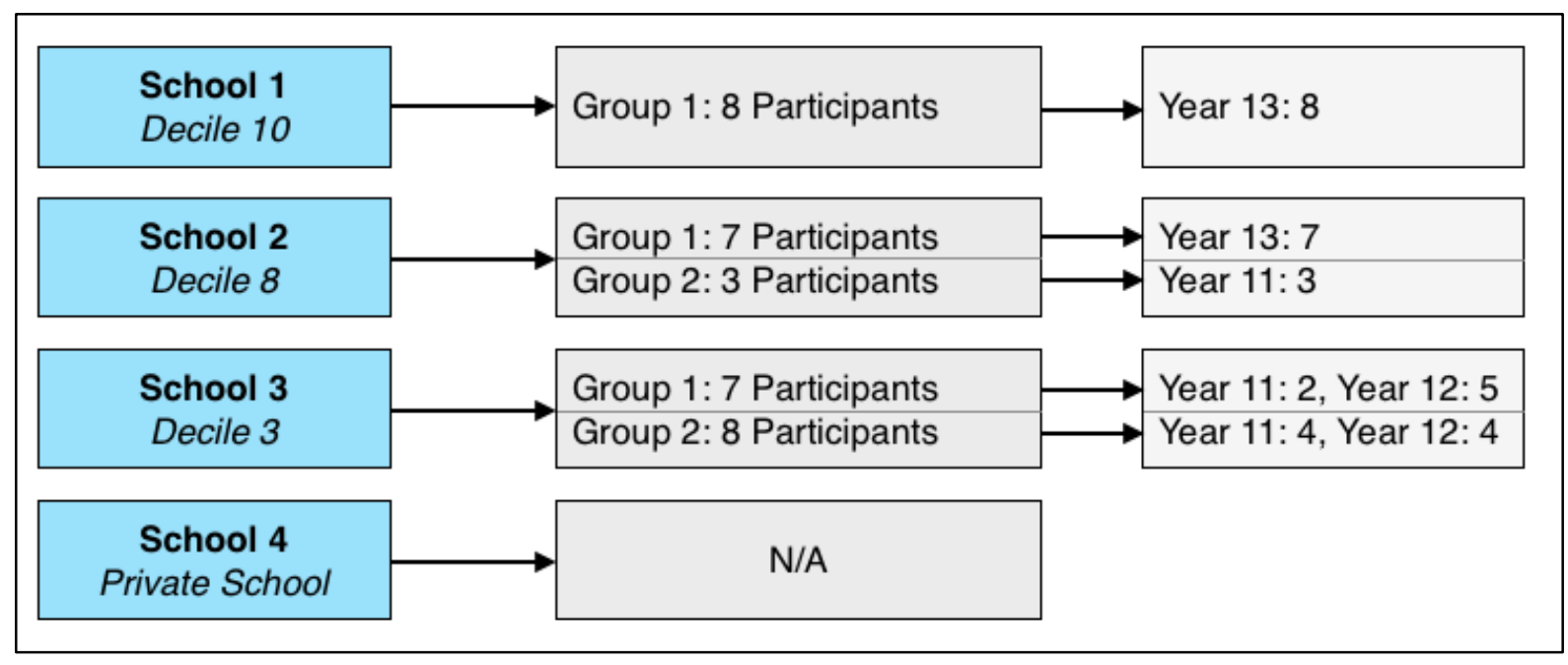

Figure 4.2 Flowchart representing number of student participants per school, group, and year level. level.

\subsection{Data Collection}

This research collected the following types of data, all commonly used in qualitative research: a pilot questionnaire, semi-structured interviews held one-on-one with teachers, semi-structured interviews held with groups of high school students, and focus groups held with university students. All interviews were audio recorded and later transcribed, with transcripts later used in the analysis process. 
Though the titles 'focus group' and 'group interview' are not always differentiated, this research utilises the two titles as distinct from one another. Focus group content is more reflective in nature, with participants drawing on experiences extending from high school into university, as well as featuring far more variation in backgrounds. Group interviews featured participants being asked about more immediate experiences as current secondary school science students. Clive Boddy (2005) suggests that focus groups feature more discussion between participants and less intervention from the researcher, resulting in more breadth of discussion, while in a group interview the facilitator has slightly more involvement in the group and increased involvement in facilitation of data collection.

"I suggest that the key differences between a focus group interview and a focus group discussion are in the level, direction, width and breadth of interaction in the group." (p. 251)

\subsubsection{Data collection: questionnaire}

A pilot online questionnaire was created prior to focus groups and interviews with two purposes in mind. The questionnaire was used in the recruitment of focus group participants and getting a background of participants prior to starting, as well as being used as a basis for constructing future interview questions. The pilot questionnaire responses were reviewed during construction of question schedules, noting where language use or layout required adjustment and removing unnecessary content.

\subsubsection{Data collection: focus groups}

A total of 42 university students attended one of nine focus groups, with between four and six students per group. Focus groups were presented in a semi-structured group framework.

Use of focus groups in this study provided the beneficial opportunity to observe how individuals' perceptions were shaped and influenced by other group members in response to the research topic (Krueger \& Casey, 2015). Multiple strengths are identified in the use of focus groups, as discussed by Morgan (1997): they are time efficient, promote participants building on their responses based on comments or thoughts of group members, and participants can experience more safety in group environments than in individual interviews. 
Given the desire for students to reflect freely and not feel constrained to questions, it was emphasised before commencing each focus group that any input was welcome and that the questions were to be considered more as guides.

It was further emphasised that no outcome of focus groups could be considered a negative, to prevent hesitation answering questions out of concern they weren't saying what they perceived researcher wanted.

Each focus group took approximately one hour, with food and drink provided. Interviews began with general questions regarding students' views on their experiences with science education, with encouragement to allow conversation to flow freely. When students appeared more relaxed and open to discussion, increasingly specific interview questions were asked. The order of questioning varied between focus groups in accordance with the direction participants took conversation.

\subsubsection{Data collection: interviews}

Upon being granted ethics approval, interviews were arranged with the available teachers, while the teachers in turn aided in sourcing students and other teachers for further interviews.

The interview data gathering instrument was an in-depth semi-structured interview guide; a qualitative research technique involving few interview participants with the aim to explore the perspectives of individuals (Boyce \& Neale, 2006).

Interviews as a technique for data collection are appropriate for qualitative research, though care must be taken in formation of questions. For interviews, question formation was influenced by recommendations from the research supervisor, from literature reviews, and from responses attained in the pilot questionnaire.

These interviews utilised a semi-structured and open-ended style to allow natural conversation and to encourage participants to express their opinions freely (Hesse-Biber \& Leavey, 2011). Participants were encouraged to dominate the conversation, with the 
facilitator offering verbal probing when required to ensure responses were understood clearly (Brod, Tesler, \& Christensen, 2009). The order of questioning varied between interviews, influenced by the open-ended nature of discussion. Flexibility of the question schedule prevented any limitations on participant responses or repetition of questions.

\subsection{Data Analysis}

Responses to focus groups and interviews were transcribed and subject to sequential analysis using the NVivo software program. A coding scheme was used to organize and summarize data. First, a provisional list of 'main themes' was drafted based on the research questions and interview questions. From this draft, main themes were assigned codes. Participant responses were separated into sentences, with complex sentences being separated into simple individual sentences. Each sentence was then categorised by theme, accompanied by the origin of response to prevent loss of context. During the process of categorising sentences, the draft list of themes was revised as necessary.

The contents of each main theme were reread, and a second round of coding was applied. In this second round of coding, some content was further categorised into subthemes when applicable. The three sets of research (focus groups, individual interviews, and group interviews) each yielded their own set of main and subthemes, though there is significant presence of crossover.

The categorisation of themes and subthemes was utilised in organising the presentation of findings, and in the process of data interpretation during analysis. A representation of themes and sub-themes can be found in Appendix E.

\subsection{Ethical Considerations}

This research was approved by the Victoria University of Wellington Human Ethics Committee, approval number HEC23331. Informed consent was sought from all participants. All research began with participants being provided an information sheet and 
a consent form to sign. In the case of students under the age of 16 , consent was attained from parents.

The names, details, and pseudonyms or codes of all participants is kept confidential to myself and my supervisor.

\subsection{Limitations}

The timeframe in which data collection was available posed limitations on the extent of research. Long-term research in which participants may have been revisited was unable to be conducted, imposing limitations on the demographic range in the participant sample. As the participant sample includes only five teachers from four schools, the sample cannot be considered a fair representation of New Zealand high school science teachers. In addition, all teachers interviewed are certified science teachers, thus the experiences of students limited by teacher shortages is not explored. A further limitation of this research was the insufficient timing to attempt creation, provision, or testing of a prototypic example of the proposed resource database.

These limitations can be attributed in part to the short nature of this 12-month course, as well as delays faced in acquiring ethical approval.

Due to the qualitative nature of research, the concern of subjectivity is not absent. This research attempts to overcome this concern by removing subjectivity wherever possible, such as through provision of structure to interviews and restricting interviewer input.

The design of the question structure was also influenced by acknowledgment that interviewees can experience a motivation to say what the interviewer appears to want. To avert the "demand characteristics" phenomenon (McCambridge, de Bruin, \& Witton, 2012), the questioning began generalised and became more specific throughout the interviews. Questioning most specifically regarding the purpose of the research, the SciNow resource database proposal, was always placed at the end of interviews. 


\section{Chapter Five:}

\section{Findings}

\subsection{Findings: Pilot Questionnaire}

The pilot questionnaire, shown in Appendix A, was primarily designed for recruiting focus group participants and advising construction of future question schedules.

Only two key questions were asked to gain insight into individual experiences, with other questions mostly pertaining to demographic information. These were:

1. Describe your feelings about science in general in one sentence

2. Describe your feelings about science in school in one sentence

Responses were examined to identify existence of any common subjects, which were:

- Contrasting attitudes towards 'science in general' and 'science in school'

- Influence of teachers

- Importance of science in society

- Relevance of science in personal life

- Interest (or lack of interest)

- Communication of science

All one-sentence responses were sorted into one of three categories: positive perception, negative perception, and mixed perception. Any sentences that were ambiguous in categorising were defined during focus groups, in which the specific participant was asked for confirmation. Table 5.1 outlines the number of participants with each attitude per category. 


\begin{tabular}{|c|c|c|}
\hline Attitude & "Science In General" & "Science In School" \\
\hline Positive & 31 & 5 \\
\hline Mixed & 9 & 8 \\
\hline Negative & 1 & 27 \\
\hline No Response & 1 & 2 \\
\hline
\end{tabular}

Table 5.1 Table of participant's attitudes towards "science in general" and "science in school".

\subsection{Findings: Focus Groups}

As detailed in methodology section 4.2.3, nine focus groups were held with a total of 42 university student participants. The question schedule can be found in Appendix B, however each interview allowed flexibility in structure and order.

\subsubsection{Themes}

Use of semi-structured interviews allowed participants to contribute content that may not have been considered. As described in Section 4.4 regarding data analysis, content was reviewed and key themes were identified. Findings will be presented head by key themes.

The key themes identified were:

- Choices and Motives

- Experiences with Teachers

- Content, Context, Curriculum, and Careers

- Science Resource Use

- Response to SciNow Proposal

\subsubsection{Choices and motives}

A prominent theme identified was discussion of reasons why students made decisions regarding involvement in science education. Decisions to continue or discontinue science varied in motive and timing, with some opting out of science as soon as it was no longer compulsory, some after additional school science, and some discontinuing science when going to university. 
Of all 42 students, only one student claimed to dislike science entirely, commenting that it was not the teachers fault or from a bad experience.:

“I’ve simply just never liked science” - Jenny

\subsubsection{Family influence}

Eight students studied science due to family influence. Of these eight, three students described being pressured into studying science.

"Mum bullied me into science. She had the perspective that school was for academics, and other stuff like music was for in your own time." - Enid

The other five participants described a positive family influence, each having at least one family member engaged in a scientific occupation.

"My step grandfather is a professor, and we would see him regularly for dinner. He'd link science to things I was interested in. He would tell me about his study isolating toxins from sponges with humorous references to Spongebob Squarepants." - Gary

Of these eight students, seven went on to study science at university. The eighth stopped school science after one year, citing a negative teaching experience as the reason.

\subsubsection{Personal interest}

Twenty students reported a personal interest as their reasoning for studying science, often describing an interest that began in early childhood:

"I just always loved science. I was a very outdoorsy child, I loved gardening, and I loved learning about plants and how they grow." - Saadia

Other students indicated their interest was supported by a natural aptitude for science or an inclination towards understanding the world: 
"I was just always interested in science, I wanted to understand the world around me." - Kate

Fourteen of these students continued science at university. Two studied alternative subjects first, then returned to studying science. Reasoning for temporary or permanent departure from science study were all attributed to negative experiences at school.

"It just never grabbed me at school. It was always about the "big picture" and never got specific, which wasn't interesting." - Jason

Of those that returned to science study, one student simply chose to follow a different interest, while the other felt she had been "put off" by a teacher grievance, though later decided she "missed science".

Some students citing personal interest offered limited details, so their personal interest may have been inspired by an alternative factor such as positive school experience or familial influence.

\subsubsection{Media}

Two students attributed their interest in science to media exposure, both citing documentaries such as the work of David Attenborough as the source of their interest in science. One student continued science through to university despite reporting negative experiences with school science, while the other student did not pursue science, also citing a negative school experience.

\subsubsection{Positive school experiences}

Three students attributed their study to enjoyment of science at school:

"I enjoyed science at school. I had good teachers for the most part, I enjoyed science fair projects, it was good." - Harman 
Students also described the link between their performance at school and enjoyment of science, explaining that when they enjoyed a class, they performed better. Contrastingly, others reported that the better they performed in a subject, the more they enjoyed it.

\subsubsection{Negative school experiences}

Six participants studied science beyond compulsory at high school, but did not continue science at university. Reasoning was attributed to lack of relevance in content being taught, lack of awareness of possible careers, disliking the curriculum or assessments, and grievances with teachers.

Some students that continued with sciences discontinued only specific subjects.

Five students cited a teacher influencing discontinuing a subject, and another four cited the curriculum.

"One teacher would never stop or slow down if somebody didn't understand, saying if they didn't understand, it was their problem. That's why at least four of my peers dropped biology." - Karam

One student broached on a complex concept this researcher had not considered, in which he referred to "teacher branding". After family problems influenced poor behaviour at school, the participant felt that teachers "branded" him as disobedient despite his behaviour returning to normal the following year.

"Before then [family problems], I was always a good student. I had one bad year of acting out. But they [teachers] had their mind made up. I had the same teacher in year 11 as I did in year 10, and I felt like from day one of year 11, she was determined not to waste a second on me."- Aaron

Seven participants did not study non-compulsory science at high school or university. While they expressed an enjoyment and interest in science, they were dissuaded by lack of reallife applications and a belief that science was "only for smart kids". Two participants cited their deterrent from science study being that "I didn't have a scientific brain". 


\subsubsection{Experiences with teachers}

Frequent discussion focused on positive and negative experiences with teachers, with all participants mentioning teachers at some point. Most students provided both positive and negative commentary, with 36 out of 42 students providing a positive response and 33 out of 42 students providing a negative response.

Responses discussing teachers were generally detailed, often demonstrating a path of "cause and effect" in which experiences with teachers were linked to a specific outcome, such as teacher or classroom trait influencing academic success or study choices.

\subsubsection{Teacher personality}

Positive traits included teachers being engaging and charismatic, with students responding very positively when believing their teacher personally enjoyed science and demonstrated passion for their subject.

Positive personality traits included twelve students describing their teacher as engaging, eight as charismatic, and seven as fun. Negative descriptions referred to teachers as boring, not being engaging, and lacking charisma. Seventeen students described their teachers having a "bad attitude", explaining that their teacher appeared to dislike their subject and/or dislike teaching.

"I had a lot of science teachers that didn't seem to like science." - Jesse

Participants mentioned that their teachers strongly influenced whether or not students found science interesting and enjoyable.

\subsubsection{Teaching method and resource use}

Participants strongly indicated an affinity for teachers that implemented variation in their teaching method, with high levels of correlation between "boring" teachers and "lack of variation in class", and "fun" teachers with "lots of variations in methodology". 
When discussing enjoyment in science, participants unanimously associated the following features as having a positive impact: variation between lessons, variation in resources used, relevance of content, interactive classes, and practical science lessons.

Student reflections on resource use in class often bore a resemblance to personality traits. For example, all teachers described as boring were noted to lack variation in teaching methodology and in resource use. Use of "outdated" resources were also described as highly disengaging.

"It was so dull. He used to use the same power points for years, so outdated. He didn't even demonstrate reactions for us, he just showed us before/after images." Saadia

Teacher methodology was found most influential on how engaging classes were. Most participants agreed that engagement was improved when teachers ensured students understood content before moving on, involved the class in lessons, and communicated at the appropriate age-level. Disengaging methodology included lack of variation, and excessive use of lessons in which students were required to simply "sit-and-listen" or take notes.

\subsubsection{Relationships and interactions with class}

Students noted the effect of positive and negative relationships between teachers and both individuals and classrooms. Importance was placed on teachers interacting with the class and including them in lessons, with all participants expressing appreciation of inclusiveness in class. Use of high levels of interaction were described as engaging, and some participants suggested that interactive classes prevented alienation of classmates.

Students described having personal relationships with teachers as having a positive effect, while classes lacking any personal relationship were considered very negative. The role of longevity was also discussed in relation to personal relationships, with participants describing the benefit of having the same teachers over multiple years. 


\subsubsection{Staff shortages}

A handful of participants had experienced teacher shortages in their schools, noting a negative impact on their education at no fault of the teacher. Three participants had reporting a large impact on their academic success and their engagement from having unqualified teachers for specialised subjects. Another student described having a teacher having to teach multiple classes during a teacher shortage, saying she was "just stretched way too thin". This resulted in disorganised classes and the participant experiencing a negative impact on their grades and enjoyment.

\subsubsection{Content, context, curriculum, \& careers}

Discussing the content of science lessons was another regular feature of discussion. In this research, "content" refers to content and information being taught in classes as the basis of lessons and education.

Discussions pertaining to science content included the level of context provided with content, curriculum and assessment content, whether content included any practical science lessons, and the level of science career information communicated. Participants often referred to context, relevance, and application interchangeably.

\subsubsection{Context}

Fourteen participants provided positive input regarding the relevance of content, though only one participant didn't also contribute negative feedback. Of those fourteen, nine students directly attributed the relevance to their teachers insisting on providing context regardless of a restrictive curriculum.

Mention of complaints regarding content relevance were in some instances directed at teachers, while other complaints were directed at the curriculum and assessment requirements.

\subsubsection{Engagement}

Participants mutually agreed that content was most engaging when it was not restricted by the curriculum. Some participant mentioned that they enjoyed occasionally expanding above the curriculum, experiencing higher level content on occasion. Ten participants noted 
that the rate of content teaching had an impact on engagement, with moving too quickly or too slowly through content both creating disengagement.

More explicit remarks regarding disengagement were targeted at outdated and uninspiring content, lack of relevance or specificity in content, and an emphasis on memorising instead of learning and understanding.

\subsubsection{Curriculum}

Critique for the curriculum and assessment were often used interchangeably, suggesting that participants were unaware that the two are written and managed by separate entities.

When discussing the curriculum as an influence on studying, many students reported feeling the content lacked engagement and depth, while others complained that the structure of assessments was overly restrictive and took focus away from education.

"Biology was my least favourite of the sciences, but the assessment for physics and chemistry was just so picky. Biology was the one with the most room to write about what you understand, so I kept it up and dropped the others." - Matt

Seventeen participants felt that the assessment schedule was "too picky", describing it as being focused on key words rather than understanding. This emphasis lead participants to feel that the curriculum was focused more on "memorising everything" than learning and understanding science. Thirteen of these participants expressed the "picky" assessment as causing excessive stress, each reporting that they had lost grades to "missing the key word, despite getting everything else correct."

Eighteen participants said they found the restrictive assessment and curriculum limited the level of relevance being taught in science. Seven participants said their teachers regularly expressed frustration at the restrictive curriculum, with participants saying the openness was beneficial for their relationships with the teachers. 


\subsubsection{Careers and relevance}

Discussion of relevance of content taught also provoked 18 participants to discuss longterm relevance of science education, in the form of science careers. These students mostly expressed negative feedback, with 15 participants complaining that they were provided no information or guidance relating to science careers. 3 expressed immense frustration at a narrow-minded perspective communicated in school that the only relevance of science to careers was if you wanted to be a doctor or an engineer, while 4 elaborated that they have faced obstacles that they believe they wouldn't have encountered had they experienced more dialogue about futures in science. For example, students reported "surprise" science papers they had not anticipated in their degrees, such as:

"I've always loved biology, and was very open about my intentions to do a cell biology degree, so I opted out of chemistry and physics at school. Now I'm at university, and discovering I have to do chemistry. I wish that at least one person had stopped me along the way and told me that chemistry could still be important for me." - Sara

One participant reported that career information was available upon request, but lamented that active discussion of careers in science was only directed at advanced students.

Only two students reported having career days at high school, however both recounted these experiences as inefficient and lacking in benefit:

"We had a full careers day . . You would walk around exhibits, talk to different people, find out what they'd done, but you never really learnt "how they got there", which was what we wanted to know." - Sara

\subsubsection{Practical science lessons}

Most participants that experienced regular practical science lessons responded positively, mentioning the benefits of "hands-on" learning and finding them fun and engaging.

Negative responses predominantly discussed either minimal or no practical science lessons, or critiquing was lessons they did have. Negative experiences were attributed to low quality 
equipment, disorganised lessons, and teacher's inability to control the class. Some participants felt that their practical science lessons were unnecessary or inefficient, with lack of linkage between science theory and the practical work.

Students also discussed disliking the decreasing presence of practical experiments as you progress into more senior sciences, feeling the decrease in labs decreases the enjoyment of the subjects.

“We did some practical work, but it wasn't very good. The teacher couldn't control the class and we were never taught the link between the lab and the theory. It felt like a waste of time." - Denise

\subsubsection{Science resources}

Resource use in class was discussed with higher frequency than had been expected, with many students mentioning resource use prior to any direct questions on the subject. Participants' opinions regarding resource use were largely unanimous.

\subsubsection{Engaging and disengaging resource use}

Eighteen participants expressed that provision of and in class use of more resources would have been beneficial. Most participants volunteered that the most engaging use of resources was offering variety in resources, with more specific preferences being use of animations, modern videos, kinaesthetic activities such as games, class discussions, and inclusion of laboratory lessons. Participants expressed that use of "sit and listen" was not necessarily problematic, but that the disengaging feature was the repetitive use of this method.

Eighteen students reported that resource use in their classes was predominantly reliant on a "sit-and-listen" lesson plan, with minimal classroom interaction. These lessons usually involved their teacher speaking while using whiteboards, reading from textbooks, or reading PowerPoint slides.

Fifteen participants expressed they preferred their classes where resources were mixed, describing their classes use of animations, videos, and games in learning. A handful or participants shared that they learned the most from resources such as educational games or 
documentaries. Nine participants emphasised how beneficial they found mixed resources in their learning, but were forced to utilise this knowledge in their own time due to the lack of variation in class.

The most criticised resource use was lack of variation and interactivity, followed by use of outdated and poor quality resources.

"As soon as teacher pulls out a PowerPoint with comic sans font and childish transitions, you knew you wouldn't be seeing anything modern that year." - Fiona

Participants regularly displayed awareness of the different engagement levels of their peers.

"Different students are definitely engaged by different teaching. That's why it's unfair when teachers always do the same thing; it only works for a fraction of the class." - Hailey

"I'm lucky that I can learn from just sitting and listening; but that doesn't mean I enjoyed such boring lessons." - Melanie

One student described being reliant on the website "No Brain Too Small", describing that:

"It pretty much taught me all my science. It had to fill in a lot of the gaps my teacher left." - Saanjali

\subsubsection{Home study}

Four students said that their teachers had worked with them to encourage creating their own study resources, with the teacher's contributions being highly commended. Seven participants reported their teachers personally making helpful resources. Thirteen students said that the only resources available to them were those made by teachers, though the quality of these varied.

Twelve participants complained that they weren't given any resources to use for study, and had to find everything for themselves. Four participants said that their schools directed them 
to various study aids, however they were always resources that had to be purchased and they often couldn't afford them.

Fourteen participants said that the only study resources they used were past exam papers and practice questions, while twelve participants expressed that they benefit from finding and making visually stimulating resources for studying.

Thirteen participants expressed they found it difficult to find resources that were in line with the "arbitrarily nit-picky NCEA requirements" - Matt.

Many participants volunteered that on top of resource provision for home study, they wish that they had been taught more about study methodology. Five participants said they had had a lesson devoted to "learning to study", however they all expressed that these were unengaging and condescending lessons about brainstorms that:

"once again showed that schools don't understand their audience anymore" Kenneth

\subsubsection{Response to SciNow proposal}

Each focus group was concluded by outlining the SciNow proposal then asking participants for their feedback regarding whether they thought it would be beneficial or not, why, and if they had any constructive criticism or other feedback.

All students responded positively, with statements such as "I would've loved that!", "that would be perfect to fill in the gaps for when your teacher isn't very supportive", and "I was looking for something like that literally last year". Most responses agreed that it would be beneficial for engagement as well as learning, with many noting that a lot of education resources needed some modernisation that SciNow intended to provide.

One student provided a mixed response, expressing that while it would be beneficial for students that wanted to study, they questioned whether it would engage those that already didn't like science, explaining: 
"My class were the lowest stream. We were given resources, we just never looked at them, we didn't care in class so why would we in our own time”. - Jenny

Seven students noted that use of SciNow would need to be balanced, explaining that it would be most beneficial if teachers incorporated it into their homework assignments, as they would be unlikely to utilise the service if they already had to dedicate home time to alternative homework.

Eight students specifically expressed that they think it would be most beneficial if teachers implemented use of the service into their teaching method, and seven students emphasised the importance of the service being free.

Thirteen students each mentioned that the particularly beneficial features to them was the idea of complete specificity to NCEA, provided regular maintenance enabled the service to keep up with:

“constantly changing NCEA requirements and expectations." - Denise

\subsection{Findings: Teacher Interviews}

As demonstrated in Figure 4.1, five teachers were interviewed from three schools. Unintentionally, all teachers interviewed were male. Appendix $\mathrm{C}$ provides the original question schedule.

\subsubsection{Themes}

Use of semi-structured interviews was beneficial in allowing interviewees to include content that had not been anticipated, however it significantly widened the subject range of content and influenced variations in the original question schedule. Due to abundance, not all interview content will be included in this research. 
The key themes identified in the teacher interview content are as follows:

- Changing Perceptions in Science Teaching

- Science Education Resources

- Teaching Method

- Assessment and Curriculum

- Response to SciNow Proposal

\subsubsection{Changing perceptions in science teaching}

All interviews began with the question: "Has your opinion and perception of science teaching altered since you began?".

$\mathrm{Mr} \mathrm{A}$ and $\mathrm{Mr} \mathrm{C}$ discussed the impact of assessment on their perception. Mr A described his disdain for the secondary school focus on assessment compared to the focus on learning in primary school. Mr C acknowledged a similar change in focus between year levels, stating:

"In year 9 and 10, it's all about engaging students, trying to get them motivated and enjoying it. Then in year 11 it's suddenly all about assessment." - Mr C.

Mr B's changing perception was influenced by developing an understanding of student engagement, teaching methodology, and planning.

"There's so much you can't plan. I can have two classes in the same day, with the same year level and ability, respond differently to the same lesson. I thought teaching would be a lot more routine or regimented, but it's not." - Mr B

Mr D's interview responses predominantly focused on comparing his experiences teaching in the Netherlands for 13 years prior to moving to New Zealand.

Mr E recounted his perception of teaching being influenced by his move from a decile 1 school to a private school, describing it as:

"just a huge change, they're completely different worlds." - Mr E 


\subsubsection{Assessment and curriculum}

While not featured in the original question schedule, all participants referred to NCEA during their interviews.

Mr A was largely scathing when discussing NCEA assessment, asserting:

"Instead of it being about what you want to know and how you want to learn it, it's about "how can we cram as many facts into you in to get maximum marks in minimum time.... It's not teaching, it's cramming. It's not understanding, it's regurgitating. " - $\mathrm{Mr} \mathrm{A}$

Mr A was the only teacher to discuss alternative assessments, IB and Cambridge. Acknowledging merits in both systems, he concluded that the alternatives offered nothing that NZ didn't have the potential to offer itself and that the alternatives didn't prevent the underlying problem that "the nature of assessing is taking over learning."

\subsubsection{Focus on assessment}

All teachers described the curriculum as overly dictated by assessments and memorizing content.

"It's all about memorizing answers, all about getting credits. Students picking and choosing where they'll work hard and where they'll slack." - Mr D

Mr A deplored the excessive focus on assessments and "chasing credits", asserting that the curriculum, assessment, and marking lacked validity and imposed restrictions on teaching methodology.

"You're basically struggling from internal to internal; you can't do, say or think anything unless it's related to an assessment." - Mr A

Mr B also criticised the restrictive curriculum and focus on assessments. 
"Sometimes you start a discussion with a student, going down an interesting path you'd like to pursue, but you have to go 'ah, have to stop, need to get this content done....,". - Mr B

Contrastingly Mr B was more positive in his response to any grievances with NCEA marking, describing his use of "holistic grades" in marking. He explained that if a student demonstrates understanding but omits a key term, he will grant the student the marks deserved provided the decision can be justified for moderation of marking.

Comparing assessment in the Netherlands to New Zealand, Mr D concluding that both systems featured benefits and negatives. While Mr A described the ongoing presence of internals as intrusive, $\mathrm{Mr} \mathrm{D}$ described the internal assessments in science as minimally disruptive, considering it a more significant disruption when students lowered the priority of science class work in lieu of any other work that is worth credits.

“The way NCEA is set up is... annoying. If there's a chance to gain a credit in ... a dance assignment for PE, students drop everything else and ignore physics because it's not focused on an immediate credit. I'll spend 3 hours marking failed tests because nobody studied, because it wasn't worth any credits. " - Mr D

\subsubsection{Workload}

Both Mr A and Mr E strongly criticised NCEA's administrative workloads. With Mr E reporting:

"The paperwork requirements are ridiculous. It's probably the biggest thing that takes away from my teaching. I'd say at least $75 \%$ of it is unnecessary. " - Mr E

Mr B and Mr C also mentioned excessive administrative workloads.

\subsubsection{Relevance}

All teachers broached the topic of relevance in assessment and curriculum. Mr A and Mr E stated that the focus on assessments and memorising reduced ability to include relevance. 
Mr B discussed the division between internal and external assessments, stating in favour of internal assessment:

"Internal assessments are much more scientifically relevant. They let students develop more of those transferable skills - like reading an article, pulling out the information, plagiarism. There's a valid point for recall knowledge, but not to the extent of externals." - Mr B

$\mathrm{Mr} \mathrm{C}$ and $\mathrm{Mr} \mathrm{D}$ found students responded very positively to inclusion of relevance, but noted that at more advanced levels it's harder to relate content to everyday life. Mr D noted that while this was restrictive, it was less problematic as most students studying senior sciences had an idea of what they needed science for.

\subsubsection{Teaching method}

Interviews were held prior to disregarding "learning styles" in lieu of "multiple intelligences", however responses regarding learning styles still conveyed relevance.

Similar concepts were mentioned by all teachers when asked how they engage and appeal to ranging learning styles. $\mathrm{Mr} \mathrm{A}, \mathrm{Mr} \mathrm{B}$ and $\mathrm{Mr} \mathrm{E}$ discussed use of variation in lessons.

"The best thing I do is try to mix it up... They're definitely more engaged when each few days is different, and when they get to be involved." - MrE

Mr B rejected the concept of learning styles, explaining "I don't actually believe they [learning styles], exists. I wouldn't say it's learning styles, it's learning abilities. ', though he applied the same emphasis of using variation to appeal to different abilities.

"I've taught classes with some students reading at year 12 level while others are at a year 6 level. I believe that both students can learn; but you can't give them the same piece of material. Mixing it up is important." - Mr B

All teachers found engagement was improved by appealing to student's interests, providing relevance to content, and utilizing interactivity in the classroom such as hands on activities 
and laboratory experiments. They also all found definite links between modes of communication and levels of engagement, comparing the disengaging response to excessive notetaking lessons to the increased engagement with stimulating communication channels.

"You need to mix it up and to appeal to them if you want to engage them, and using different modes of content has been the best way for me to do that." $-\mathrm{Mr} E$

$\mathrm{Mr} \mathrm{C}$ divulged that sometimes the hands-on activities may not necessarily be the most educational, they're effective in engaging the students.

$\mathrm{Mr} \mathrm{E}$ also registered a positive response to giving students options when lesson planning. Three teachers identified differences in attitudes between students based on whether their involvement in science class was compulsory or chosen, noting that the hardest students to engage were those that went into science classes with a belief that they didn't like science and/or weren't good at it.

"The big thing I found that grows engagement is to show them that they can do it... It's not that they don't like it, it's that they don't think they can do it." $-\mathrm{Mr} B$

Causes for lack of engagement included lack of interest, lack of self-confidence, and poor relationships with teachers. Mr A proposed that the NCEA content itself can be very disengaging, specifically when the nature of the content conveys little relevance or meaning to students.

“When the lessons and achievement standards don't mean anything to them, when it doesn't mean anything to their lives or their interest or curiosity, of course they're not engaged. When they go into each standard knowing that they have no influence on the direction of learning, they're put off from the start." - Mr A

Mr E also attributed family influence with engagement levels:

"Students with a background where their family don't put much value on academia, they're far less likely to care when they're at school." - Mr E 


\subsubsection{Resource use}

Four teachers felt well supplied by school resource provision, yet all five teachers identified an abundance of materials as problematic whether from school provisions or via the internet. $\mathrm{Mr} \mathrm{D}$ and $\mathrm{Mr} \mathrm{E}$ critiqued the lack of maintenance of resources provided, resulting in masses of unusable and outdated materials. Mr B noted that with the abundance:

"Teachers end up pack ratting and storing everything. You end up spending a lot of time sifting through everything and a lot of time making it "yours". - Mr B

Three teachers described use of internal and external resource sharing systems; sharing internally within school departments and externally through Facebook groups for teachers and official educational institutes. Mr $\mathrm{C}$ described finding materials and then adjusting as needed, noting:

“if something doesn't work in class, I'll change it or make a new resource. It's important to read your classroom and how they respond." $-\mathrm{Mr} C$

Mr A condemned his provision of 'boring books and worksheets' and instead makes his own resources, as well as extensively using The Pond, an online community where educators share resources. Mr B discussed The Pond conversely to Mr A, saying:

"It was created with the best intentions, to have one space where teachers could collaborate and do things, but most teachers have no idea how to use it." - Mr A

All teachers reported creating some of their own resources and expressing the desire to make more if not for time limitations. Whether creating resources or sourcing already made resources, time limitations were mentioned. Mr E noted:

"You can spend hours finding and making resources only to get to the lesson and tell straight away that what you have just isn't engaging the class, they're just not getting it." - MrE 
He expanded his complaint to allude to the abundant resources, stating:

"There's so much stuff out there on the internet, trying to find something that covers the curriculum demands and engages the students can be really challenging, really time consuming. Even in a great school with lots of stuff provided, there's this mass accumulation of over a decade of content, despite changing technology and NCEA assessment requirements. Being given a video from 1990 just isn't going to work for anymore, and the onus ends up on the teacher to find an alternative." $-M r E$

When asked if they were satisfied with availability of resources, $\mathrm{Mr} \mathrm{C}$ was the only teacher to conclude that he was satisfied, while the other teachers all expressed that they would welcome adjustments.

\subsubsection{Response to SciNow Proposal}

When asked about whether interviewees perceived the SciNow proposal to be beneficial, responses were mixed. While it was accepted by all teachers as a beneficial idea, execution was debated.

Mr A noted similarity to The Pond, saying he could see the benefit provided users were educated how to use it effectively. Mr B agreed that if executed well, SciNow would be highly beneficial, though emphasised the requirement for the service to be free.

Mr C explained felt it would be very beneficial, but was doubtful of its likelihood.

"I think it would be beneficial - but I'm a pessimist. I don't think it would happen, it would be too hard to organize. But it would be beneficial."

He also noted that the abundance of resources includes an abundance of databases, all with varying quality. He did however perceive benefit in having a "fall-back" option when you're stuck "so you don't have to spend so much time googling and looking for things."

Mr D agreed it would be beneficial, noting that while schools attempted similar systems, they lacked the manpower or time to maintain and update them, resulting in their overabundance. 
Mr E was emphatically positive, stating:

"I truly think that that would be immensely beneficial." - Mr E

He outlined features he perceived as essential, such as the importance of the "voice" of the content being designed in mind with the target audience and their age group. He most strongly emphasised the importance he perceived that the service be provided for free.

\subsection{Findings: Student Interviews}

Demonstrated in Figure 4.2, 33 students from five schools participated in interviews. The question schedule can be found in Appendix D, though structure and order of questioning varied due to flexibility in interviews.

\subsubsection{Themes}

Use of semi-structured interviews was again beneficial in allowing participants to contribute content that may not have been considered.

The key themes identified in student interview content are:

- Science Education Experiences

- Learning Styles and Resources

- Education Content: Relevance, Careers, and Curriculum

- Response to SciNow Proposal

\subsubsection{Science education experiences}

\subsubsection{Enjoying science}

Eighteen students reporting loving science in class, but felt they had limited access to science outside of class. Some students reported having always loved science, while fourteen students attributed enjoyment to 'great teachers', teaching methodology, and being taught "science that has a purpose". Enjoyment was exacerbated by academic success. Three students reported loving science despite finding it boring in class. 
Twelve students hated school science, though two students reported enjoying a science school holiday program. Those that didn't enjoy science attributed this to grievances with teachers, such as disliking their attitude, describing them as boring, or a lack of teaching content relevance.

Most participants responded that the classroom experience was predominantly influenced by teachers, the content, and assessments. 28 participants expressed that relevance of content increased engagement, while "boring" teachers decreased engagement and academic success.

"If I was to describe science class last year, I'd say 0/10. But this year? 9/10. And it's all because of the teacher." - Alison, Year 11

\subsubsection{Non-compulsory science}

The nine participants in their last year of compulsory science (year 11) were asked if they intended to study science beyond compulsory. Four responded that they did.

Two students attributed their continuity to inspiring teachers.

"Having an interest inspired by an amazing teacher. Mr C made me see that science is all around is, and that's it's actually really amazing." - Mark, Year 11

One student attributed continuity to parental pressure, and the fourth expressed an interest in technology as motivation.

One student chose not to continue science due to specific interest in alternative subjects, while the other four students chose to discontinue science based on perceiving science as "boring", "too hard", or disliking teachers.

"I've never had a science teacher that seemed like they even liked science. Or teaching. "- James, Year 11 


\subsubsection{Practical science lessons}

Most participants detailed both positive and negative experiences with practical science lessons.

Positive responses described ideal lessons as fun and engaging, and most educational when related theory was taught prior to practical work.

"The best labs had us do a theory lesson one day and then the lab lesson the next. It meant you could be fully focused on the lab and know what was going on, e.g. we learnt about eyes with a theory lesson one day and a dissection the next." - Rachel, Year 13

Negative responses mentioned disorganised teachers and lack of quality equipment. A more significant focus was on criticising practical lessons being 'out of sync with the theory'. Students disliked practical lessons when related theory was not covered or understood, or when the lesson took place significantly before or after learning the theory.

\subsubsection{Relevance and careers}

\subsubsection{Relevance}

All participants expressed the importance of content relevance and application. Positive responses emphasised that the best teachers worked hard to make content relevant, and believed that curriculum requirements imposed the limitations.

“<Teacher> makes science awesome. He puts all his lessons into a google docs folder we can access, and if there's no time in class then he'll add extra information to communicate why the lesson matters and how it affects us." - Andrea, Year 13

Many participants describing their favoured teachers expressed a desire for other teachers to replicate favoured teaching method and behaviour.

Further discussion noted the benefits of content being modern, with participants expressing a desire to focus more on science and technology involved in their daily interactions. 
"I understand that a lot of old science was ground breaking, but learning about research done in the 60's isn't exciting. Teach me what's happening here and now, about the research I might one day be contributing to!" - Tim, Year 12

Some students felt they had developed the ability to apply certain skills to their lives despite limited relevance being taught.

"Studying science has given me a better understanding of things around me... like knowing to question dumb clickbait headlines everywhere!" - Karen, Year 12

Some students suggested the lack of application likely contributed to why some students "hate science and find it boring."

\subsubsection{Science careers}

All participants felt science career information was limited or absent, noting a generalisation that science was only for medicine or engineering. Most participants believed non-medical science careers had limited potential salaries. Almost all year 13 participants reported feeling "lost and uncertain" regarding their career options, with many expressing exasperation at the call for STEM students and graduates.

'It's in the news, it's on social media, it's on career posters: we need more people in STEM. Well, here we are, all 'STEMmed up'. But what now? What exact degrees should we be doing?" - Dan, Year 13

\subsubsection{Resources and learning styles}

\subsubsection{Learning styles}

Discussion of learning styles yielded an array of feedback, with the most common point being that regardless of learning style, the most significant influence was when a class lacked any variety. All students alluded to disliking consistent lessons restricted to notetaking as the teacher talked and spending lessons silently working through workbooks. 
Students were scathingly negative regarding classes that lacked variation, describing them as disengaging, boring, and inefficient for learning. Resources in these environments were also criticised, describing language used as condescending.

"I hate all the condescending material. I hate watching a youtube video that talks in a voice like they're talking to a 8 year old. What is this, Blue's Science Clues?" - Maddy, Year 12

"I've never been taught science in anything except from those awful SciPad books. Seriously, SciPad? What idiots do they take us for? Like we're going to think 'ooh well it rhymes with iPad so it must be cool'?" - Carlos, Year 12

Positive responses described teachers utilising a variety of resources and teaching methods, as well as mentioning the engaging effects of visual stimulation. It was noted that teachers whom utilised variety were usually those with the most positive attitudes.

One third of participants felt aware of their most personally efficient learning mode, while the rest expressed lack of certainty. All participants expressed a significant preference for variation in the classroom regardless of personal preference, with some also noting they had different learning preferences for different sciences.

Inclusion of class discussion was also regularly mentioned as beneficial. Few students proposed that a prominent benefit from class discussions was the translation of material into familiar language.

"Class discussions are best, and I think a large part of that is communicating the content in more familiar language. My understanding is always best after a class discussion." - Raj, Year 13

Many students, with both positive and/or negative experiences, noted observing the different needs of their classmates. 
"As a student, you can see everybody needs something different, and so we can see when each other's needs aren't being met. All the people I know that dropped science asap, they just weren't being engaged." - Katrina, Year 13

“What's most important is variation. I mean, not every lesson is going to appeal to everyone and be the most educational for them, but it keeps us engaged. I mean, if I spend a whole lesson bored, I'm not going to go home to read up on what I missed from not paying attention. When class is interesting, I'm way more likely to go home and try to fill in the blanks."- Adam, Year 13

\subsubsection{Educational resources}

Responses were prevalently negative when discussing educational resource use and provision.

Positive discussion involved students reiterating the benefits of variation in class, noting resource variation was a significant component of these benefits, in conjunction with preferred teachers. Most students reporting positive class resource use also reported positive experiences with home study resources, stating that their teachers provided resources for home study and/or directed them to further resources.

Negative responses reiterated the lack of resources in conjunction with lacking learning styles and classroom variation.

All negative responses described limited, poor quality, or absent provision of resource for home study. Those least enthused by science education felt the lack of provision or awareness of resources contributed to their failure to study.

Most participants acknowledged the multitude of online resources, with mixed responses regarding whether they were beneficial or not. Some sources would be commended by some participants yet criticised by others. Critical feedback including describing the abundance of online content as time consuming and confusing, while others struggled to find resources that were personally engaging while also appeasing the specific NCEA information requirements. Criticism also mentioned instances of condescending language choices and 
unengaging aesthetics. Ultimately, all participants expressed desire and requirement for variation in resources for home study as well as in class.

\subsubsection{Curriculum and assessments}

Most participant contributions included references to the NCEA curriculum and/or assessments. References were predominantly but not exclusively negative.

The most frequently mentioned criticisms, with every participant mentioning at least one, were as follows: Excessive focus on credits, lack of synchronicity between lesson plans and assessments, lack of uniformed link between workload and credit value, curriculum content restricting classroom conduct, and an overemphasis on memorising content rather than demonstrate understanding.

"The curriculum isn't always in time with assessments - doing an internal a term after you did the content, or not doing it till you've just started a subject!'”-Angela, Year 13

"A whole bunch of assessments require so much work but their credit value just isn't worth it. It's completely erratic." - Jane, Year 12

Five students expressed a preference of NCEA over alternative systems, with two expressing that studying NCEA included more potential to focus on a New Zealand context, though they felt this focus was absent in the science curriculum.

Two students balanced slight criticism by noting that the faults discussed were more likely to be regarding assessment itself, not specifically NCEA.

"It's not necessarily NCEA though... you probably don't come across many teenagers that praise assessments no matter what system they're in." - Matthew, Year 13 


\subsubsection{Response to SciNow proposal}

All responses to the SciNow proposal were favourable. Participants with the most negative experiences with science education were the most enthusiastic about the potential benefit of SciNow. Responses included describing SciNow as most beneficial for the classes when:

"we're mostly left to our own devices a lot. The teacher walks in and tells us to fill out the workbook. SciNow could be a far more engaging and educational alternative" - Adam, Year 13

Some participants expressed doubt that teachers with such limited use of method would utilise SciNow considering their failure to appropriate the already available content.

"It would be great to have everything in one spot - there's so much stuff online, all scattered everywhere." - Raj, Year 13

Most participants indicated most prominent beneficial feature was providing content through multiple modes, explaining that having one source for all the different styles would:

"save the time spent moving from source to source based on your needs for each achievement standard." - Dean, Year 12

Constructive feedback accentuated the importance of appealing to the correct age group in language and aesthetic design. It was also emphasized that the service would need to be well organized.

"Sometimes what deters me from the websites available is the sheer busyness of the webpages and the content." - Nalini, Year 13

Suggestions for further components recommended inclusion of a communication channel between teachers and their students, and seeking endorsement by NZQA to help promote it and raise awareness. Six students proposed using the SciNow model to:

"Replace StudyIt, the outdated, unattractive, and poorly maintained Ministry endorsed one." - Dan, Year 13 


\section{Chapter Six:}

\section{Analysis of Findings}

\subsection{Introduction to Analysis}

In this chapter, the data presented in findings will be analysed in relation to the project assumptions and research questions, discussing whether the assumptions can be proven or not, and whether the research questions are answered.

The main themes used to head each research group throughout findings have been combined and restructured for this chapter, to provide a clear summary of analysis. Findings will first be interpreted and summarised by theme, and then discussed relation to the assumptions and questions.

\subsubsection{Observation of interchanging terminology}

Through analysis of content, it was observed that some responses included interchanging use of terminology. These have been outlined below to improve clarity in interpretation of findings.

\subsubsection{Content and context}

Throughout the findings, focus group and secondary school students often referred to context, relevance, and application of content. Similar discussions held with teachers more often discussed validity. The context of interviews demonstrates that despite variation of wording, the underlying concepts are either the same or highly similar.

\subsubsection{Assessment and curriculum}

Participants of focus groups and secondary school interviews frequently demonstrated inconsistency regarding the distinction between the NZ curriculum and NCEA assessment. At some points, participants appeared to use either term interchangeably. The level of awareness of the distinction unfortunately cannot be clarified in each instance. 


\subsubsection{Acronym use}

Throughout the analysis, the acronyms FG and SS have been used to denote Focus Groups and Secondary Students respectively.

\subsection{Studying Science: Choices, Motives, and Experiences}

Almost all FG and SS participants indicated an interest in science, with only one student explicitly saying they did not like science. Interestingly, the level of interest in science is not matched by the level of engagement in science study, with many participants expressing that science at school does not appeal to their interest.

Choices regarding science study, whether continuing or discontinuing, were mostly influenced by personal interests, family, and school experiences, with school experiences encompassing teachers, content, and assignments.

Negative experiences and discouraging influences were described in more detail than positive experiences, though the reason for this is unknown. This may reflect the disproportionate relationship between student interest in science and involvement in school science, or it may have been influenced by a false perception that the researcher was primarily seeking complaints.

The most regular criticisms regarding the experience of studying science targeted teachers, content being boring or lacking relevance, assignments being overly restrictive and not conducive to education, and lack of self-belief. The mass inclusion of these themes indicates that they are all highly influential in long term science education. Critiquing targeting teachers is additionally important to consider, as obstacles were not primarily at personality or competence of a teacher but also at the relationships formed between student and teacher. 


\subsection{Science Education Content}

\subsubsection{Context, relevance, application, and validity}

Teachers expressed dis-satisfaction regarding the lack of validity in lessons and in assessment, describing content as unappealing to students' interests and the assessment as inefficiently focused on memorisation. The lack of validity in assessments was described by one teacher as not up to date with the changing skillsets most relevant to the current scientific landscape, thereby fails to prepare students for actual science application.

"Students with a background where their family don't put much value on academia, they're far less likely to care when they're at school." - Mr E

SS and FG both wanted more relevance, considering it highly influential on levels of engagement, interest, enjoyment, and educational performance. FG and SS students were not unanimous regarding who they held accountable for relaying content relevance. Some students attributed inclusion of context to their teachers, while others blamed teachers for lack of context. Other held the curriculum and assessment accountable for deficient context. SS participants also expressed a strong desire for more modern content.

The conclusive feature identified is that the content being taught has a significant impact on the perspective of science education.

\subsubsection{Relevance to careers}

Between FG and SS, remarkably few felt they had been provided with information regarding science careers, with many final year secondary students feeling 'lost' and 'without direction' based on insufficient information.

This lack of direction was reported as a dissuasive factor for both short and long term science study. 
While levels of information are available, students clearly believe that the school and curriculum should be required to provide more specificity regarding science career information. Interestingly, FG and SS also expressed wanting to see science content related to non-scientific careers.

This may be related to the level of interest in sciences outside a school setting, though FG participants primarily wanted this knowledge to prepare them for unexpected science requirements.

\subsubsection{Curriculum and assessment}

Discussing assessment and curriculum, all teachers observed and disliked an emphasis on memorising rather than learning. Further dissatisfaction was related to an excessive administrative workload, impairing their teaching ability.

The credit-focus of assessments was panned not only for reducing validity of science class content, but an awareness that students focus in science was diminishable based on credit availability in other subjects.

With SS and FG participants echoing the sentiments of teachers, the curriculum and/or assessment are largely considered significant obstacles in science engagement and performance.

\subsection{Teaching Method, Learning Styles, and Experiences with Teachers}

\subsubsection{Changing perceptions as a teacher}

The emphasis on assessment and credits was further reiterated when teachers noted the stark contrast between the pre-assessment level and the subsequent assessed level science as influencing their perception of science teaching.

Factors attributed with changing perceptions towards science teaching may indicate discrepancies between the emphasised factors of teacher training and the reality of teaching, 
such as Teacher B's revelation that lesson plans need to be flexible rather than finite to most efficiently keep students engaged.

\subsubsection{Teaching method}

Teachers, FG, and SS all conveyed similar views regarding teaching methodology, with emphasis placed on the benefits of lesson variation.

Teachers' use of variation is influenced by acknowledgement of differing students' needs, with changing methodology maximising the likelihood of reaching all student requirements. Teachers also demonstrated recognition that students enjoy relevance in content and respond well to having their interest appealed to, as corroborated by FG and SS feedback.

All teacher, FG, and SS participants acknowledged that performance waivers when students are disengaged, disinterested, or have poor relationships with teachers, and that this disengagement and disinterest is most prominent when science education lacks relevance of content and variation in lesson methodology. Interestingly, individual students conveyed awareness of when peers were unengaged or weren't having their educational needs met. Even in individuals that felt aware of their personal optimal learning environments, variation was desired to successfully appeal to all class members.

FG and SS responses also emphasised the influence of attitudes teachers displayed towards both their subjects and their students, with students being highly receptive to teachers perceived as lacking enthusiasm for science.

FG and SS input revealed a strong correlation between teachers with favourable attitudes, teachers that offered variation in lessons, and teachers with high variation in resource use.

The benefits of variation in lessons and resources are unanimously recognised, with FG and SS participants emphasising the importance of resource quality and interactivity in classes. Further insistence is placed on teachers displaying positive attitudes towards science and their students.

Ultimately, it is evident that science classroom environments are significantly implicit in engagement, interest, and educational outcomes in science. 


\subsubsection{Practical Science Lessons}

Teachers and some students acknowledged that not all practical lessons are the most educational, but that they were beneficial for engagement.

All FG and SS participants indicated that they wanted and enjoyed practical lessons, though specific requirements were essential in their operation. When these ideals were not met, practical lessons are received negatively.

Features of ideal practical lessons include: organisation, a level of equipment quality, and a link between the practical lesson and theory. The biggest influence on effectiveness was the link between practical work and theory lessons, with many participants reporting lack of synchronicity between practical work and theory and/or related assessments.

Ultimately, students had an affinity towards practical science experiences, with the main emphasis being on the educational value.

\subsection{Resource Use and SciNow Proposal}

\subsubsection{Resource use}

Four out of five teachers felt well supplied with resources by their schools. However, they also reported an overabundance of resources of varying levels of quality. Lack of maintenance of resource storage resulted in significant levels of outdated content.

All expressed benefit from creating their own but being regularly prohibited due to lack of time. Some noted that a lot of content benefits from being altered to suit individual classes. Teachers described use of both internal and external channels in which resources can be shared, however they noted excessive time often went into sorting through the many channels to find ideal content.

FG and SS participants all indicated a preference for teachers that avoided excessive use of textbooks and whiteboards. An affinity was demonstrated towards interactive and visually stimulating resources. 
Most FG and SS participants were provided with little or no resources for home use and study, some reporting having one or so teachers that were unique in their effort to provide home resources. While some students were aware of online sources of materials, many students were unaware of their existence and felt teachers should've promoted these more.

A common complaint described resources as condescending, feeling that the authors were "out of touch or just unaware of our age".

Past exam papers were the predominant resource for exam preparation, with students feeling the best way to study was memorising answer information such as structure and key words. While this may be encouraged by lacking available resources, it reiterates the concern that an overemphasis is placed on memorising rather than learning and understanding.

Though the extent to which is unclear, there is a demonstrable link between resources and engagement both in class and in home study. It is also evident that obstacles are present for both students and teachers in sourcing ideal resources.

\subsubsection{Response to SciNow proposal}

Responses to the SciNow proposal provided valuable input, with all university students and secondary school students perceiving that the service would be beneficial, as well as valuable feedback questioning its potential.

FG and SS participants indicated the most prominently beneficial feature is availability of content through multiple modes. An additional feature likely to be well-received is in line with participants expressing desire for more modernisation of resources. Due to the utilisation of modern technology and content, this demand is easily appealed to.

Despite the prominence of positivity in responses, many obstacles have also been identified. While resource quality and availability are identified as contributing factors to engagement and interest in sciences, assisting this factor will not overcome issues from other major influences. Teachers that currently use minimal variation in methodology and resources are doing so despite presence of alternatives, indicating that it is unlikely for SciNow to change. 
Additionally, SciNow would have minimal influence on the more innate educational obstacles; that is, criticisms directed at the curriculum and NCEA.

\subsection{Unexpected Findings}

Throughout the research, some responses illuminated factors that had not been anticipated yet demonstrate relevance to the purpose of this research.

While availability of certain resources was acknowledged prior to research, responses indicated a more substantial abundance of resources than had been assumed. Teachers referred to use of internal and external channels for sharing resources, as well as the provision of resources from their schools. This instead revealed an alternative challenge, in which the overabundance of resources had a similar impact to that perceived from lack of resources. The unanticipated availability of resources is particularly poignant when considering the minimal variation in methodology or resource use reported in teachers; with the possibility that the different levels of resource use is linked to whether certain teachers are aware of resources available.

A further unexpected finding was the extent of contrasting attitudes students often held regarding science, with significantly more students expressing an interest in science than expected and the disinterest in science often being specific to science at school, rather than science itself.

A factor that had been anticipated but underestimated was the influence teachers had on students based on attitude and personality traits. While personality traits such as charisma were anticipated to be influential, the attitude towards science was often featured, with students regularly expressing a strong negative influenced when they believed their teacher disliked science. 


\subsection{Assumptions and Research Questions}

\subsubsection{Analysis of proposal assumptions}

The following addresses the analysis presented in this chapter in relation to the proposal assumptions, outlining to what extent the assumptions are proven or disproven.

\section{Use of multimodality will engage and interest students.}

Participants regularly expressed the influence of teaching methodology and resource variation on engagement and interest in sciences. As multimodality incorporates both factors, it is likely that emphasis on multimodality will improve engagement and interest.

Further research is required to conclusively confirm this assumption, in which implementation of multimodality can be assessed.

\section{Students will utilise the service for study.}

While responses to the service were fundamentally positive, expressing appeal to the service is not sufficient to conclude it would be utilised.

This research demonstrated an array of attitudes and awareness towards available resources. Obstacles that may reduce the likelihood of students utilising SciNow include lack of awareness, sufficient provision of resources from alternative sources, and lack of appeal.

Whether SciNow can overcome these obstacles cannot be proven or disproven without trialling implementation, however they can be taken into consideration during development. These obstacles will be further assessed in the SciNow business case recommendation. Additionally, there is no evidence to guarantee that availability of preferred resources will motivate students that ordinarily do minimal study to do more.

Regardless of these obstacles, it is plausible that the service will be beneficial and utilised if executed effectively and able to deliver the intended features. 


\section{Teachers would willingly adopt use of the service into their classes.}

While teachers acknowledged the potential benefit of SciNow, both teachers and students perceive barriers to implementation by teachers, for example: rather than countering the problematic abundance of resources, introduction of SciNow may be perceived as simply adding to the abundance rather than providing an organised alternative; users that already utilise alternative channels to source resources may be reluctant to change; and teachers that don't implement variety in class despite current availability of resources are unlikely to utilise SciNow.

Fundamentally, this assumption is inconclusive without further understanding the motives behind different teaching pedagogies used.

\section{Labour will be available to create, develop, maintain, and update the service.}

Availability of labour was not assessed in this research, thus this assumption cannot be proven or disproven at this point.

\section{Implementation and use of the service will encourage more secondary students to study} science.

Due to the subjective nature of findings, this assumption cannot be conclusively proven or disproven. While some participants expressed belief that the SciNow service could encourage further science study, the contribution is purely speculative. In addition, research provided limited responses in which it was suggested that the SciNow proposal could overcome any of the other barriers dissuading students from studying science.

The assumption is also countered by one participant's expression of doubt, in which she questioned whether people that didn't like science were likely to utilise the service:

"My class were the lowest stream. We were given resources, we just never looked at them, we didn't care in class so why would we in our own time". - Jenny 


\section{The SciNow service will aid overcoming the challenges identified.}

Based on the analysis of findings, it is possible that SciNow will tackle some of the identified challenges, however it is unlikely to singlehandedly overcome the many challenges faced by science education.

Further investigation and testing of a prototype is essential to determine what capacity SciNow may have to appease any challenges.

\subsubsection{Analysis and research questions}

1. To what extent do students and teachers identify challenges in line with those identified from literature, and/or are there any disparities between challenges identified?

The challenges identified in literature are all strongly corroborated by this research. Student disengagement was regularly discussed, as were the challenges identified in NCEA. Shortages of teachers and limitations in specialist subject qualifications were reported, and all teachers included mention of time limitations when compiling resources.

Inequality in education was the least addressed challenge, but it was not absent from discussion, for example Mr E's comparison between teaching at a low decile school versus private school. In addition to corroborating the identified challenges, responses alluded to other potential challenges that were not addressed, but may benefit from further investigation.

\section{To what extent do students and teachers express a want or need for this resource} service and/or any other educational resource provision?

While the extent to which the service would be utilised, the findings of this research do indicate that the service is wanted and/or a needed to varying degrees.

The findings from teacher interviews indicate that creation and implementation of the service would be challenging, however they do perceive a potential benefit. Similarly, while some students expressed doubt that teachers would expand their methodology to 
implement the service, many expressed that the service could aid in bridging the gap between what the student needs and what the teacher provides.

3. To what extent is it feasible to provide this service for free, considering the challenges identified and the proposed benefits?

The existence of other free databases indicates feasible provision of SciNow. However, this does not consider the features SciNow intends to provide or other factors that may differentiate SciNow from alternatives. The research conducted is insufficient in determining the extent to which the SciNow proposal would be able to overcome the challenges proposed, however it also doesn't indicate a definite lack of feasibility. 


\section{Chapter Seven:}

\section{Discussion}

\subsection{Reviewing Research Purpose}

The purpose of this project was to research the perceptions of science teachers and students regarding science education, the provision of educational resources, and in response to the SciNow proposal. The overall intent of this research was to determine if the SciNow service concept proposed would be beneficial in overcoming the challenges in science education earlier identified, and whether the service could feasibly be commercialised. The initial challenges were identified through literature review, with a selection of unanticipated challenges being revealed during research. In addition to identification of challenges, investigation included a focus on the market for science education resources.

The initial plan was for this resource service concept to be commercialised to schools and students. The service would be made available through personal subscription fees for individuals, and more comprehensive subscription plans for school. This focus was altered early in the research process as it became apparent that commercialisation of the service was counterintuitive in tackling elements of the underlying issues identified, most specifically the significance of inequality in science education. Even if the SciNow service proved highly successful in improving student engagement and performance, in the case of commercialisation the benefits would likely be reaped most by those that need it the least; that is, the already high performers and those from higher socioeconomic backgrounds. Based on this factor, the research focus direction was shifted to instead determine if the service could feasibly be implemented for free access to all. In this case, research and development of the service as well as ongoing maintenance would require funding. Further exploration can be found in the following chapter, in which a strategic assessment business case identifies target investors and proposes a phased business model for execution of research and development, followed by creation and implementation. 


\subsection{Impact of Research Findings}

\subsubsection{The impact of main findings on challenges}

The challenges identified in the literature review were predominantly corroborated by the research conducted, although limitations reduced the expanse of research and extent of challenge exploration. The core issues of declining science engagement, academic success, and literacy validated by quantitative data, and so these base challenges were never intended to be qualitatively assessed. Due to the expanse of literature in economic, political, and educational research and reviews, it is established that these challenges are present and formally acknowledged. Limitations prevented the ability to specifically explore the performance gaps between highest and lowest achievers or the overrepresentation of Maori students, Pasifika students, and students from disadvantaged socioeconomic backgrounds in the low achieving population.

Findings from interviews with teachers reiterated many of the challenges regarding NCEA. Some teacher responses discussed the lack of interlinking between science disciplines, inconsistency in assessment requirements, and a detrimental impact of a "credit hunting" focus demonstrated in student attitudes. The expansive workload was also mentioned extensively.

Regarding expectations relating to educational resources, teachers predominantly agreed to struggling to attain adequate sources and facing obstacles in acquiring these. Contrary to expectations though was the extent of resources available. While the expected obstacle was that resource supply was limited, it was revealed that the obstacle was instead an overabundance of resources. Although the quantity was the opposite of expected, the effect of abundance quantity was in fact the same, with teachers finding it time consuming to locate ideal and good quality resources from the masses available.

Additional to resource matters, teacher and student interviews strongly corroborated the importance of variation of resource use and methodology in class to keep students engaged. The challenge of student disengagement and the potential benefit of SciNow assumed that availability and use of multimodality in science education could appeal to the different learning intelligences thus engage a wider audience, and that the application of real-world 
context would also convey more relevance thus interest to content. Findings from teachers and students very strongly corroborated this, outlining content delivery and content relevance as prominent components in student engagement.

Reference to teaching shortages were few, with the only reflections of shortages being contributed by focus group participants. The impact of shortages described were as expected and students perceived that SciNow would appeal to this challenge as proposed. However, the limited number of responses are insufficient to conclusively state that SciNow can assist the challenges imposed by specialist teacher shortages.

Revelations in challenges also yielded information in some cases contradictory of assumptions, and in other cases not considered when identifying challenges.

Student input revealed that the relationship between interest in science outside of school and inside of school is not mutually inclusive, with often significant contrasts between attitudes to each. The most regularly discussed influences on student perceptions were in relation to experiences with teachers. Students indicated strong influence from resource and methodology use in class, though they also placed emphasis on the significant impact of teacher personality and attitude on engagement and enjoyment in science education. This finding negates elements of the SciNow objective, as a resource service is unlikely to have any influence on teacher attitudes or personalities.

Findings yielded a mixed response regarding whether teachers would willingly adopt use of the service into the class. The unexpected extent of resources available and the expansive reports of teachers failing to utilise resources indicates that there are many factors implicated in teacher's resource use, which may or may not be influenced by the SciNow service. Findings demonstrate that resource availability does not directly correlate to resource awareness, and neither resource awareness or availability directly correlate with resource utilisation.

Regarding study use at home, regular responses described use of NCEA exemplars as the predominant study aid. This may be related to the perceived restrictive exam assessment requirements. In this case NCEA exemplars are likely to remain the predominantly used 
resource, as they would be considered the most ideal resource for academic success based on the perception that memorisation is the key to exam success regardless of level of understanding or engaging.

\subsubsection{Impact of main findings on project feasibility}

Relating the findings of this research to the core research questions, it is evident that the challenges acknowledged in literature were extensively resembled in this research.

Most students and teachers indicated a want for the SciNow service, however additional features that had not been planned in the initial design may be worth considering in future designs. Considering the abundance of resources available, an emphasis was placed on having an organised and maintained system, with content updated to reflect curriculum and assessment updates and removal of outdated content. In addition, public awareness appears to be a barrier to use of resources, indicating that publicity would be highly beneficial if the service were to be created. A unified and publically shared resource database may be advantageous, as having the effort invested into quality resource creation being provided for wide scale use may reduce the ongoing creation of duplicate content. This duplicate content is the result of creators developing resources for individual databases, as while an adequate set of resources may be available in one database, those unaware of this database may invest the same time into creating essentially the same resource. It is further worth reviewing the content that is available to educators but not to students, as certain elements of these may be beneficial for students to utilise for study.

The question of whether SciNow could be provided for free yields mixed responses. To an extent, there is a want for the service. However, the extent to which it could deliver on its intentions and quality are strongly influenced by external contributions, be in in terms of funding or through curation of already existing resources (provided approval for use is granted by content creators).

Certain finding support the likelihood of SciNow being implemented and providing benefits, while other findings indicate areas in which the research assumptions are 
inconclusive and/or the challenges identified would not be effected. For example, determining whether students would utilise the SciNow service for study is inconclusive as qualitative research based on a hypothetical scenario can only provide subjective and hypothetical responses. Future research would need to measure activity based on trialling usage and drawing comparisons to control groups.

Additionally, the ability for SciNow to accommodate the challenges identified in literature and in research findings is mixed due to the myriad of factors involved in engagement and academic success. A comprehensive database utilising modality and content application is likely to provide some level of benefit; though resources are only one part of a complicated network of influences on science education in New Zealand.

The more unknowns that are found in relation to the deeper education system, the harder it is to conclusively respond to the hypothetical assumptions of SciNow. Ultimately, based on the research, findings, and review of findings, and ongoing unknowns, the most efficient way of determining the effect of the SciNow concept proposal is through prototype development and testing.

\subsection{Progression of Initial Assumptions}

Assumptions established early in the research remained largely consistent, however previously unconsidered factors were found to influence these assumptions as well as yielding persisting unknowns and room for further research.

Certain proposed benefits of the SciNow concept assumed that easily accessible and high quality resources would be able to affect engagement in science education, in part because of the innovative emphasis on multimodality and content relevance. Considering literature reviews, research, and the business case exploration, it is evident that engagement levels are often circumstantial between individuals, with no set level of influence per factor.

The initial assumption that multimodal resource innovation could accommodate engagement persists, though expanding on it yields a carryon assumption that improvement 
in engagement will result in improved scientific literacy. Additional factors linked with science literacy include parental education levels, parental involvement in student engagement, and levels of English speaking at home; all factors unlikely to be influenced by resource availability.

An additional consideration is the link between academic success and literacy. Due to the many features implicated in success and literacy, the two are evidently not directly equated. Considering participant feedback questioning the validity of NCEA assessment, the relationship between academic success and scientific literacy becomes increasingly difficult to define. Another assumption lies in the difficulty to define what counts as an improvement in each issue identified as established in section 2.1.1.3, as limitations are present in the ability to assess student performance. These limitations are exacerbated when student performance measurement is sought for factors that are predominantly subjective.

Building on awareness of the complex relationships between educational influences and outcomes yields an array of unknowns, as academic success, engagement, and interest are not mutually inclusive nor is there an established priority among them.

Without understanding these complex relationships and their influences, many assumptions will likely remain unknowns.

\subsection{Links to Previous Research}

After completing the analysis of findings, further literature was reviewed in relation to certain unexpected findings. For example, an NZ Post Primary Teachers Association (PPTA) survey in 2010 (New Zealand Post Primary Teachers Association [PPTA], 2010) revealed further corroboration regarding the abundance of resources and resource locations, with teachers stating that they lacked time to develop and find resources for teaching and struggled to locate up-to-date information on assessments and curriculum:

"Hours and hours chasing my tail to locate the most update and relevant information from NCEA, NZQA, TKI and Techlink websites - so many changes - so little time.” (p. 8). 
Further literature found regular reporting of these challenges and ongoing acknowledgement of a need for change, often with follow-up reports lamenting the lack of activity (PPTA, 2016). Friction between different education entities is also evident in literature, for example ongoing reports of disagreement between the MoE and the PPTA regarding NCEA workloads, implementation of national standards, and changing protocol regarding appointment to the Education Council (Radio NZ, 2015). With research participants echoing each other's complaints regarding infrastructural education components, such as assessment and curriculum restrictions, it is likely that many of the persisting challenges reported are unlikely to be overcome without a more united collaborative and communicative effort between entities.

Investigation for the upcoming business case section included reviewing international examples of initiatives for student engagement in sciences, with many different models demonstrating different levels of success. While significant diversity exists between projects, a certain element appeared featured in most successful examples: the development of a coherent overarching strategy focusing on education systems in their entirety.

\subsection{Implications of Research and Future Recommendations}

\subsubsection{Implications of research}

Implication of research findings indicate that there is potential viability in continuing with the project, however certain features outlined need to be taken into consideration. Continuity of the project will face limitations imposed by the decision not to commercialize, but not render it futile.

Additional implications of the research and analysis of findings is the acknowledgement that a focus on resources is limited in the extent to which it can aid the ongoing challenges in science education. The success of research and development of the service is important, though it wouldn't necessarily be the decisive factor regarding the extent of its potential benefit. Provided the lean start-up model discussed in the upcoming business case is 
followed, the ongoing build-measure-learn feedback loop will allow continued fine-tuning throughout growth of the service.

In the case of limited funding, the potential for SciNow is present but limited to that of a database with organised curation of available content enabling timesaving. Different sources of funding will be discussed in the upcoming business case; however, the optimal execution identifies at least some relationship with the MoE resource services. Through this relationship, SciNow could work with NZQA and other MoE funded resources to streamline the connections between different material sources and users (such as teachers and students). To further this organisation, support from the MoE would improve successful public engagement, as well as potentially encourage other existing resources to contribute their resources to the SciNow service to form a unified access point.

Regardless, even with optimal funding, development, and implementation, it is again important to acknowledge that many of the most significant challenges faced in science education are far more inherent in the overarching education system. To overcome the issues identified most successfully, more important changes are likely to be required. In the meantime, provision of better resources may bridge this gap to accommodate certain ongoing challenges while the educational system is reviewed.

\subsubsection{Recommended future research}

To optimise the development of the concept proposed, further research is crucial to ensure ideal functioning of the service. Additionally, indirect benefits would be derived by research into the general landscape of science education.

As limitations prevented research into the potential impact of the SciNow concept on inequality in science education, this area would be a crucial priority to explore before beginning development of the prototype. While insight into inequality may be limited in directly influencing the SciNow design, awareness of lack of influence would be ideal compared to unawareness potentially perpetuating the inequality. In addition, conducting this research may yield insight into indirect ways in which the SciNow design and its implementation can appeal to the imparity of educational outcomes. 
Based on the complex unknowns identified in the findings, research delving into the interrelated factors involved in influencing student perceptions to science would also yield invaluable insight into educational engagement. A specific line of inquiry may especially benefit from exploring the relationships between the many educational entities involved in the ongoing educational challenges, for example through researching international education network models.

In a case of successful implementation of the SciNow concept, long-term research endeavours would allow continued benefits from further research. Inspired by Edwards (2015) research into use of multimodality in teaching physics, this research agrees with the recommendation that research should be conducted into "which constellation of modes best opens up the possibility for experiencing each of the particular ways of knowing physics" (p.165), however with an elaboration that multimodality should be researched in relation to all distinct disciplines in science.

Finally, as will be elucidated on in the upcoming business case, research is recommended to assess the cost/benefit analysis of embracing Open Education Resources (OER) into all New Zealand education systems, taking into consideration the benefits of potential public return on tax funded investment as is being modelled in international research (Wiley, Green, \& Soares, 2012). 
Chapter Eight: Strategic Assessment Business Case Located on the following page. 


\title{
Strategic Case
} Strategic Assessment to proceed to Business Case Development

\section{SciNow: Multimodal Educational Resource Database}

\begin{abstract}
A Proposal to Improve Science Education in New Zealand April 2017
\end{abstract}




\section{Business Case - Table of Contents}

Executive Summary............................................................................................................... 4

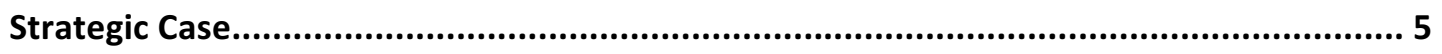

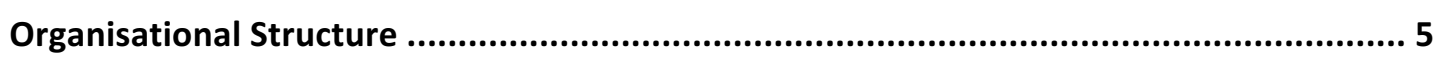

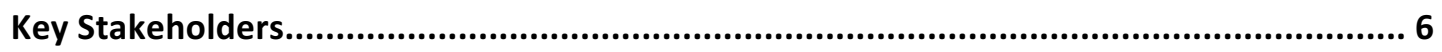

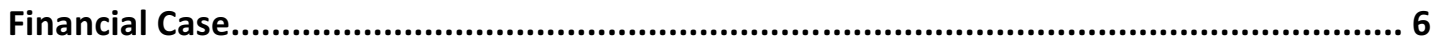

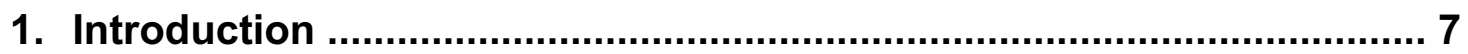

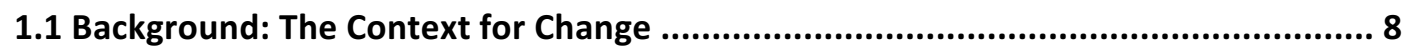

The current context of science education in New Zealand ............................................ 8

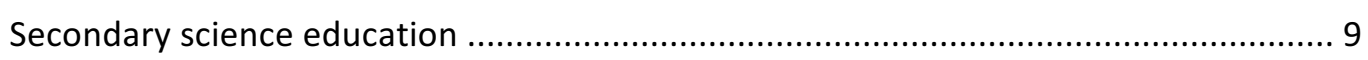

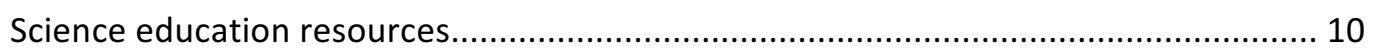

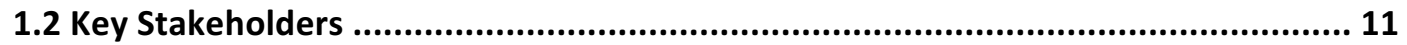

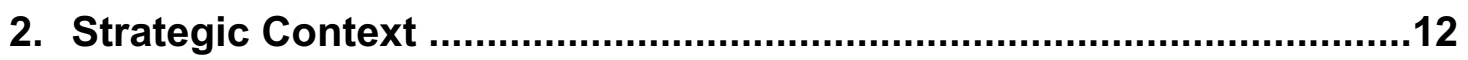

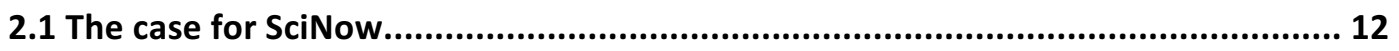

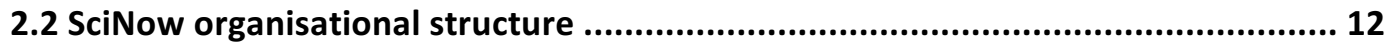

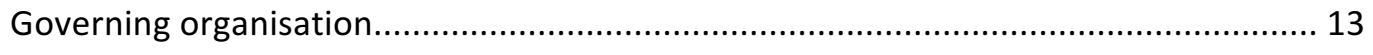

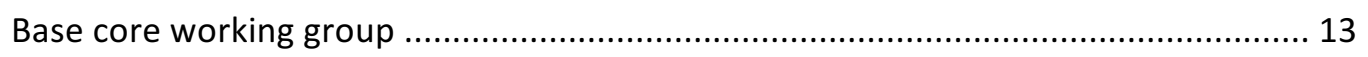

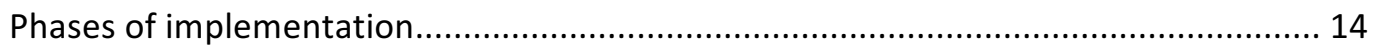

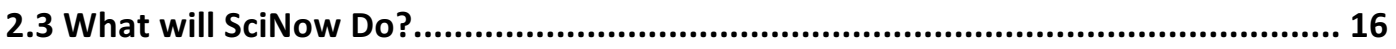

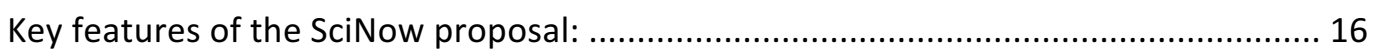

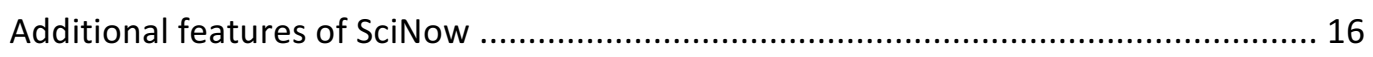

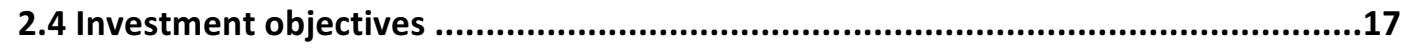

3. The Current Environment ........................................................................19

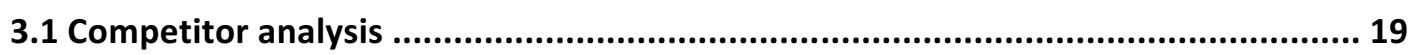

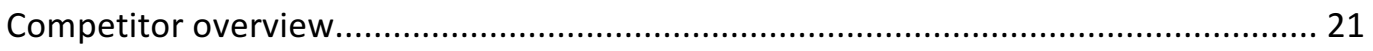

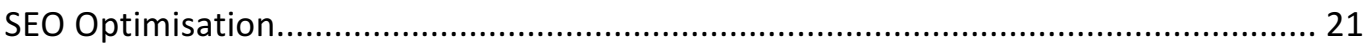

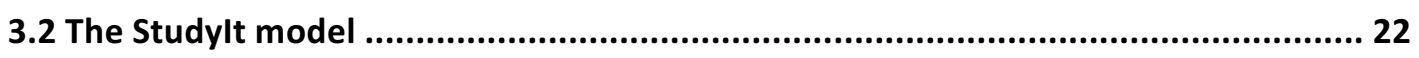

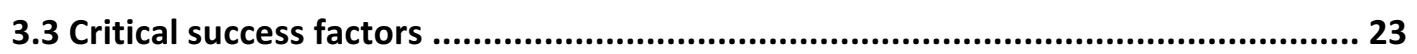

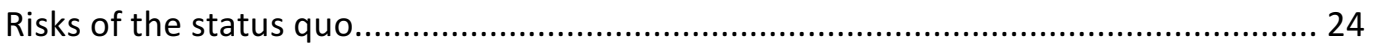

3.4 Identification of additional potential opportunities .................................................. 25

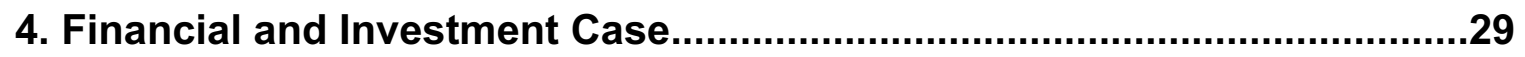

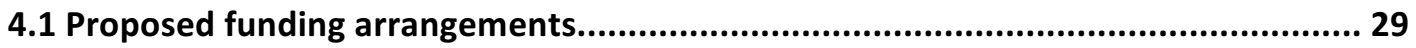

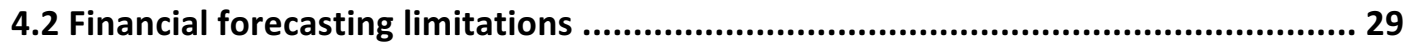

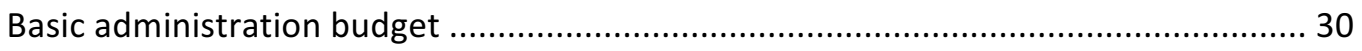


4.3 The need for investment in SciNow ...................................................... 31

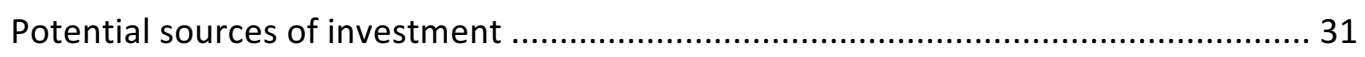

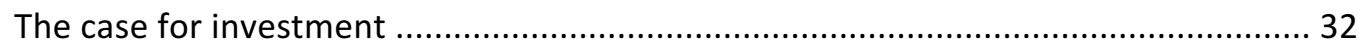

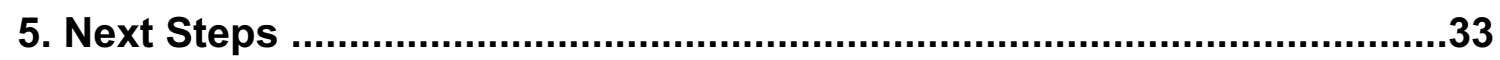

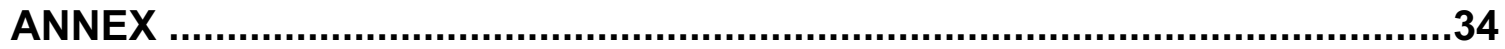

Annex A: Literature Review: Curriculum Support in Science .................. 34

Annex B: Competitor Analysis Table 1................................................. 37

Annex C: Competitor Analysis Table 2................................................... 38 


\section{Executive Summary}

The purpose of this document is to propose a case to targeted investor audiences, seeking approval to enable design, development, and implementation of the SciNow Multimodal Science Education Resource Database.

The ongoing success of the fast-growing science and technology industries in New Zealand is dependent on a continued supply of a sufficiently skilled workforce. Education has been identified as a crucial component in this endeavour, as the content communicated is highly influential during the formative years of citizens. To enable New Zealand to maximise the growing potential in sciences and technology, an emphasis on science education is critical.

Despite the pivotal role science education may play in New Zealand's economic future, numerous studies carried out by various private and public sector organisations have acknowledged gaps persisting in provision of this education. It is these gaps that warn us that operating at the status quo may long-term result in a workforce ill-equipped for labour demands. Listening to these warnings, communication with today's youth is identified as an essential key to unlocking the most efficient and fitting workforce.

Sir Peter Gluckman, Chief Advisor of Science to the Prime Minister, has emphasised the need to be proactive in improving science education and accommodating increasing technological demands.

It is these concerns that has influenced the creation of SciNow, a multimodal science education resource database. While the encompassing project report explores multimodality and other science education literature, this business case discusses the functional business aspects required to create SciNow. 


\section{Strategic Case}

The development of SciNow is proposed to be implemented through a three-phase plan. The first phase is intended to be initiated upon acquisition of funding. This phase will focus on utilising the lean start-up business model and work to develop a minimum viable product (MVP). This MVP will be designed to be used as a prototype, with implementation of the MVP being tested in classroom environments with ongoing analysis as well as comparison to control group classes.

The initial MVP will focus on an isolated selection of NCEA science achievement standards and curriculum national standards, for which an assortment of multimodal resources will be curated and created to satisfy a desirable range of modal representation. Using the lean start-up feedback mechanism, the prototype will undergo developmental updates based on ongoing prototypic research. Following completion of a satisfactorily successful prototype, phase two will focus on expanding the minimum viable product from the selection of standards to encompass all NCEA and NZQA standard requirements. The final phase is proposed as indefinite in length. Beyond completion of the project, the third phase is devoted to raising public awareness of the implemented service, as well as providing ongoing maintenance and updating in accordance with the outlined intention to be adaptable to changing technologies.

\section{Organisational Structure}

The organisational structure proposed, as will be more thoroughly outlined in upcoming sections, strongly instils an element of flexibility and malleability based on the project process and the transition through phases. A core working group is proposed to form a governing body. Using the skillsets, knowledge, and connections of working group members, a charitable trust will be registered. Upon formation of a charitable trust, the working group will evolve into an advisory board to operate alongside the more commercially focused charitable board. 


\section{Key Stakeholders}

The key stakeholders identified are the relevant New Zealand Government ministries, most likely centered around the Ministry of Education (MoE) and the Ministry of Business, Innovation, and Employment (MBIE). Further key stakeholders include teachers, principals, and students. There is potential for further stakeholders to be identified and/or approached, including educational entities such as those that oversee curriculum and assessment in New Zealand, as well as Crown Research Institutes (CRIs), State-Owned Enterprises (SOEs) and other commercial entities that may reap future benefits from the evolving science education focuses.

\section{Financial Case}

Ongoing operations of the SciNow proposal will be based on potential joint venture partnerships. Through investment and/or sponsorship from contributing stakeholders, the SciNow entity will be able to develop with a supportive network, while also providing potential benefits such as name association for sponsors. 


\section{Introduction}

This strategic assessment case outlines the background that inspired the SciNow proposal, the context of science education to which the SciNow proposal relates, the benefits SciNow aims to provide, the proposed developmental process, and the investment requirements for implementation.

The encompassing project report has outlined the want for improved accessibility to high quality science education resources, as well as presenting both direct and indirect anticipated outcomes. Direct results are anticipated in improved engagement, interest, involvement, and academic success in science education. These improvements include an emphasis on equality in science performance, as well as an emphasis on encouraging students to pursue further studies in STEM subjects.

Indirect results anticipated are those that will result from increasing the supply of STEM qualified workers to prevent the currently anticipated skill shortages in the workforce thus influencing economic gains. Socioeconomic gains are also anticipated through increasing science literacy in the population.

The SciNow service intends to provide multimodal science education resources through a free website database. The resources will be directly aligned with the New Zealand curriculum and assessment requirements, with each achievement standard equipped with a comprehensive set of resources. Within each comprehensive set, the core content will be available through multiple modes of communication including verbal, audio, and kinetic resources. Additional content will also provide real life context to each lesson, including application to both science and non-science careers when applicable.

Emphasis will be placed on the aesthetic design of the website, with the interface required to be organised, user-friendly, and easily navigated. 


\subsection{Background: The Context for Change}

The current context of science education in New Zealand

Advancements in sciences and technology through the last decade have rendered the fields increasingly relevant focuses for global and local economic prosperity. Reflecting this, New Zealand has identified the huge potential impacts on economic returns from investments in science and innovation. Increasing recognition of these impacts has fuelled the demand for STEM (science, technology, engineering, and mathematics) specialists in the workforce presently and more so in the future.

With the role of science in modern society changing, the challenges we face as a community are increasingly dependent on scientific education and literacy. With these challenges in mind, education is increasingly being targeted as an important contender in influencing the science literacy and future workforce. Studies have outlined why certain changes are pertinent to create an adequately scientifically literate population, and propositions as to why we are currently facing these risks.

Ongoing changes in NZ science education aim to overcome students lacking interest and engagement levels in science and influence more students to pursue higher education and careers in sciences. New ways to communicate and maintain science education need to be developed, with emphasis on creating an education system that can be adapted as needed to suit changing economic and societal pressures.

In the last decade, the Government has initiated multiple reports and projects in recognition of the importance of science education adjustments. An extensive Science in Society project has been headed by the Ministry of Business, Innovation, and Employment (MBIE) and the National Statement of Science Investment (NSSI), while the MBIE and MoE have been implicit in creating the strategic plan "A Nation of Curious Minds - He Whenua Hihiri I te Mahara". The Curious Minds plan emphasises three specific goals to be achieved by 2024, one of which is devoted to "enhance the role of education in sciences". 
The 2015 NSSI report identified the fundamental economic importance of scientific literacy and skillsets in society, stating that "New Zealand's future economic development and wellbeing are contingent on having a highly skilled workforce ${ }^{\text {miii }}$ with an emphasis that "the education system will underpin this and it must be able to prepare all New Zealanders to be participants, and leaders, in a 21st economy and society". Further down the line, increased scientific literacy can lead to economic growth, as explained in the statement that "investment in basic sciences reveals a rational, decision-making atmosphere within a country and among its leaders, as well as promoting economic growth."

\section{Secondary science education}

The multiple efforts to improve science education include objectives directed at secondary level science, with the MBIE Science in Society's youth targeting actions identifying the need to "Consider how to strengthen science literacy in senior secondary schooling particularly at year $11^{\mathrm{N}}$.

Initiatives directed at secondary science education have been proposed through multiple avenues. During 2012 and 2013, the New Zealand Council of Educational Research (NZCER) published a series of reports devoted to Science in the New Zealand Curriculum, with the series broken into three strands: curriculum support for science, science community engagement, and e-learning in science.

Efforts pertaining to e-learning in science are in part inspired by acknowledging that ICT is "changing the way.... Education is delivered, and how people and communities interact"vi. Discussion of introducing e-learning into education has yielded an introduction of digital technologies to the New Zealand curriculum, being trialled in 2017 for intended implementation from 2018.

\footnotetext{
iii MBIE, National Statement of Science Investment 2015 - 2025, http://www.mbie.govt.nz/info-services/scienceinnovation/pdf-library/NSSI\%20Final\%20Document\%202015.pdf

${ }^{i v}$ Jaffe et al, Productivity in Physical and Chemical Science Predicts the Future Economic Growth of Developing Countries Better than Other Popular Indices

${ }^{v}$ MoE and MBIE. A Nation of Curious Minds: A National Strategic Plan for Science in Society.

${ }^{v i}$ MBIE, Science Innovation, Digital-Economy, http://www.mbie.govt.nz/info-services/science-innovation/digitaleconomy
} 


\section{Science Education Resources}

Further investigation into science education areas for improvement has included targeting the current patterns of use of science education resources. Research has identified barriers for both teachers and students regarding perceived availability, accessibility and quality of resources, as well as patterns of use and alignment with the curriculum.

The efforts to bring technology into the New Zealand classroom can in fact be applied to the acknowledgement of resource improvement. The Digital Technologies in Education range of initiatives includes a focus on "Access to Quality Content \& Resources"vii, with objectives including making online content easy to find, share, and create; promoting resource development by teachers and students; and developing and promote smart online tools". Similarly, the 21st Century Learning Reference Group report on "Future-focused learning in connected communities"viii included the need to "Invest in high-quality digital content and systems to make content easily accessible" as one of ten strategic priorities. Each priority was equipped with recommendations to the MoE for achievement, with the following recommendations outlined for high-quality digital content investment:

1. That the Ministry of Education work with stakeholders and agencies to procure and curate appropriate international and New Zealand content, including Māori and Pasifika content, and make it easy and inexpensive to access.

2. That the Ministry of Education support the development of tools and systems that make it easy for users to find, share, re-purpose and create content.

3. That the Ministry of Education develop improved mechanisms and incentives for encouraging teachers and students to work collaboratively in creating and sharing digital content and resources

\footnotetext{
${ }_{\text {vii }}$ MoE Towards Digital Fluency, https://education.govt.nz/assets/Uploads/Towards-Digital-Fluency.pdf viii $21^{\text {st }}$ Century Learning Reference Group, Future-focused learning in connected https:/education.govt.nz/assets/Documents/Ministry/Initiatives/FutureFocusedLearning30May2014.pdf 
Current resource provision and availability will be reviewed in the competitor analysis, followed by which the SciNow model will be discussed with consideration of benefits and negatives observed in competitors.

\subsection{Key Stakeholders}

Key stakeholders identified include: The Ministry of Education and other ministries with a relationship with science, such as the Ministry of Business, Innovation, and Employment (MBIE); school staff, specifically teachers and principals; curriculum and assessment entities, such as NZQA and NZCER; and students.

The designated 'end consumers' are students and teachers, while the enablers consist of any parties involved in funding and/or implementation of SciNow.

Additional stakeholders may be included through funding or other partnerships. For example, Crown Research Institutes (CRI) or commercial businesses may recognise benefits from supporting science education. Through these relationships, commercial entities and businesses are contributing to their own future growth by encouraging availability of a skilled workforce, as well as procuring potential relationships with future employees. This is not an unheard-of incentive for investment, with Fortune Global 500 companies being called on to increase their investment in education above their current contributions of approximately $13 \%$ of total annual corporate social responsibility budgets ${ }^{\mathrm{ix}}$.

\footnotetext{
${ }^{\mathrm{ix}}$ The Guardian, 10 Companies Spending Millions on Education, https://www.theguardian.com/sustainablebusiness/2015/jan/14/10-companies-business-school-education-philanthropy-inequality
} 


\section{Strategic Context}

This strategic context outlines the identified case for change in education resource quality and availability as a response to the observed challenges. The SciNow organisational structure is presented, followed by the outcomes SciNow seeks to achieve through its operations. Value propositions and critical success factors are also described.

\subsection{The case for SciNow}

As exemplified in the Introduction section, it has been established that there is a case for improving science education resources. Corroboration of this can be seen in the MoE contracted research project "e-in-science"”, in which the opportunity was outlined: "we think there is an opportunity for teachers, school leaders, the science community, resources developers, technology developers, policy makers, researchers and others to engage with some of the ideas that emerged in this research on e-in-science, and use these to begin shaping more future-oriented science education for young New Zealanders".

SciNow proposes to appeal to this opportunity, with design features being influenced by the suggestions, recommendations, and requests identified in the encompassing project reports' literature review and research.

\subsection{SciNow Organisational Structure}

This strategic assessment case proposes forming a charitable trust to be managed by a governing organisation, with potential project development through joint venture partnerships. The proposed management components are open to adjustment based on funding availability.

${ }^{\mathrm{x}}$ NZCER, Digital technologies and future-oriented science education, 


\section{Governing Organisation}

The SciNow proposal is based on a three-phase plan for development and implementation. Administrative and labour requirements will vary between phases, as will organisational structuring. Regardless of the final business structure, the SciNow implementation process will begin by being headed by a core working group as the governing body.

The core working group will begin as the point of organisation, heavily reliant on member skillsets and tasked with recruiting and coordinating any parties that may be involved with the SciNow project. This core working group will later evolve into an advisory board, while a separate charitable trust board will be established upon registering as a charitable trust. The chair of the working group will evolve into the chair of the advisory board, as well as being the chair of the charitable trust board.

The charitable trust board will be a small and more commercial group focused on current business and tasked with supervising management, finances, and strategic directions. The advisory group membership will be based on knowledge and skills contributions to act alongside the charitable board, aiding in forming connections, providing advice and/or contacts, and managing relations between any partner bodies.

In the case of successful development and implementation of the SciNow service the core working group will remain tasked with ongoing curation, creation, data analysis, and maintenance. In phase two and three, a selection of subgroups will be arranged based on skill requirements.

\section{Base Core Working Group}

The core working group will be composed of 4-8 members. This base group will require an array of key specialities to fulfil requirements at each stage of implementation, with additional labour being contracted when needed for carrying out subsequent steps. 
The ideal core working group membership will include the following members, however changes in membership requirements and roles are subject to change upon evolution into an advisory board. Dependent on resources, a selection of 'subgroups' will also be established to optimise the execution of different objectives based on skills and required labour.

\begin{tabular}{|c|c|}
\hline Member & Role \& Responsibilities \\
\hline Chairperson & Head of operations, manage team \\
\hline Lead Web Developer & $\begin{array}{l}\text { Research and develop infrastructure for service. } \\
\text { Future head of web development subgroup. }\end{array}$ \\
\hline $\begin{array}{l}\text { Ministry Representative(s) - } \\
\text { MoE and/or MBIE }\end{array}$ & $\begin{array}{l}\text { Representative of the MoE, ensuring ongoing MoE } \\
\text { support and alignment with MoE objectives. }\end{array}$ \\
\hline NZCER Representative & $\begin{array}{l}\text { Representative of NZCER for educational research } \\
\text { support. }\end{array}$ \\
\hline PPTA Representative & $\begin{array}{l}\text { Representative of the PPTA to ensure constant } \\
\text { dialogue with the requests and needs of teachers (as } \\
\text { end consumers). }\end{array}$ \\
\hline $\begin{array}{l}\text { Content Developer(s) for } \\
\text { Curation and/or Creation }\end{array}$ & $\begin{array}{l}\text { Member(s) focused on curation of available } \\
\text { resources and creation to fill gaps, will lead content } \\
\text { curation/creation subgroups during Phase Two } \\
\text { development. Tasks include attaining permission to } \\
\text { use existing content. }\end{array}$ \\
\hline Chief Officer of Equality & $\begin{array}{l}\text { Member tasked with ensuring all the SciNow service } \\
\text { design is representative of the requirements of } \\
\text { different populations of New Zealand education. }\end{array}$ \\
\hline
\end{tabular}

\section{Phases of Implementation}

While the phases indicate a linear sequence of events, actual implementation is open to flexibility and adjustment. Some steps within and between phases may occur simultaneously, as the process may reveal different ideal practices as research and development progresses. Through carefully planned implementation, the adoption of any new practice has the potential to influence a systems capacity for change. 


\begin{tabular}{|c|c|}
\hline Phase & Activities \& Objectives \\
\hline Phase One & $\begin{array}{l}\text { Development and testing of minimum viable product/prototype. } \\
\text { - MVP design focused on NCEA Level } 1 \text { science. Prototype } \\
\text { design to include multimodal resources for one achievement } \\
\text { standard per science discipline } \\
\text { - Develop basic infrastructure for web service } \\
\text { - Determine method for analysing success } \\
\text { - Recruit six schools to participate testing } \\
\circ \quad \text { Include two schools per decile range (low decile, mid } \\
\text { decile, high decile) } \\
\text { - Coordinate teaching timeline of achievement } \\
\text { standards to match prototype focus } \\
\text { - Initiate prototype testing } \\
\circ \quad \text { Present to science teacher with at least two year } 11 \\
\text { classes } \\
\text { One class will incorporate SciNow (second class is } \\
\text { control) } \\
\text { Perform any "introduction" testing designed for } \\
\text { analysis } \\
\text { - Upon completion of prototype testing, analyse effects of } \\
\text { SciNow } \\
\circ \quad \text { Attain thorough teacher and student feedback } \\
\text { (separately) } \\
\text { Assess all factors that may have influenced outcomes } \\
\text { Establish Phase One Completion Report } \\
\text { Include recommendations and requirements for } \\
\text { ongoing phases. }\end{array}$ \\
\hline Phase Two & $\begin{array}{l}\text { Development of complete service } \\
\text { - Formation of subgroups for: content curation, creation, and } \\
\text { quality assurance; web development; implementation } \\
\text { coordination (training if necessary); public outreach } \\
\text { (campaign to reach maximum target audience); } \\
\text { representative subgroup (representatives of any influential } \\
\text { organisations or other stakeholders); and subgroup for } \\
\text { feedback and troubleshooting. } \\
\text { - During full service development, continued research will be } \\
\text { conducted to monitor any ongoing changes within the science } \\
\text { education system }\end{array}$ \\
\hline Phase Three & $\begin{array}{l}\text { Phase Three may be initiated before completion of Phase Two. } \\
\text { Implementation of service and ongoing maintenance } \\
\text { - Service will be published, supported by public outreach and } \\
\text { ongoing analysis of web service functioning } \\
\text { - Core working group will perform ongoing duties regarding } \\
\text { critical success factors, value propositions, and objectives. } \\
\text { - Potential to expand and/or collaborate with other e-learning } \\
\text { technologies } \\
\text { S Such as student management systems and data } \\
\text { progress measurement tools currently in development }\end{array}$ \\
\hline
\end{tabular}




\subsection{What will SciNow Do?}

The SciNow multimodal resource database will first and foremost provide resources for science education to teachers and students, allowing students easy access to resources for study at home, and allowing teachers immediate access to resources for teaching and lesson plans.

To appeal to the different student preferences regarding engagement and interests, multimodality is a central component of the SciNow proposal. The fundamental value proposition offered is an engaging, modern, and relevant system to aid secondary science education.

The following features are key to the ultimate SciNow proposal:

1. Multimodality

a. With emphasis on "critical engagement factors" (relevance)

2. Universal Access

a. Service provided free of charge

3. Encompassing Information Provision

a. Career information

b. Assessment information for NCEA and NZC

4. Communication portal

a. Between MoE and teachers, NZQA, TKI, other key things

5. Collaborative Creation

a. Include work of many experts, high quality, curate content already available

Additional features of SciNow

Based on the success in design and implementation and scope for expansion, long term potential may lead to SciNow providing the following features

1. Catalyst and Accompaniment for Change

- Successful acceptance and use of SciNow may result in SciNow acting as a catalyst in changing pedagogies used in science education. 
Additionally, ongoing development of SciNow will allow it to adjust to accommodate changes in curriculum.

2. Two-way Communication

- SciNow will likely feature an open forum, in which parents, teachers, families, and students will be able to provide feedback. Prominent feedback can be monitored, collaborated, and then relayed to entities such as NZQA or the MoE

3. Facilitating Community Science Engagement

- Optimal implementation of SciNow would include having a positive response from consumers and stakeholders regarding the benefits and value of the database, and the SciNow organisation. Involvement in campaigns for science engagement have the potential to aid raising awareness about the social and economic value of science education, and aiding the relationship between different education entities.

\subsection{Investment Objectives}

SciNow has been designed to help solve the challenges outlined and emphasise the economic and social benefits of improved science education. Successful execution of SciNow is dependent on investment in order to fulfil of the following objectives:

1. Provide an easily accessed resource database to students and teachers to utilise for science education. The database will include a curation of current resources and creation of further resources. Every curriculum and assessment standard will be accompanied by a set of multimodal resources to appeal to students different ideals for engagement, as well as content devoted to providing real life context and career related information for each standard.

2. Improve the environment of science education through this comprehensive database by overcoming challenges identified by literature. These challenges include the excessive workloads on teachers limiting time for 
attaining resources for lessons, and student struggles to find optimal resources for personal study.

3. Facilitate the changing nature of the New Zealand science curriculum, accommodating various initiatives targeting science education, such as through implementation of digital technologies and efforts to reduce inequality between students. Emphasis on provision and free access to all students and teachers is to prevent inequality in access based on financial barriers. 


\section{The Current Environment}

The following section discusses the current environment of science education resources. Education resources will be reviewed in terms of market analysis and identification of a problem; addressing how the problem is or isn't currently being solved; any barriers to changing market behaviours; competitor analysis; and identification of critical success factors.

\subsection{Competitor Analysis}

The current availability of resources for science education are available through an array of different services. A selection is funded by the Ministry of Education, certain resources can be purchased, and there are many websites provided free resources can be found.

Due to the abundance of minor resource providers along with the various nonscience, non-secondary, and non-New Zealand specific options, the resources included in the following table are selected based on two features: a) if the resource was mentioned by any participants during research, b) researchers found based on an "example scenario" analysis.

This "example scenario" sourced resources through a standard online search engine (google), with the search command "NCEA science study"xi. The first 20 organic ${ }^{\text {xil }}$ links were reviewed.

Analysis of science resources is largely subjective. To avoid use of subjectivity, the following features listed have focused on basic features. The features selected for comparison were driven by literature and research findings, along with isolating easily observable objective elements.

\footnotetext{
xi "Google search" was performed on a public library computer. All caches that may influence results were cleared prior. The only influential factor will be the location (Wellington)

xii Organic: Non-advertised
} 
Annex A provides a selection of literature content assessing teacher use of science resources, derived from the report "Curriculum support in science:

Patterns in teachers' use of resources".

Annex $B$ and Annex $C$ contains tables demonstrating a comparison of quantitative website features of a selection of the following competitors.

A brief overview of competitor search yielded the following:

Top five links in google (in order of appearance):

1. Studylt

2. No Brain Too Small

3. StudyPass

4. NZQA

5. StudyTime

Resources mentioned in research that were not featured in first 20 google links:

1. LearnCoach

2. Pathwayz

3. Khan Academy ${ }^{\text {xiii }}$

4. Science Learning Hub

5. Te Kete Ipurangi (TKI)

6. Assessment Resource Banks (ARBs)

7. The Pond

Resources funded by the MoE or MBIE:

1. NZQA

2. Science Learning Hub

3. TKI

4. ARBs

\footnotetext{
xiii Khan Academy is the only non-New Zealand based resource that was regularly mentioned by participants.
} 
Resources targeted towards educators:

1. ARBs

2. TKI

3. The Pond

\section{Competitor Overview}

The MoE run sites TKI, NZQA, and Studylt contained regular links to external sources, including linking between each other (for example Studylt linking to TKI or TKI linking to NZQA). No Brain Too Small, StudyTime, Pathwayz, Learn Coach, Science Learning Hub and The Pond are populated with resources created directly for or contributed to the website. Due to being educator focused, access to sources within The Pond or ARBs are limited.

The modes available between sources varied. Use of videos was regular in StudyTime, Khan Academy, Science Learning Hub, and Learn Coach, however many of these visual aids were stylised much like lectures (excluding Science Learning Hub). Use of animation was limited in most sites, most likely due to the intensive and costly workload to create.

Within the top five google search sites, the number of links to external websites for further resources exceeded 50, with all Studylt content material being provided through links to other education websites.

- "Ministry made/funded resources are not so good. They ironically do not fit the NZ curriculum at all."

\section{SEO Optimisation}

Search Engine Optimization (SEO) is an internet marketing strategy. The use of SEO affects the visibility of a website to web search engines, usually making websites appear higher in search result rankings thus attracting more visitors. Optimization of a website can include editing visible content on the page, however efforts to improve SEO of a website targets adding relevant keywords associated 
with the website and its content to the websites metadata ${ }^{\mathrm{xiv}}$. Of all the top links observed, application of SEO was only significantly present in the Science Learning Hub.

\subsection{The Studylt Model}

The Studylt model has been identified as featuring a basic backbone in line with what is intended for the SciNow proposal, except for the exclusive focus on NCEA content in Studylt compared to the SciNow intention to align content with NCEA and NZC outlines. It is important to note that the modelling similarity is based only on certain structural features, with many features of the Studylt website being less than ideal based on common website design preferences ${ }^{\mathrm{xv}}$.

Regardless of certain features of the Studylt model that can be deemed as disadvantageous to success for a modern web service, such as: high number of outdated links to absent websites; no design update since 2002; and poor organisation features, it is the initial establishment of the website that appeals as a good route to model in the development of SciNow. Initially funded in 2002 as part of the MoE Digital Opportunities project, Studylt attained ongoing funding and development and has continued to be run by the MoE for over 14 years since. Additionally, the basic organisation structure is much like that intended by SciNow, with clear and simple pathways leading clearly to each defined NCEA achievement standard. Within each achievement standard, the categorisation of official NCEA source materials are also clearly outlined. A further feature well received in Studylt and found to be largely used ${ }^{\mathrm{xvi}}$ is the forum aspect dedicated to providing communication between students and teachers and students being able to pose specific questions.

\footnotetext{
xiv Metadata: "data that provides information about other data"

${ }^{x v}$ Robert L Nunez and Rebecca J Hall, Graphic and Web Design Principles, http://works.bepress.com/rlnunez/9/

${ }^{\mathrm{xvi}}$ Education Counts, Evaluation of student facing web-based services,

http://www.educationcounts.govt.nz/publications/e-Learning/23917
} 
Further websites that demonstrate appealing features are Learn Coach, Study Time, and No Brain Too Small. These sites in part offer their appeal through some of (though not necessarily all) the following: aesthetically pleasing website designs; up-to-date website operations; use of up-to-date and well-designed visual resources; inclusion of more stimulating modes of information communication; and hosting more directly available resources rather than desultory patterned linkages. While there is evidently significant evidence of disparity between Studylt and other models, it is proposed that the negatives identified in Studylt may be in part the result of diminished funding preventing maintenance and content updates.

Through utilising the basic structure of Studylt while incorporating the modernity, multimodality and aesthetics of alternative sites, SciNow has the potential to combine and build upon the features students find most beneficial, engaging, and educational.

\subsection{Critical Success Factors}

The literature and research thus far has reviewed opportunities for improvement in science education, identified the opportunity to advance education resources, and investigated how implementation could progress. The following matters have been identified as critical success factors in establishing the SciNow Resource Database.

- Optimal leadership and maintenance of SciNow is critical. Any decisions that may impact educational provision need to be supported and trusted by the relevant audiences.

- Widespread engagement and collective effort is crucial. SciNow needs to be inclusive of all parties involved in secondary science education, with an emphasis on listening to the feedback of the teachers whom which SciNow intends to be utilised. This inclusion extends to the important of ensuring different cultural values are provided for. 
- Must be adaptive and agile. SciNow needs to be able to adapt to any pressures, and actively seek out any policy, curriculum, or assessment changes that may require rapid responses. Adaptability may also be essential if early execution yields negative feedback.

- Successful design and execution is key. The service needs to successfully offer the proposed features.

To fulfil the critical success factors, multiple development and management approaches have been considered options in establishing the SciNow service, with the multi-phase implementation plan allowing flexibility in modelling.

Regulation and directives between different contributing parties will require strategic management, as conflicts of interest and requests create potential conflict between critical success factor fulfilment. Extent of control by any particular parties may create negative repercussions, for example the ongoing contention between the PPTA and MoE in response to the Education (Update) Amendment Bill.

Considering these implications, it is important when making formal choices in objectives, management, and actions that representatives from various educational entities be consulted. In cases of conflicting requests or priorities, the advisory board and charitable trust board will take into consideration the various stakeholders, with a focus on appealing to those most implicit in the use of the service.

\section{Risks of the status quo}

Risks are present if New Zealand doesn't focus on the current state of educational resources provision, as identified in literature and the research conducted for the encompassing project report.

As identified in Chapter 4: Findings, awareness of resources available strongly varies between students interviewed in relation to both Ministry provided resources and alternatives. Without intervention designated to increasing awareness of best 
quality resources, many of these will continue to be underutilised by. In lieu of resources considered most engaging and beneficial for certain pedagogies, it is entirely possible that some students feel reliant on outdated 1990's curriculum resources [mentioned in Annex A].

While the impact of varying resource awareness and use cannot be directly measured, it is possible that the current resource use patterns are to an extent relevant to the equality gap in science education performances. Though the cause of which is not ascertained, an MoE contracted evaluation of Studylt did find that the user base of the service had an under-representation of students attending lower decile schools. The status quo risks NZ falling further behind in science education access and a continued decline in international performance indicators, along with the risk of not achieving the societal benefits of an effective science education.

\subsection{Identification of Additional Potential Opportunities}

Having assessed the current competitors and solutions proposed, the following potential opportunities have been determined.

\section{Potential for implementation of Open Education Resources (OER)}

Many public and private organisations contribute to the provision of assorted educational resources, however as evidenced by the competitor analysis, limitations are present in the current resource landscape.

A barrier is created by the combination of free materials, education provider access only materials, funded materials, purchasable materials, and the extensive interlinking of related sources (for example, between the many ministry funded initiatives). This barrier imposes on the ability to simply and directly access all applicable content. In addition, the combination of sources and regulations means there is no consistent quality assurance. 
In response to these hurdles, implementation of a secondary education based OER allows access to all resources free of exclusions, and with the potential implementation of quality oversight. Implementation of an OER would also improve New Zealand's current level of involvement in the unanimously approved 2012 UNESCO World Open Educational Resource Declaration, in which the importance of OERs were highlighted along with a call on governments to openly licence publicly funded educational materials.

2. Potential for innovation to create economic and social value, and to support future innovations through collaborative tool interactions.

Through improving science education, science engagement, and interest in sciences, the base level science literacy is expected to rise. Improvements in science literacy is likely to align future workforce skillsets with expected economic demands.

Inspired by these potential values, multiple educational tools are currently being developed. For example, current tool developments include intentions to optimised student management systems and progress measurement. A demo Progress and Consistency Tool (PaCT) has been released by the Ministry of Education, to support teachers in overseeing individual student progress and achievement in NZ curriculum National Standards.

Due to the concurrent focus on various alternative e-learning tool developments, potential exists for the SciNow design to collaborate with other projects currently in progress, enabling inclusion of interactive properties to optimise long-term output of all tools.

\section{Potential to improve navigation of the current science education resource landscape}

Mentioned in the competitor analysis and discussed in the encompassing research findings, elements of the current science education resource landscape are considered hard to navigate. These navigational difficulties have been referred to as time consuming, inefficient, and unnecessarily complicated. The competitor 
analysis briefly alluded to this by demonstrating the crossovers in the "chain of links" found between MoE and non-MoE run sites.

As there is no clear presence of an organised authoritative guide regarding education resource requirements, it creates room to focus on potential navigational improvement. Through the lean start-up feedback models, coordination between teachers, students, and respected web designers could create an organised structure based on the ideals of the users.

The importance of the feedback model is demonstrated in the criticisms regarding alternative e-learning tools, for example mixed responses to the launch of the PaCT progress monitoring tool. While the official MoE publication reported that PaCT had been met with "overwhelmingly positive feedback"xvii, non-MoE run publications featured a range of different perspectives, such as a PPTA article describing it as a "wasted resource".

In addition to optimising organisation, having an experienced web developer aiding in development of a resource database would likely prevent repeating the point established in competitor analysis that many resource databases do not demonstrate application of search engine optimisation. Lack of SEO use is likely implicated in the limited awareness of resource availability due to impacting website traffic.

\section{Potential to improve dialogue between science education entities regarding ongoing projects and initiatives}

Based on reflection from teachers and research yielding ongoing problems with understanding what's available and communicating with "higher ups", resource related requests, feedback, and issues could be managed through a communication channel. In the case of successful implementation and reception to SciNow, potential expansion could be directed at creating a communication channel and/or an additional database section devoted to ongoing science education initiatives.

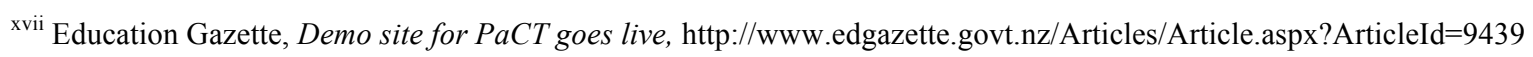


In addition to literature reviewed and research content attained in the encompassing project report, more comprehensive validation outlining this potential is in an NZCER report ${ }^{\text {xviii }}$ that refers to inefficient investment in futureoriented science education endeavours.

The report discussed that there was "no shortage of goodwill, energy, and commitment" (p. 7) based on the large number of ongoing initiatives, opportunities and programmes devoted to connecting science education and the science community. Gilbert and Bull (2013) explained that the limiting features included the "ad hoc" nature of initiatives, reliance on personal networks of few individuals, shortterm funding, making many projects unsustainable. In addition, the isolation of individual investments aren't built on nor in collaboration with similar endeavours, thus spending different channels of funding into the same endeavour, reproducing the same early benefits that are then "lost to the system"

Providing a space for collaborating the ongoing initiatives may allow ventures to aid and/or engage one another, as well as overcoming the inequality derived from the note that "Some schools are able to forge connections more easily than others: often the connections arise from personal relationships and networks."

\footnotetext{
xviii NZCER (Jane Gilbert and Ally Bull, NZCER, 2013), Building a future-oriented science education system in New Zealand: How are we doing?
} 


\section{Financial and Investment Case}

\subsection{Proposed funding arrangements}

As outlined in the competitor analysis, this SciNow research report recognises certain successes in the MoE funded Studylt website. Based on this assessment, the optimal development of SciNow is considered to be through a model based on the backbone of Studylt's establishment.

Studylt was funded in 2002 as part of the MoE Digital Opportunities projects, with development being carried out by CWA Media joint with MultiServ Educational Trust (now Cognition Education Limited). Additional funding in 2005 allowed expansion, with further funding reported in $2014^{\mathrm{xix}}$

Cognition Education Limited, though potentially no longer linked to Studylt, is one of five companies that make up the Te Toi Tupu - Leading Learning Network education consortium, alongside NZCER, CORE Education, University of Waikato, and Waikato-Tainui College for Research and Development.

This business case proposes that funding from the MoE and other viable sources allow the first implementation phase to be carried out, with potential for support from the education consortium. Based on the success of phase one research and development, a not-for-profit company or trust-type entity can be created for future SciNow operations, at which point management and operational procedures can be reviewed.

\subsection{Financial Forecasting Limitations}

Due to the early stage of this project proposal, detailed financial forecasting cannot currently be calculated with any accuracy.

\footnotetext{
${ }^{\text {xix }}$ This report has been unable to locate information regarding current management, development, and operating.
} 
Without further developmental feedback, the neither costs nor benefits can be accurately calculated. Completion of phase one will include financial forecasting and cost/benefit analysis for continuing into phase two and three, in which further forecasting can be informed by increased data available. The total cost of each phase of SciNow will be driven by how government and non-government agencies response. Responses to business case by different agencies will results in varying contributions of resources both in terms of possible cash and non-cash capital. Extent of funding for phase one and two may influence timing and quality of production per stage, thus influencing assessment of perceived benefits at each stage.

The following basic administration budget for setting up and providing support for core working group operating expenses is modelled on similar e-learning tool development, however it is only looking into likely expenses, not dollar amounts. Capital expenditure will be required, with different capital requirements at each implementation phase.

\section{Basic Administration Budget}

The main components of the basic administration budget for Phase 1 are:

- Payments for core working group

- Payments for prototypic subgroups (R\&D)

- Phase 1: Contractors tasked with web design/development and content design

- Phase 1: Creation and curation of initial content - potential to purchase rights from alternative resources available

- Public engagement expenses (higher after phase 1 completion), for communication campaigning and securing support

- R\&D material expenses

- Technology, software, web hosting

- Commissioning post-implementation evaluations after each phase

- Regular meeting expenses 


\subsection{The need for investment in SciNow}

Feedback from research and investigation into stakeholders and public perceptions show areas NZ needs to improve in educational resource provision.

The MoE currently funds an array of learning ventures specific to science education, for example LEARNZ and a Network for Learning initiative. Beyond the MoE, other New Zealand investments include the projects encompassing elearning and the MBIE funding of the Science and Biotechnology Learning Hubs. e-Learning in New Zealand's formal education system is being further stimulated by conferences such as ULearn and Learning@School, in which teachers are being exposed to different ways to integrate ICT into the classroom.

\section{Potential Sources of Investment}

As previously established when reviewing stakeholders, there is an expanse of potential investment sources. In addition to this, it is important to consider that investment options include attaining investment from multiple sources. While MoE involvement and collaboration would be highly beneficial for the process of curating resources and publicising the service, this does not mean progress is dictated by MoE funding or lack thereof.

Funding possibilities include the earlier suggested possible stakeholders such as from CRIs, as well as through sponsorship or partnership with science sensitive state-owned enterprises or technology industry suppliers.

Openness to joint venture partnerships would allow the SciNow entity and its partners to be at the centre of an alliance of contractually bound partners, while sponsorship opportunities will give partners benefits such as name association with the SciNow project, in turn providing an indirect return on investment. 


\section{The Case for Investment}

Given the recognised potential for New Zealand to realise greater economic and social value from innovation in science education, the key question is how to support these proposed aims.

Advantageous to any educational investment endeavour is the annual OECD reports inclusion of the benefits of investing in education. As an OECD member, New Zealand is embodied in the OECD Education at a Glance calculations outlining the payoff from investment in education. Through public contribution, social contribution, and greater tax revenue, the Net Present Value ${ }^{\mathrm{xx}}$ (NPV) for achieving upper secondary school qualifications exceeds approximately $\$ 70,000$ USD per person.

\section{For consideration}

- This proposal is about implementing a service to facilitate secondary school science education to enable nationwide, high-quality, and reliable access to a comprehensive array of science education resources

- The investment is intended to benefit years $11-13$ students studying science and all science teachers across New Zealand, reaching approximately 300,000 students per year. ${ }^{\text {xxi }}$

- The implementation of SciNow will accompany the many other changes proposed over the next decade endeavouring to advance New Zealand science education in line with the needs

- This business case proposes how these changes may be managed to make implementation unobtrusive and enable maximal benefits to be attained

\section{This business case seeks the following approvals}

- Approval of business case to enable three phase implementation of the SciNow service

- Approval for capital and expenditure for research and development

- Approval to engage relevant Ministry experts

\footnotetext{
${ }^{\mathrm{xx}} \mathrm{NPV}$ : the value used in calculating the economic total returns from education

${ }^{x x i}$ Education Counts, Secondary Sciences by School 1996-2015
} 
- Approval to appoint specialists by contract required for each phase

\section{Next Steps}

The anticipated steps following this strategic assessment in broad terms are predominantly focused on securing funding and formation of the core working group.

Following on from these primary steps will be the focus on product validation and development of the minimum viable product. 
Annex A

\section{Literature Review: Curriculum Support in Science}

Prominent feedback regarding current resource use can be found in 2012 report "Curriculum support in science: Patterns in teachers' use of resources" by Rosemary Hipkins and Edith Hodgen. Within this report, 343 teachers contributed to research by filling out a survey accessed online regarding patterns of resource use.

One of the conclusive statements of the reports echoes the observed desire for more resources:

"Given the methodology employed for soliciting responses, and some clear indications of a sample skewed towards engaged and actively networked teachers, it seems safe to assume that the need for resources in the is even more acute than these responses would suggest."

The following is a selection of conclusions derived from the report with relevance to this project:

(Only content regarding secondary teachers is included in this assessment)

- $16 \%$ of teachers were still using 1990's curriculum documents due to absence of more recent equivalents.

- NCEA Science Exemplar use:

- $89 \%$ of teachers had used NCEA science exemplars as a regular resource in the last 12 months.

- Cluster analysis of all results suggested that NCEA resources were the main - and in some cases, the only - source of curriculum support for $20 \%$ of teachers 
- This corroborates an ongoing perception that NCEA is seen by some as a barrier to curriculum, changes, with $51 \%$ of teachers agreeing with the statement and $22 \%$ being unsure.

- While use of NCEA exemplars is prominent, the guides developed specifically for the NZ Curriculum were never nominated as a "best resource"

Several of the purposes listed referred to the following specific pedagogical challenges: integrating literacy learning with science; integrating e-learning and science; supporting inquiry approaches to science; and locating science learning in real-world contexts.

In every instance, "Electronic resources (websites, YouTube clips, short videos)" was either the first or second highest used, with "Web-based New Zealand-specific resources (Science Learning Hub, TKI, ARBs, LEARNZ)" always significantly behind.

For example, asked about the best resources to use for engaging students:

- $47 \%$ found electronic resources the best for engaging students, $20 \%$ said resources to support practical work, and 7\% Web-based New Zealandspecific resources (Science Learning Hub, LEARNZ)

\section{Digital Resource Use}

- Use of ICT and computers is very prominent, with teachers likely to "three times a week" use the internet to find science learning resources; find activities for students to download; and demonstrate concepts using video clips or similar e-resources.

- $54 \%$ of teachers strongly agree and $41 \%$ agree that use of ICT should be an important part of a science programme

- $98 \%$ of secondary teachers reported using the internet to find resources for students on a weekly basis, 
- $98 \%$ again saying they demonstrated concepts using video clips or similar e-resources, mostly weekly,

- $89 \%$ sometimes or often find student activities to download.

- An array of e-learning activities were infrequently used, however teachers expressed a "wish" to include them more.

\section{Open Response Commentary}

The following comments were contributed in open response questions, specifying certain challenges or requests:

- "I have created my own resources for science in Māori contexts-have NEVER been able to find useful ready-made ones and feel there is only waffly help available for this."

- "Ministry made/funded resources are not so good. They ironically do not fit the NZ curriculum at all."

- "[We need] Blogs that EVERYONE knows about and can contribute to."

- "[We need] Decent texts professionally written and illustrated." 
Annex B

Comparison of competitor resources based on selected quantitative features. ${ }^{\vee}$

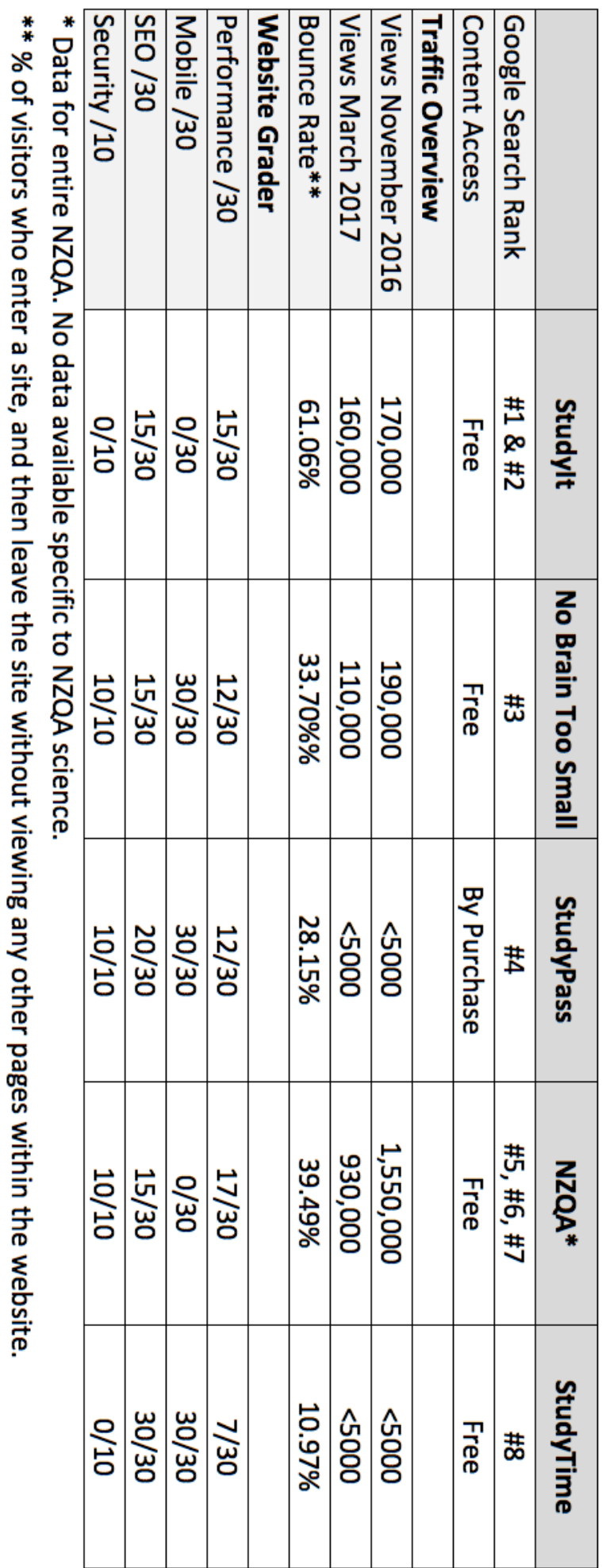

${ }^{\mathrm{v}}$ Website grading data attained with use of https://website.grader.com/ tool

Traffic overview data attained with use of https://www.similarweb.com tool 
Annex C

Comparison of competitor resources based on selected quantitative features. ${ }^{\text {w }}$

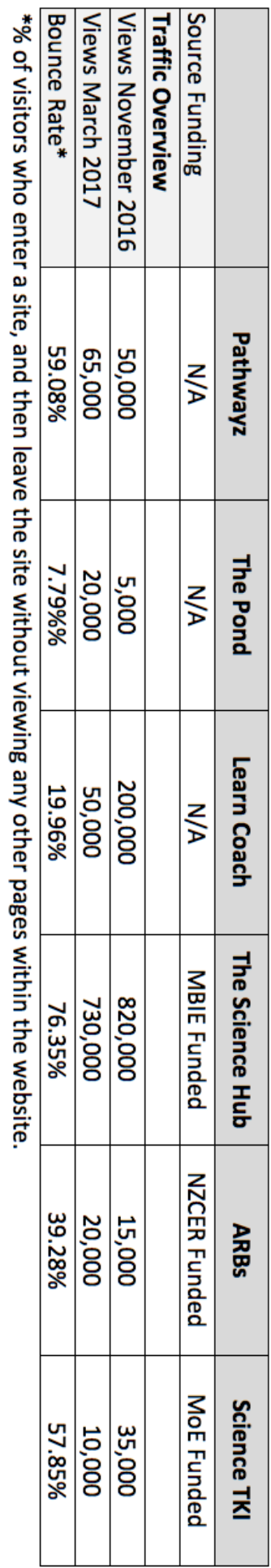

${ }^{\mathrm{w}}$ Traffic overview data attained with use of https://www.similarweb.com tool 


\section{Chapter Nine: Conclusion}

\section{Project Background}

The international economy has been rapidly changing, influenced by the advancements made in science and technology. Reflecting this growth, New Zealand has acknowledged the importance of science and technology for our own prosperity. As the importance of these disciplines is recognised, light is shed on the unfavourable trends New Zealand is experiencing in science education performance. Regular performance measurement has revealed an ongoing decline in academic success, engagement, and scientific literacy, while the gap between highest and lowest performers increases. In addition to the growing equality gap, further concern is incited by a persistent overrepresentation of Maori and Pacifica students and students with low socioeconomic backgrounds in the lowest performing populations. These trends pose a long-term risk for New Zealand, with the educational outcomes threatening our capacity to provide a future workforce with the required skillsets along with ongoing educational inequality. Considering these risks, literature has been devoted to assessing the state of science education in attempts to curb these concerns.

The purpose of this project report was to conduct investigation into science education with a focus on potential causes of declining engagement and success levels, and determining the presence of any opportunities that may appeal to these declines. This inspired the SciNow web service proposal, intended to provide a comprehensive resource database to all students and teachers. Specific investigation was focused on utilising the concept of multimodality to appeal to student engagement preferences. Following research into the experiences of teachers and students, a strategic assessment business case was created, proposing a model through which the SciNow multimodal resource database could be developed and implemented.

\section{Key Outtakes and Implications}

The key outtakes of the research findings are demonstrated through addressing the research questions and assumptions. Most significantly, the findings from both literature and research suggest that the SciNow proposal is not without credibility. While the initial 
assumptions were met with varying levels of confirmation, the open inquisition of the research questions yielded responses that suggest feasibility in continuity of the project.

Addressing the research questions, the challenges identified in science education during research were very much in line with the challenges identified in literature. The interviews with teachers all included responses describing struggles with extensive workloads, criticisms towards the assessment focused restrictions, and an emphasis on the use of ranging communications and methods in class to maximise student engagement. Students from both university and high school almost unanimously expressed a preference for mixed resource use in classrooms, responding very enthusiastically to the multimodal nature of the SciNow proposal.

Whether there is a want or a need for a resource service akin to the SciNow proposal, in the simplest sense, was defined by the unanimously positive responses to proposal of the SciNow model.

Considering both the research and presence of countless sources of multimedia for science education, there are benefits awaiting the infusion of pedagogy with researched based cognitive and media practices.

Taking advantage of the broad abilities modern technology affords, providing a resource with common content for both teacher and student can allow a new level of relationship between educator and learner. From this, an opportunity is created for more interaction and communication within a classroom environment. Implementation of this unitary system not only promotes the learner-teacher relationships, but it also provides coordination of education between the classroom and home. Introduction of a new framework in line with the awareness of how fast technology can advances instils the necessity for the technology to be designed with ongoing refinement in mind.

The business case demonstrates a business model for the service proposal, outlining a flexible implementation plan. The most significant outtakes from the business model include the emphasis placed on the need for more research, and the crucial requirement for funding to enable further action within this project scope. The competitor analysis 
corroborated the research findings that there is a more expansive selection of resources available, however it also revealed the shortfalls. This ultimately emphasised a different feature that SciNow could offer, as a database linking all current content in an organised and easily accessed structure. It also revealed reports of complication experienced from the interweaving of $\mathrm{MoE}$ resources, identifying the importance of resource types being displayed categorically and clearly. An additional revelation was the importance of providing clear distinction between NZC resources and NCEA resources.

While New Zealand currently produces many academically successful scholars, use of knowledge is limited in true capacity without an interest in and an understanding of its relevance. Thus, a further important impact of this research is encouraging the awareness that New Zealand students have demonstrated having levels of interest in science and that these interests are encouraged when taught relevance of content. In addition to the benefits of content relevance, patterns of resource use in literature and the participant feedback's majority consensus validates the proposed benefits of utilising modes in education, be it through verbally and graphic descriptive modes; kinaesthetic interactive modes; or experimental, auditory, and written modes.

\section{Limitations and Future Research}

Limitations on the amount of research completed prevented the ability to assess certain challenges, such as the inequality in science achievement between students based on cultural, racial, and socioeconomic backgrounds.

Future research is necessary to determine what issues the proposal is and isn't likely to be able to accommodate. Without implementation, the true benefit of the proposed service cannot be known. To ensure students attain optimal benefits from these resources and the teaching approaches they promote, the underlying technology needs to be designed with performance analysis in mind. To maximise output of any new technology, it is worth taking advantage of the improvements in technology infrastructure in NZ. Through instillation of fibre broadband, ongoing analysis of technology use can produce invaluable ongoing information. For example, long term analysis may isolate what characteristics it is within different modes that most directly influences the user's engagement and/or education. This 
insight may shed light on the existence of misconceptions or limitations regarding what a single mode can convey.

\section{Most Implications and the Project Future}

The most thought-provoking implications derived from this project are presented in the confirmation, negation, and undetermined conclusions of the project assumptions. The level of interconnection between the vast plethora of educational entities was unanticipated; though uncovering the array of inputting factors inspires the conclusion that in a complex society, the role and execution of education is dynamic and ever-changing, and must be considered as such in research. It is reflecting on this that I propose another assumption was unknowingly present upon initiation of this research; the assumption that education can be considered a stationary subject of exploration.

Reflecting on the research question findings and the business case recommendations, taking into acknowledgement the remaining unknowns and necessary future research, two key outtakes are derived from this project.

The first is that pursuance of the SciNow developmental recommendations is a viable endeavour, while the second is the acknowledgement that even the most successful implementation of the SciNow proposal is limited in its ability to overcome the array of challenges faced in science education. Resource provision, as previously alluded to, is only one element of the significantly complex overarching educational system. Both literature and research illuminated the presence of far more deep-rooted instabilities in the education system, not limited to the science discipline. Infrastructural components of the system need review and development to be able to overcome the most significant problems, and until then, provision of comprehensive resources is offered more as an aid, to adapt alongside the evolving educational system, with the potential for more significant integration in the future.

Based on the remaining perceived potential that the SciNow resource database could offer, upon completion of this project report, I intend to persevere within the realm of this research. Beginning with further literature reviews, I intend to further focus on the recommended additional research alongside expanding the business case. Upon more 
comprehensive analysis of the strategic assessment dynamics, I will begin approaching potential project partners and investors. 


\section{Bibliography}

Centre for Educational Research and Innovation [CERI]. (2001). OECD Review educational research and development in New Zealand: examiners' report. Paris.

al, H. e. (N.D).

Association of Cambridge Schools in NZ. (2009). ACSNZ Members. Retrieved from www.acsnz.org.nz:

http://www.acsnz.org.nz/acsnzschools.cfm?utm_source=newzealandnow.govt.nz

Barett, J. R. (2007). The researcher as instrument: learning to conduct qualitative research through analyzing and interpreting a choral rehearsal. Music Education Research, 9(3), 417-419.

Boddy, C. (2005). A rose by any other name may smell as sweet but "group discussion" is not another name for a "focus group" nor should it be. Qualitative Market Research, 8(3), 248-255.

Boyce, C., \& Neale, P. (2006). CONDUCTING IN-DEPTH INTERVIEWS: A Guide for Designing and Conducting In-Depth Interviews for Evaluation Input. Pathfinder International Tool Series. Watertown: Pathfinder International.

Brod, M., Tesler, L. E., \& Christensen, T. L. (2009, November). Qualitative research and content validity: developing best practices based on science and experience. Quality of Life Research, 18(9), 1263-1278.

Bryman, A. (2012). Social Research Methods (4th ed.). Oxford: Oxford University Press. Bull, A., Gilbert, J., Barwick, H., Hipkins, R., \& Baker, R. (2010). Inspired by Science. New Zealand Council for Educational Research. NZCER for the Royal Society of New Zealand and the Prime Minister's Chief Science Advisor.

Campbell, L. C., Campbell, B., \& Dickinson, D. (1996). Teaching and Learning Through Multiple Intelligences. Boston: Allyn \& Bacon.

Chen, J.-Q., Moran, S., \& Gardner, H. (2009). Multiple Intelligences Around the World. New York: John Wiley \& Sons Inc.

Citizens Advice Bureau. (2014, June 5). School Qualifications. Retrieved from www.cab.org.nz: http://www.cab.org.nz/vat/el/school/Pages/Schoolqualifications.aspx

Clarke, P. N., \& Yaros, P. S. (1988). Research Blenders: Commentary and Response: Transitions to New Methodologies in Nursing Sciences. Nursing Science Quarterly, 1(4), 147-149.

Cohen, L., Manion, L., \& Morrison, K. R. (2007). Research Methods in Education (6 ed.). London: Routledge.

Davis, K., Christodoulou, J., Seider, S., \& Gardner, H. (2011). The theory of multiple intelligences. In S. B. Kaufman, \& R. J. Sternberg (Ed.), The Cambridge handbook of intelligence (pp. 485 - 503). Cambridge University Press.

Dougan, P. (2016, December 6). Hundreds of teacher roles vacant, as schools struggle to fill crucial science, maths and English jobs. Retrieved from The New Zealand Herald: http://www.nzherald.co.nz/nz/news/article.cfm?c_id=1\&objectid=11760706

Education Counts. (2017). Science literacy achievement: senior secondary schooling. Retrieved from www.educationcounts.govt.nz: https://www.educationcounts.govt.nz/statistics/indicators/main/education-andlearning-outcomes/science_literacy_achievement_senior_secondary_schooling 
Education Counts. (2017). Student Numbers: School Rolls. Retrieved from www.educationcounts.govt.nz:

https://www.educationcounts.govt.nz/statistics/schooling/studentnumbers $/ 6028$

Education Review. (2016). PISA Results Expose Inequality Within NZ Education. Retrieved from www.educationreview.co.nz:

http://www.educationreview.co.nz/news/new-news-feed-issue-2/pisa-resultsexpose-inequality-within-nz-education/\#.WKJ6DRJ962w

Education Review Office [ERO]. (2014). Statement of Intent 2013-16. Wellington: New Zealand Government.

Edwards, N. (2015, Jan). Multimodality in science education as productive pedagogy in a PGCE programme. Perspectives in Education, 33(3), 165.

ERO. (2016). School Evaluation Indicators: Effective Practice for Improvement and Learner Success Published. Education Review Office. Education Review OFfice.

Gilbert, J. (2004, June). Models and Modelling: Routes to More Authentic Science Education . International Journal of Science and Mathematics Education, 2(2), 115-130.

Gilbert, J., \& Bull, A. (2013). Building a future-oriented science education system in New Zealand: How are we doing? New Zealand Council for Educational Research, Wellington.

Gracie, G. (2015, July 06). 'NCEA is a failed experiment', teacher says. Retrieved from Stuff.co.nz: http://www.stuff.co.nz/stuff-nation/assignments/would-you-givencea-top-marks-or-put-it-bottom-of-the-class/12147257/NCEA-is-a-failedexperiment-teacher-says

Growing Minds Limited. (n.d.). Study Pass Store. Retrieved from studypass.com: https://studypass.com/product-category/study-packs/

Haug, A., Jaforullah, M., \& Alexander, W. J. (2010, October). A two-stage doublebootstrap data envelopment analysis of efficiency differences of New Zealand secondary schools. Journal of Productivity Analysis, 34(2), 99-110.

Hesse-Biber, S. N., \& Leavey, P. L. (2011). The practice of qualitative research (2nd ed.). Thousand Oaks: SAGE Publications.

Hipkins, R. (2013). NCEA one decade on: Views and experiences from the 2012 NZCER National Survey of Secondary Schools. Wellington: NZCER.

IB Schools of New Zealand. (n.d.). IB World Schools in New Zealand. Retrieved from www.ibschoolsnz.org.nz: http://www.ibschoolsnz.org.nz/schools.html?utm_source=newzealandnow.govt. $\mathrm{nz}$

Inspiration Education Limited. (2010). Inspiration Education. Retrieved from inspirationeducation.co.nz/: http://inspirationeducation.co.nz/

Jewitt, C. (2008). Multimodality and Literacy in School Classrooms. Review of Research in Education, 32, 241-267.

Kirkham, S., \& May, S. (2016). PISA 2015: The science context for PISA. Wellington: Ministry of Education.

Krueger, R. A., \& Casey, M. A. (2015). Focus Groups: A Practical Guide for Applied Science. (5, Ed.) New Delhi, India: SAGE Publications.

Lauer, C. (2009). Contending with the terms: "Mulitmodal" and "Multimedia" in the academic and public spheres. Computers and Composition, 26(4), 225-237. 
McCambridge, J., de Bruin, M., \& Witton, J. (2012). The effects of demand characteristics on research participant behaviours in non-laboratory settings: a systematic review. (H. R. Baradaran, Ed.) Public Library of Science, 7(6).

Ministry of Education [MoE]. (2014, September 19). We get the job done: Organisation Briefing to Incoming Minister. Retrieved from www.education.govt.nz: http://www.education.govt.nz/assets/Documents/Ministry/Publications/Briefings -to-Incoming-Ministers/WeGetTheJobDoneOrganisation.pdf

MoE. (2015, September 15). The National Education Guidelines (NEGs). Retrieved from www.education.govt.nz: http://www.education.govt.nz/ministry-ofeducation/legislation/the-national-education-guidelines/

MoE. (2016). DELTA Programme Student Information Sharing Initiative Report - Final. Digital Era Learning, Teaching and Assessment Programme. Wellington: Ministry of Education.

MoE. (2016, March 31). Education Council of Aotearoa New Zealand. Retrieved from www.education.govt.nz: http://www.education.govt.nz/ministry-ofeducation/specific-initiatives/education-council/

MoE. (2016, August 25). Establishing a regulatory framework for online learning. Retrieved from www.education.govt.nz: http://www.education.govt.nz/ministryof-education/legislation/the-education-update-amendment-bill/establishing-aregulatory-framework-for-online-learning/

MoE. (2016, April 19). The role of the Ministry of Education. Retrieved from education.govt.nz: http://www.education.govt.nz/ministry-of-education/ourrole-and-our-people/what-we-do/

MoE. (2016, December). What is PISA. Retrieved from www.educationcounts.govt.nz: https://www.educationcounts.govt.nz/publications/series/2543/pisa-2015/whatis-pisa

MoE. (2017). About Curious Minds. Retrieved from Curious Minds: http://www.curiousminds.nz/about/

MoE and MBIE. (2014). A Nation of Curious Minds: A National Strategic Plan for Science in Society. Wellington: New Zealand Government.

Moreno, R. (2006). Learning in High-Tech and Multimedia Environments. Current Directions in Psychological Science, 15(2), 63-67.

Morgan, D. L. (1997). Qualitative Research Methods: Focus groups as qualitative research (2nd ed.). (J. V. Maanen, Ed.) SAGE Publications.

Murcia, K. (2010, March). Features Multi-modal representations in primary science: What's offered by interactive whiteboard technology. Teaching Science, 56(1).

National Association of Independent Schools. (2014). 2014 NAIS Report on the High School Survey of Student Engagement. Bloomington, Indiana: National Association of Independent Schools.

New Zealand Post Primary Teachers Association [PPTA]. (2010). The cost of change: PPTA Survey on NCEA Workload 2010. PPTA.

New Zealand Qualifications Authority [NZQA]. (n.d.). New Zealand Qualifications Authority: Our Role. Retrieved from www.nzqa.govt.nz: http://www.nzqa.govt.nz/about-us/our-role/

New Zealand School Trustees Association. (2015). New Zealand School Trustees Association: Who we are and what we do. Retrieved from www.nzsta.org.nz: http://www.nzsta.org.nz/about 
NZQA. (2011). ENSURING CONSISTENCY OF QUALIFICATION OUTCOMES - A DISCUSSION PAPER. Wellington: New Zealand Government.

NZQA. (2016). Secondary Statistics Consolidated Data Files. Wellington: NZQA.

NZQA. (n.d.). Our Role: What We Do. Retrieved from http://www.nzqa.govt.nz/: http://www.nzqa.govt.nz/about-us/our-role/what-we-do/

OECD. (2016). Launch of 2015 Results of the OECD Programme for International Student Assessment (PISA). Retrieved from OECD.Org: http://www.oecd.org/pisa/launchof-pisa-2015-results.htm

OECD. (2016, December 6). Launch of PISA 2015 Results. (E. P. Institute, Producer) Retrieved from www.oecd.org: http://www.oecd.org/pisa/launch-of-pisa-2015results.htm

Organisation for Economic Co-operation and Development [OECD]. (2016). PISA FAQ. Retrieved from www.oecd.org: http://www.oecd.org/pisa/pisafaq/

Organisation for Economic Co-operation and Development. (2016). Singapore tops latest OECD PISA global education survey. Retrieved from OECD Education News: http://www.oecd.org/education/singapore-tops-latest-oecd-pisa-globaleducation-survey.htm

PPTA. (2014).

PPTA. (2016). PPTA Workload Taskforce Report. Auckland: PPTA.

Provost, L. (2016). Education for Māori: Using information to improve Māori educational sucess. Office of the Auditor-General. Wellington: Controller and Auditor-General.

Qin, J. (2016). An Empirical Study of New Zealand Secondary School Performance under the Qualification System of National Certificate of Education Achievement (NCEA). 2.

Radio NZ. (2015, March). PPTA confirms boycott of teacher body. Retrieved from Radio NZ: http://www.radionz.co.nz/news/national/269386/ppta-confirms-boycott-ofteacher-body

Ritchie, J., \& Lewis, J. (2003). Qualitative Research Practice: A Guide for Social Science Students and Researchers. London: Sage Publications.

Sale, J. E., Lohfeld, L. H., \& Brazil, K. (2002). Revisiting the Quantitative-Qualitative Debate: Implications for Mixed-Methods Research. Quality and Quantity, 36(1), 43-53.

Shuttleworth, K. (2016, October 23). Schools to axe core subjects as shortage of specialist teachers reaches 'crisis point'. Retrieved from www.stuff.co.nz:

http://www.stuff.co.nz/national/education/85632668/shortage-of-specialistteachers-reaches-crisis-point

Standley, M., \& Standley, J. (2011). About Us. Retrieved from No Brain Too Small: http://www.nobraintoosmall.co.nz/html/Site/info.html

Taylor, A. L. (2014). Students' Search for Identity as Credit Hunters or Science Students. Auckland, New Zealand: The University of Auckland.

Taylor, S. (2014, August 17). THE SEEDLING: STUDENTS' PERCEPTIONS OF SCIENCE EDUCATION. Auckland: New Zealand Science Teacher.

Teach First NZ [TFNZ]. (n.d.). Teach First NZ: About Us. Retrieved from teachfirstnz.org: http://teachfirstnz.org/organisation/about-us

Tytler, R. (2007). Re-imagining Science Education: Engaging students in science for Australia's future. (C. Glascodine, Ed.) Camberwell, Victoria: ACER Press. 
Vaishnav, R. S. (2013). LEARNING STYLE AND ACADEMIC ACHIEVEMENT OF SECONDARY SCHOOL STUDENTS. Voice of Research, 1(4), 1.

Wiley, D., Green, C., \& Soares, L. (2012). Dramatically Bringing down the Cost of Education with OER: How Open Education Resources Unlock the Door to Free Learning.

Woods-McConney, A., Oliver, M., McConney, A., Maor, D., \& Schibeci, R. (2013). Science engagement and literacy: A retrospective analysis for Indigenous and nonIndigenous students in Aotearoa New Zealand and Ausralia. Research in Science Education, 43(1), 233-252.

Wylie, C. (2013). Secondary schools in 2012 - Main findings from the NZCER national survey. NZ Council for Educational Research [NZCER], Wellington. 
APPENDICES 
Appendix A: Pilot Questionnaire Question Schedule

Name:

Email:

Area of study:

Are you a first-year student:

What level of science did you complete in high school?

Please list what science subjects you studied and to what level:

Describe your feelings about science in general in one sentence:

Describe your feelings about science in school in one sentence: 


\section{Appendix B: Question Schedule for Focus Group Research}

Research was conducted using semi-structured interviews with 4-6 university students. Questions were grouped under proposed theme headings prior to research, thus headings may not correspond with themes identified in results and analysis.

\section{Reasons for Study}

Why did you choose to study science or not to study science at high school? Why did you choose to study science or not to study science at university?

\section{Teachers}

Regarding high school teachers, what features do you recall that were most inspirational and or influential (whether positive or negative)?

Do you recall anything that was particularly effective?

To what extent did specific science subjects stand out to you? If so, for what reasons?

\section{Application/Relevance}

To what extent do you feel your high school science provided application or relevance outside of the classroom?

To what extent do you feel relevance and application of science lessons is or isn't necessary?

To what extent were you taught about careers in science?

To what extent were you taught about the involvement of science in predominantly non-scientific careers?

To what extent do you feel your high school science has or hasn't influenced your interactions in everyday life?

\section{Experiences and Engagement}

To what extent did you experience/engage in laboratory-based or other practical science lessons?

What elements of high school science do you feel most influential (whether positive and/or negative) in your engagement with science?

\section{Reflection}

To what extent do you believe changes to high school science may have influenced your ongoing relationship with science? For example, changing teaching methods, changing assessment, changing resources.

\section{Resources}

How did you feel about resources provided in high school science (both in class, and/or online)?

To what extent did you find use of different resources (both in class and/or online) influential to your enjoyment, engagement, and/or learning in sciences?

\section{SciNow}

I'm looking to create a resource service for high school science. This service would be a resource database, available to be used in class and/or at home. 
This database would be filled with content designed specifically for NCEA.

Every achievement standard would be coupled with a set of resources, with each resource using a different method to communicate content. For example, verbal content, written content, visual content, kinetic content.

Do you think this service would be beneficial or not, any why?

Note: All questions were subject to change during interviews. 


\section{Appendix C: Question Schedule for Teacher Interviews}

Research was conducted using one-on-one semi-structured interviews. Questions were grouped under proposed theme headings prior to research, thus headings may not correspond with themes identified in results and analysis.

\section{General}

Has your opinion and perception of science teaching altered since you began?

\section{Resources}

How do you attain resources for helping teach sciences?

- Do you make them, find them online, are they school provided, etc

Would you change your accessibility of resources if given the chance, or is it sufficient?

\section{Teaching Method}

What do you do to appeal to the range of learning styles of students in your classroom?

Do you communicate with your students about their ideal learning styles? Do you attempt to explore different methods of communicating lessons to help students explore their optimal learning style?

\section{Interactive Lessons}

What practical activities have you done in science this year?

What has worked well, and what has not?

What did you intend for students to learn from the practical activities?

\section{Perception of Students}

How do you believe your students perceive your classroom, and you as a teacher?

\section{SciNow}

I'm looking to create a service that helps teachers communicate core aspects of the science education curriculum to appeal to the wide variety of learning styles of students.

How do you think I should go about doing this?

Note: All questions were subject to change during interviews. 


\section{Appendix D: Question Schedule for Secondary School Student Interviews}

Research was conducted using semi-structured interviews, with groups ranging in size from 3-8 participants. Questions were grouped under proposed theme headings prior to research, thus headings may not correspond with themes identified in results and analysis.

\section{Enjoyment of Science}

Do you enjoy science?

In the classroom? Outside the classroom?

Do you intend to study science beyond the compulsory science curriculum?

\section{Classroom Experiences}

How would you describe your classroom experiences with science theory? How would you describe your classroom experiences with practical science? What practical activities have you done in science this year?

- What have you enjoyed?

- What have you found educational?

- Do you feel you learned the intended lessons from these practical activities?

\section{Relevance}

How would you describe your classroom science and its application in your every day life?

\section{Learning}

Do you feel like you have a particular "learning style"

- E.g. reading, writings, memorizing, flash cards, listening to a teacher, watching videos

Do you feel your "learning style" and corresponding needs are met in class?

\section{Teachers}

Describe your experiences with teachers during high school.

\section{Resources}

Describe your experiences with resource use in class.

Describe your experiences with resource use at home.

\section{SciNow}

I'm looking to create a service that helps teachers communicate core aspects of the science education curriculum, for example through providing animations, diagrams, a range of methods of teaching each achievement standard. This may also be accessible from home for study. Do you feel like you would benefit from this service?

Note: All questions were subject to change during interviews. 
Appendix E: Themes and Sub-Themes

Themes Presented in Findings

\section{Focus Groups}

- Choices and Motives
- Family influence
- Personal interest
- Media
- Positive school experiences
- Negative school experiences

- Experiences with Teachers

- Teacher personality

- Teaching method and resource use

- Relationships and interactions with class

- Staff shortages

- Content, Context, Curriculum, and Careers

o Context

$\circ$ Engagement

- Curriculum

- Careers and relevance

- Practical science lessons

- Science Resource Use

- Engaging and disengaging resource use

○ Home study

- Response to SciNow Proposal

\section{Teacher Interviews}

- Changing perceptions in science teaching

- Assessment and curriculum
- Focus on assessment
- Workload
○ Relevance

- Teaching method

- Science education resource use

- Response to SciNow proposal

\section{Student Interviews}

- Science education experiences
- Enjoying science
- Non-compulsory science 
- Practical science lessons

- Relevance and careers

- Relevance

- Science careers

- Resources and learning styles

○ Learning styles

- Educational resources

- Curriculum and assessments

- Response to SciNow Proposal

Themes Presented in Analysis

- Studying Science: Choices, Motives, and Experiences

- Science Education Content

- Context, relevance, application, and validity

- Relevance to careers

- Curriculum and assessment

- Teaching Method, Learning Style, and Experiences with Teachers

o Changing perceptions as a teacher

o Teaching method

- Practical science lessons

- Resource use and SciNow proposal

○ Resource use

- SciNow 


\section{Appendix F: Example of Ethics Information Sheet}

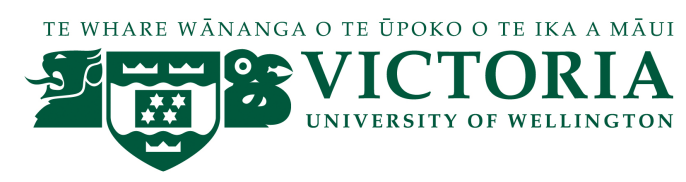

\section{Master of Innovation and Commercialisation INFORMATION SHEET FOR PARTICIPANTS}

Thank you for your interest in this project. Please read this information before deciding whether or not to take part. If you decide to participate, thank you. If you decide not to take part, thank you for considering my request.

\section{Who am I?}

My name is Bronte Ammundsen and I am a Masters student in the Master of Innovation and Commercialisation programme at Victoria University of Wellington. This research is work towards developing a project report for my innovation and commercialisation project.

\section{What is the aim of the project?}

This project relates to assessing the development and commercialisation of science education resource databases and the content design. This includes assessing the benefits of and ability to use resources to better communicate core aspects of the science education curriculum in a range of modes of communication, to appeal to the wide variety of learning styles of students (e.g. visual, auditory, diagrams, animations, etc).

This programme has been approved by the Victoria University of Wellington Human Ethics Committee; approval number HEC23331

\section{How can you help?}

If you agree to take part in this survey, I will ask you questions about my project. The survey should take between 10 and 30 minutes. You can withdraw from the study up to four weeks after completing the survey. If you withdraw, the information you provided will be destroyed or returned to you.

\section{What will happen to the information you give?}

This research is confidential. You have the option to have name suppression. I will not include any information that would identify you without your permission. Only my supervisors and I will read the notes and results from this survey. All responses will be kept securely and destroyed 3 years after the research ends.

\section{What will the project produce?}

The information from my research will be used in my Masters report. I may also use the results of my research for conference presentations, and academic reports. 


\section{If you accept this invitation, what are your rights as a research participant?}

You do not have to accept this invitation if you don't want to. If you do decide to participate, you have the right to:

- $\quad$ choose not to answer any question;

- $\quad$ ask for the recorder to be turned off at any time during the interview;

- $\quad$ withdraw from the study up until four weeks after your interview;

- $\quad$ ask any questions about the study at any time;

- $\quad$ receive a copy of your interview recording (if it is recorded);

- $\quad$ read over and comment on a written summary of your interview;

- $\quad$ agree on another name for me to use rather than your real name;

- $\quad$ be able to read any reports of this research by emailing the researcher to request a copy.

If you have any questions or problems, who can you contact?

If you have any questions, either now or in the future, please feel free to contact either:

\section{Student:}

Name: Bronte Ammundsen

ammundbron@myvuw.ac.nz

\section{Human Ethics Committee information}

If you have any concerns about the ethical conduct of the research you may contact the Victoria University HEC Convener: Associate Professor Susan Corbett. Email susan.corbett@vuw.ac.nz or telephone +64-4-463 5480.

\section{Supervisor:}

Name: Azra Moeed

School: Faculty of Education

Azra.Moeed@vuw.ac.nz 


\section{SciNow: Developing Multimodal Educational Resources CONSENT TO INTERVIEW}

This consent form will be held for 3 years.

Researcher: Bronte Ammundsen, School of Chemical and Physical Sciences, Victoria University of Wellington

- I have read the Information Sheet and the project has been explained to me. My questions have been answered to my satisfaction. I understand that I can ask further questions at any time.

- I agree to take part in a (video/audio) recorded interview.

I understand that:

- I may withdraw from this study up to four weeks after the interview and any information that I have provided will be returned to me or destroyed.

- The information I have provided will be destroyed 3 years after the research is finished.

- $\quad$ Any information I provide will be kept confidential to the researcher and the supervisor. I understand that the results will be used for a Masers report and a summary of the results may be used in academic reports and/or presented at conferences.

- My name will not be used in reports, nor will any information that would identify me.

- $\quad[O R]$ I consent to information or opinions which I have given being attributed to me in any reports on this research:

- I would like a summary of my interview:

Yes $\square \quad$ No

- I would like to receive a copy of the final report and have added my email address below.

Signature of participant:

Name of participant:

Date: 